Alexandre Miguel Benjó

\title{
Avaliação da função endotelial e da cinética de quilomícrons em homens saudáveis com redução isolada do HDL-colesterol: efeitos da niacina
}

Tese apresentada à Faculdade de Medicina da Universidade de São Paulo para obtenção do título de Doutor em Ciências Área de Concentração: Cardiologia Orientador: Protásio Lemos da Luz

São Paulo

2004 
"Se eu não for por mim quem será? Mas se eu for somente por mim quem eu sou? E, senão agora,quando?

Hilel

À memória da minha avó Meriam, do meu bisavô Jonas e do meu tio Mito que sempre me inspirarão pela bondade, caráter e amor. Ao meu padrinho e avô Miguel por seu exemplo e aos meus avós Imre e Riveca pelo seu carinho.

Aos meus pais, Cezar e Solange pelo amor e educação; e às minhas irmãs llana e Andréa pela amizade irrestrita.

À minha esposa Zilda pelo amor e companheirismo nestes anos difíceis mas gratificantes. Com ela fiz minha melhor obra, meu filho Jonas. 
Meu agradecimento especial ao meu orientador, Prof. Dr. Protásio Lemos da Luz, exemplo de excelência em medicina, pesquisa e humanismo, pela oportunidade, pelo convívio, pelo estímulo e pelos ensinamentos; com ele aprendi que "não basta fazer, há que se fazer bem feito e todos os dias".

À Dra. Silmara Regina Coimbra e ao Dr. Marcos Sleiman Molina, sem os quais esta tese não seria possível.

Aos Profs. Drs. Antonio C. P. Chagas, Whady A. Hueb e Maria Cecília Solimene, pelo conforto e estímulo nos momentos difíceis de minha vinda para São Paulo.

Ao Dr. Desidério Favarato, à Mestra Laura I. V. Brandizzi, à enfermeira Marisa Goés e à Srta. Vanda M. Yoshida pelo auxílio fundamental à realização deste estudo. Aos demais colegas da Unidade Clínica de Aterosclerose do InCor, pela convivência, amizade e colaboração.

Às Sras. Sílvia M. Furtado e Celeste B. Menezes e Srta. Fabiana N. S. Lima, secretárias da Unidade Clínica de Aterosclerose do InCor, pela colaboração diuturna. E às Sras. Neusa R. Dini e Eva M. G. Oliveira e Srta. Juliana L. Sobrinho, pelo incansável trabalho aos alunos desta casa. 
Ao Prof. Dr. Raul C. Maranhão, pela cessão do material nescessário à tese, e mais ainda pelas orientações.

À Dra. Célia M. Strunz pelo material e equipamentos cedidos para realização da tese.

Aos meus pacientes, muitos dos quais viajavam horas para vir ao hospital, pela imprescindível participação. E a todos os funcionários do InCor que de uma forma ou de outra contribuíram para realização deste trabalho.

À Deus, que me permitiu chegar até aqui e concluir este estudo. 
RESUMO

SUMMARY

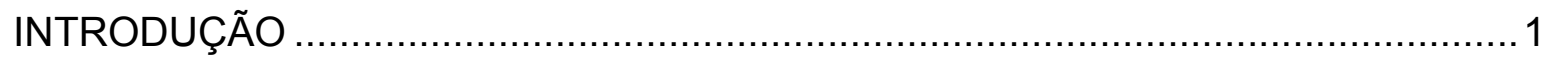

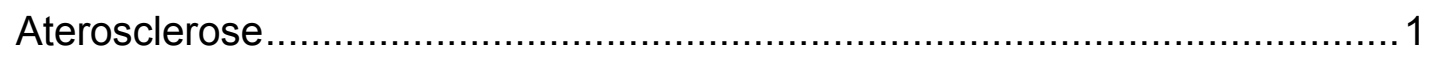

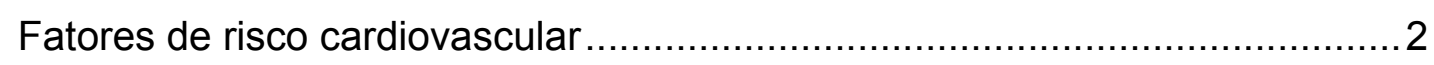

Metabolismo do HDL-C e transporte reverso do colesterol .............................. 4

Outros papéis fisiológicos do HDL-C ………………………………......... 10

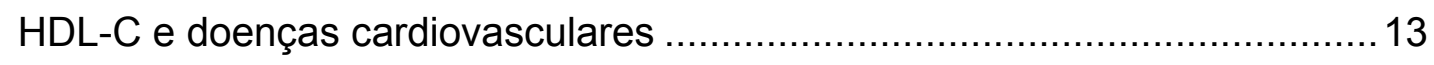

HDL-C, função endotelial e risco cardiovascular .......................................... 17

HDL-C e função endotelial .......................................................... 19

Cinética de quilomícrons e seus remanescentes .......................................20

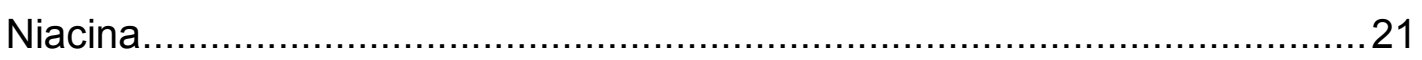

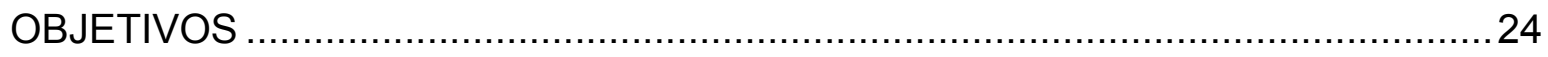

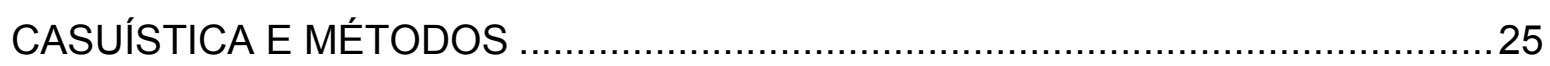

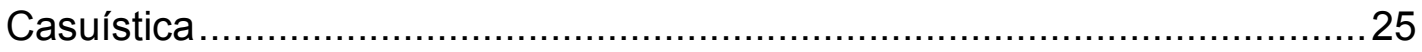

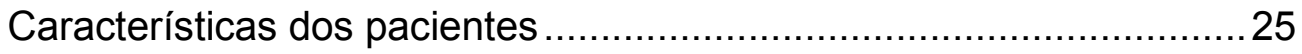

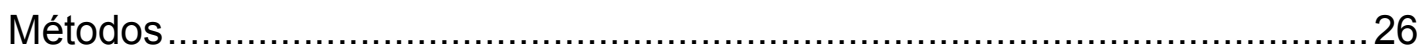

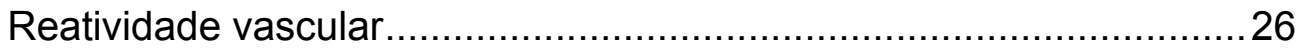

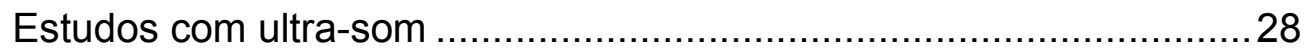

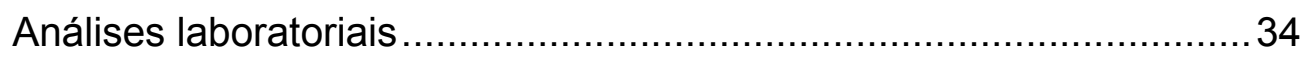

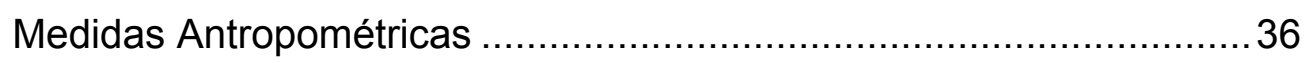

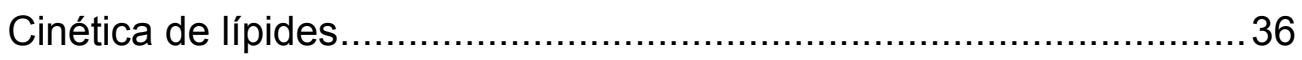

Material utilizado no preparo da emulsão lipídica artificial ....................38

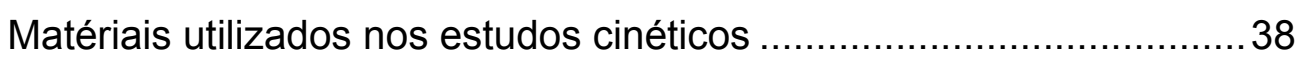

Preparo da emulsão artificial de quilomícrons ....................................39

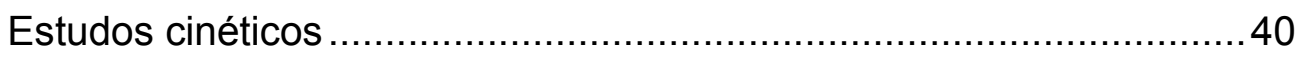

Análise dos dados cinéticos .......................................................... 41

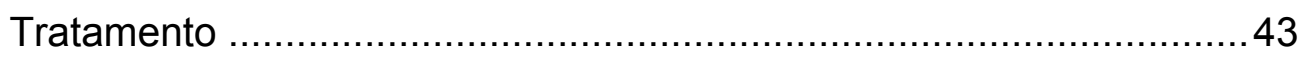




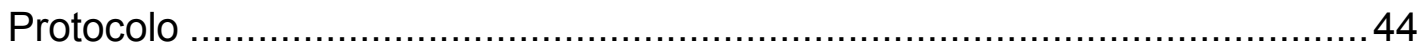

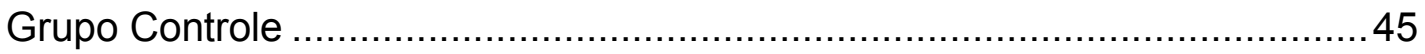

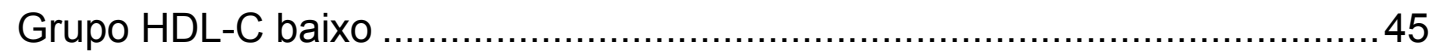

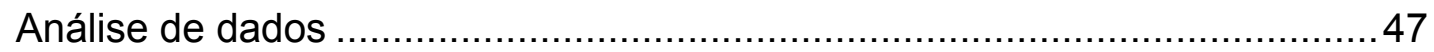

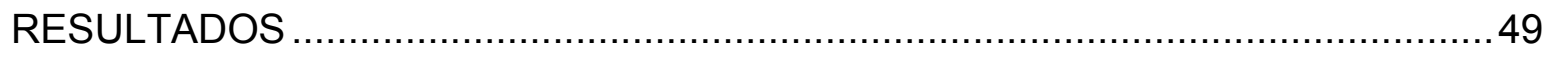

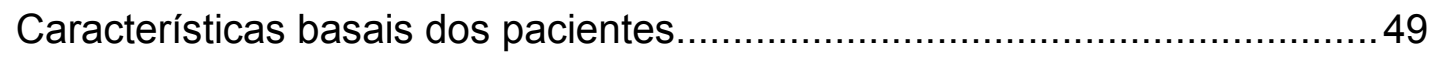

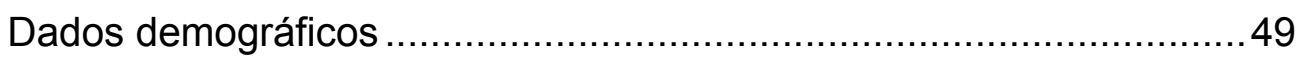

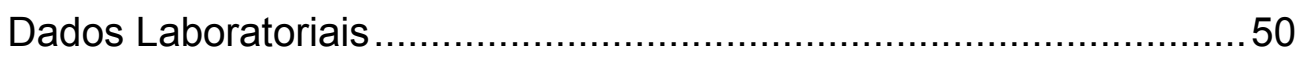

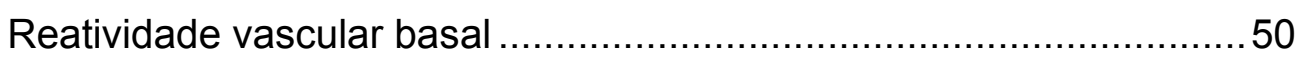

Dados de cinética de quilomícrons artificiais ...................................51

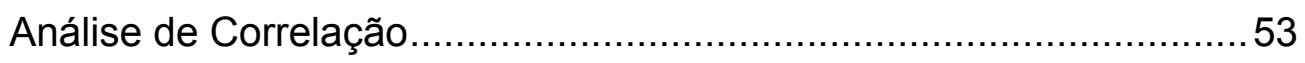

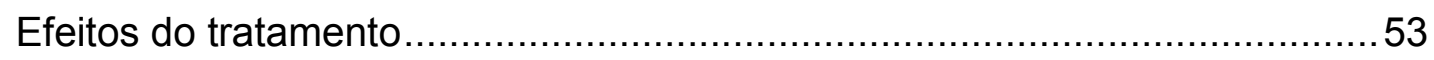

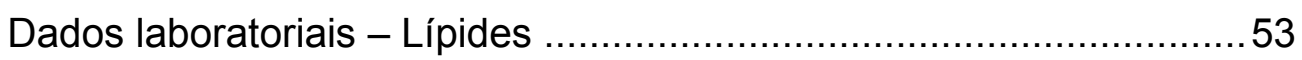

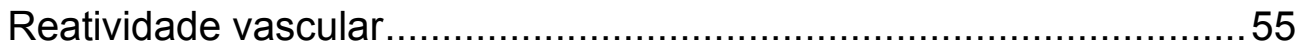

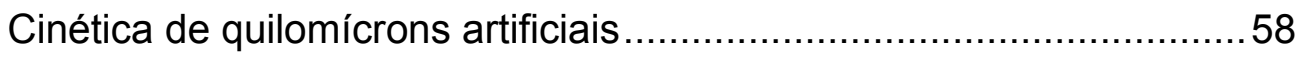

Efeitos colaterais - Dados clínicos e laboratoriais ..............................58

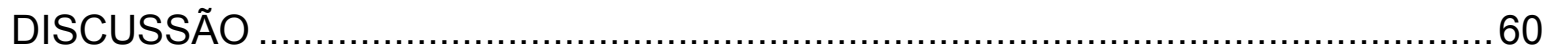

Valores basais - Comparação entre os grupos .............................................60

Resultados do tratamento - Niacina X Placebo ............................................65

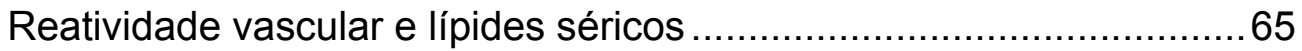

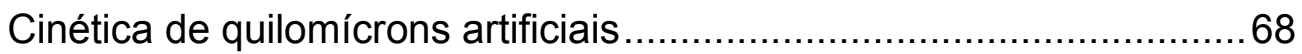

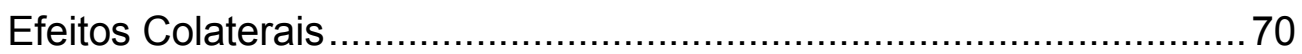

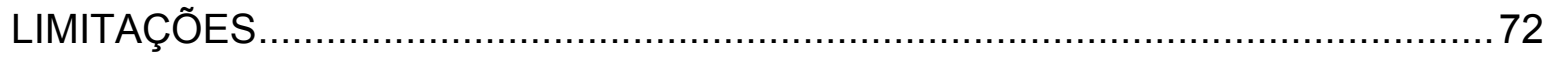

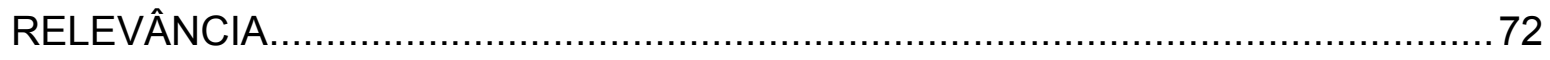

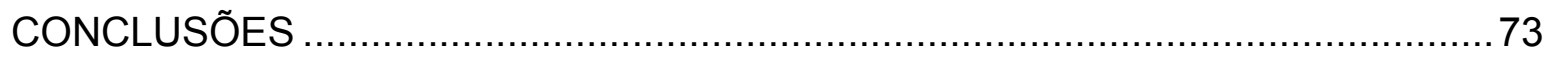

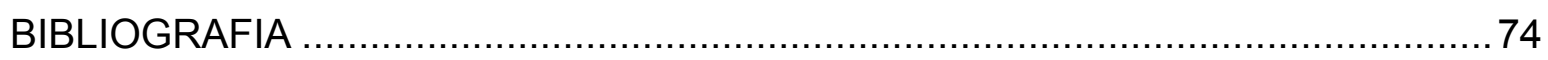

ANEXOS 


\section{LISTA DE ABREVIATURAS:}

ABC - "cassete"transportador de ligantes, quando de adenosina vem seguido de A (i.e.ABCA1), e quando de guanosina vem seguido de $G$ (i.e.ABCG1)

ALT - alanina aminotranferase

AMPc - adenosina 5'monofosfato cíclico

Apo - apolipoproteína

AST -aspartato aminotransferase

AVC - acidente vascular cerebral

C.Abdo. - circunferência abdominal

CETP - proteína de transferência de colesterol éster

DAC - doença arterial coronária

DM - diabetes mellitus

DMF - dilatação mediada por fluxo

DMN - dilatação mediada por nitrato

ECG - eletrocardiograma ou monitorização eletrocardiográfica

EL - lípase endotelial

eNOS - sintase de óxido nítrico endotelial

GMPc - guanosina 5'monofosfato cíclico

gp - glicoproteína

HAS - hipertensão arterial sistêmica

HDL-C - lipoproteína de alta densidade

HF - histórico familiar de doença coronária

HL - lípase hepática

ICAM-1 - molécula de adesão intracelular-1

IL - interleucina (i.e.IL-6 = interleucina-6)

IMC - índice de massa corporal

LDL-C - lipoproteína de baixa densidade

LCAT - lecitina colesterol acil transferase

LP - lipoproteína

LPL -lípase lipoproteica 
NF-Kappa B - fator nuclear Kappa B

NO - óxido nítrico

NOS - sintase de óxido nítrico

PA - pressão arterial

PAD - pressão arterial diastólica

PAl-1 - inibidor de ativador de plasminogênio-1

PAS - pressão arterial sistólica

PLTP - proteína de transferência de fosfolípides

PON - paroxonase (i.e.PON1 = paroxonase 1)

PPAR - receptor ativado de proliferador de peroxissoma

QM - quilomícrons

RQM - remanescentes de quilomícrons

SR-B1 - receptor "scavenger" B1

TG - triglicérides

TNF - fator de necrose tumoral

TRF - taxa de remoção fracional

TRF-CE - taxa de remoção fracional de colesterol éster

TRF-TG - taxa de remoção fracional de triglicérides

t-PA - ativador de plasminogênio tecidual

TX - tromboxane

VCAM-1 - molécula de adesão vascular-1

VLDL-C - lipoproteína de muito baixa densidade 


\section{RESUMO}

Benjó, A.M.. Avaliação da função endotelial e da cinética de quilomícrons em homens saudáveis com redução isolada do HDL-colesterol: ação da niacina . São Paulo, 2004. 144p. Tese (Doutorado) - Faculdade de Medicina, Universidade de São Paulo.

A aterosclerose é um processo inflamatório crônico e sistêmico, responsável pelo surgimento de eventos cardiovasculares, uma alteração precoce na aterosclerose é a disfunção endotelial. Fatores de risco clássicos, em geral, associam-se a aterosclerose. Porém, cerca de 35\% dos coronariopatas não apresentam estes fatores. Estudos têm relacionado concentrações baixas de HDL-C com coronariopatia e disfunção endotelial. Sabe-se também que a lipemia pós-prandial está relacionada alterações na cinética de quilomícrons (QM) e associa-se à doença coronária.

Nossa hipótese foi que concentrações baixas de HDL-C, isoladamente, estariam associadas a disfunção endotelial e a diminuição da remoção de remanescentes de quilomícrons; e que o tratamento com niacina de liberação lenta poderia reverter estes efeitos.

Estudamos 30 pacientes com HDL-C inferior a $40 \mathrm{mg} / \mathrm{dl}$ e 11 controles. Avaliamos a função endotelial por ultra-sonografia de alta resolução da artéria braquial aferindo a dilatação mediada pelo fluxo (DMF) e pela dilatação mediada pelo nitrato (DMN). Avaliamos também a cinética de quilomícrons utilizando a técnica de clearence de quilomícrons artificiais.

Idade e altura foram similares em ambos os grupos, porém os pacientes do grupo HDL-C Baixo apresentavam maior peso, IMC e circunferência abdominal. Os pacientes do grupo HDL-C Baixo apresentaram concentrações mais baixas de HDL-C (34,3 +/- 4,6 vs. 50,6 +/- 11,7 mg/dl), p <0,001. As concentrações de Colesterol Total e LDL-C foram semelhantes em ambos os grupos porém, as concentrações basais de triglicérides e glicemia foram mais elevadas no grupo HDL-C Baixo (113,1 +/- 43,9 vs. 78,9 +/- 35,1; e 96,2 +/- 8,6 vs. 89,9 +/- 7,8), $p<0,02$ e $<0,05$ respectivamente. A DMF e a taxa de remoção fracional de colesterol éster (TRF-CE) foram menores no grupo HDL-C Baixo (7,4 +/- 4,1 vs. $12,8+/-4,6 \%$; e $0,0036+/-0,0051$ vs. $0,0122+/-0,00840,0036+/-$ $\left.0,0051 \mathrm{~min}^{-1}\right), \mathrm{p}<0,001$ e $<0,008$ respectivamente; a DMN e a taxa de remoção fracional de triglicérides (TRF-TG) foram similares. Os 22 pacientes apresentaram DMF diminuída (<8\%) e foram divididos aleatoriamente em 2 grupos de 11 indivíduos. Um grupo recebeu 1,5 g/dia de niacina de liberação lenta e o outro placebo. Após 3 meses de tratamento os pacientes do grupo niacina apresentou normalização da DMF que aumentou de 5,44 +/- 1,89\% 
para $11,13+/-3,4 \%$, $p<0,01$. Os demais parâmetros não se alteraram em ambos os grupos.

Baixas concentrações de HDL-C associaram-se a disfunção endotelial, pela menor DMF, e a menor TRF-CE, ou seja maior permanência de RQM. A niacina corrigiu a disfunção endotelial sem agir nas concentrações lipídicas ou na cinética de lípides. 


\section{SUMMARY}

Benjó, A.M. Endothelial function and chylomicron-like emulsion kinetics assessment in healthy men with isolated low HDL-cholesterol: Niacin's effect São Paulo, 2004. 144p. Tese (Doutorado) - Faculdade de Medicina, Universidade de São Paulo

Atherosclerosis is a chronic and systemic inflammatory process that causes the cardiovascular disease. Classical risk factors are, in general, associated to atherosclerosis; however about $35 \%$ of the patients do not have those factors. Low HDL-C has been associated to coronary artery disease (CAD) and endothelial dysfunction. Postprandial lipemia is related to changes in chylomicron kinetics and are also related to CAD.

Our hypothesis were that low HDL-C would be associated to endothelial dysfunction and slower clearence of chylomicron and remnants; and that treatment with slow release niacin could revert those abnormalities.

We studied 30 men with $40 \mathrm{mg} / \mathrm{dl}$ or less of HDL-C and 11 controls. We used high resolution ultrasonography on the brachial artery to evaluate flow-mediated dilation (FMD) and nitrate-mediated dilation (NMD) to estimate the flow independent dilation. We also assessed chylomicron kinetics trough the chylomicron-like emulsion clearence technique.

Both groups were comparable regarding age, height and total cholesterol and LDL-C concentrations. The low HDL-C group had higher weight, body mass index, abdominal circumference and triglycerides and glucose concentrations $(113.1+/-43.9$ vs. $78.9+/-35.1$; and $96.2+/-8.6$ vs. $89.9+/-7.8), p<0.02$ and $<0.05$ respectively. This group also had lower concentrtions of HDL-C $(34.3+/-$ 4.6 vs. $50.6+/-11.7 \mathrm{mg} / \mathrm{dl}, \mathrm{p}<0.001$ ) as expected. The FMD and the cholesterol ester fractional clearence (CEFC) were reduced in the low HDL-C group $(7.4+/-4.1$ vs. $12.8+/-4.6 \%$; and $0.0036+/-0.0051$ vs. $0.0122+/-0.0084$ vs. $0.0036+/-0.0051 \mathrm{~min}^{-1}, \mathrm{p}<0.001$ and $<0,008$ respectively). The NMD and the triglycerides fractional clearence were similar in both groups. Twenty two low HDL-C patients had a reduced FMD $(<8 \%)$ and were randomized in 2 groups of eleven. $1.5 \mathrm{~g} /$ day of niacin were given to the first group while the other received placebo. After 3 months the niacin treated patients showed a normalization of FMD (from $5.44+/-1.89$ to $11.13+/-3.4 \%$, p <0,01) while the placebo group had no changes (from $5.21+/-2.07$ vs. $5.69+/-2 \%$ ). The other variables remained unmodified.

In conclusion, low concentrations of HDL-C were associated with endothelial dysfunction and slower chylomicron clearence. Niacin corrected the endothelial dysfunction without affecting the lipids concentration or chylomicron kinetics. 


\section{Introdução}

\section{Aterosclerose}

A aterosclerose é um processo inflamatório crônico, sistêmico, responsável pelo surgimento de eventos cardiovasculares, que são a principal causa de mortalidade no Brasil e nos países ocidentais (Lotufo, 1996).

A aterosclerose se inicia precocemente com alterações anatômicas do tipo estrias gordurosas, que já são encontradas na infância e na juventude, como demonstrado no estudo PDAY (McGill Jr. et al, 2000). Seu desenvolvimento tem magnitude e rapidez variáveis, conforme predisposição genética e exposição ambiental a fatores de risco.

Diversos mecanismos estão envolvidos na formação e progressão da placa aterosclerótica, em especial a disfunção endotelial (Kinlay et al, 2001; Luscher, 1994 ; da Luz et al, 2003). Entre as funções mais importantes do endotélio relacionadas com a formação da aterosclerose estão a modulação do tônus e da dilatação vascular, dos mecanismos inflamatórios e de coagulação.

As lesões ateroscleróticas iniciam-se após algum tipo de agressão à camada endotelial (Ross, 1995 e 1999; Libby et al, 2002) levando à disfunção endotelial como o evento inicial do processo aterogênico. Após este fato ocorrem diversos eventos, como a expressão de sítios de ligação de leucócitos, a produção de fatores de crescimento, moléculas quimiotáticas e 
vasoativas; a alteração nas capacidades de oxi-redução de LDL-C e de resposta às lipoproteínas oxidadas, na capacidade de expressar atividade pró e anticoagulantes, e na modulação da permeabilidade vascular; da interação LDLC-macrófagos formam-se células espumosas e há migração e proliferação de células musculares lisas, bem como produção de matriz. Esses fatores levam à lesão na camada íntima da parede arterial aumentando a permeabilidade endotelial a lípides, monócitos, linfócitos T e plaquetas circulantes. A complexa interação desses e de outros fatores leva ao desenvolvimento e progressão da placa aterosclerótica.

A aterosclerose também apresenta diversas características de uma típica doença inflamatória, na qual ocorrem muitas reações celulares e moleculares. Vários marcadores de resposta inflamatória aguda, como proteína $\mathrm{C}$ reativa e citocinas pró-inflamatórias, têm sido relacionados à gravidade, prognóstico, extensão e agudização da doença. O processo inflamatório na placa vascular consiste na migração leucocitária para o subendotélio e a complexa interação entre células endoteliais, plaquetas, e leucócitos (Williams et al, 1998; Ross, 1999).

\section{Fatores de risco cardiovascular}

Inúmeros estudos epidemiológicos prospectivos, como os de Framingham (Kannel et al, 1961) e o PROCAM (Assmann et al, 2002), estabeleceram que alguns fatores se associam ao aparecimento das manifestações clínicas da doença arterial coronária (DAC). 
Nos estudos de Framingham demonstrou-se um risco cardiovascular mais precoce em homens do que em mulheres. No estudo PROCAM só foram analisados homens. Em ambos, idade, história familiar (HF), hipertensão arterial (HAS), diabetes mellitus (DM), hipercolesterolemia (em especial o aumento nas concentrações de LDL-C) e tabagismo foram os fatores de risco principais, ficando estes e o sexo masculino definidos como os fatores de risco clássicos.

A importância destes fatores de risco é comprovada por diversos outros dados. Por exemplo, a redução das concentrações de LDL-C diminuiu o número de eventos cardiovasculares e mortalidade global, tanto em prevenção primária, como nos estudos WOSCOPS (Shepherd et al, 1995), AFCAPS/TexCAPS (Downs et al, 1998), HPS (2002) e ASCOT-LLA (Sever et al, 2002), quanto secundária, como no 4S (1994), no CARE (Sacks et al, 1996) e no LIPID (1998).

Collins et al (1990), avaliando a relação da pressão arterial diastólica com risco para AVC (acidente vascular cerebral) e DAC, em meta-análise de estudos com anti-hipertensivos, demonstraram que a diminuição dos valores pressóricos está diretamente relacionada à diminuição de acidentes vasculares cerebrais e eventos coronários. Comparando a importância do diabetes mellitus em brancos e negros, Cooper et al (1984) encontraram impacto importante na mortalidade em ambos os grupos. Winniford (1990) descreve que o tabagismo aumenta o risco cardiovascular por diversos mecanismos, tais como a ativação do sistema nervoso simpático, o aumento na reatividade plaquetária e nas concentrações de fibrinogênio, e a redução das concentrações de HDL-C. O impacto do tabagismo é de tal monta na 
incidência de eventos cardiovasculares que mesmo o consumo de 1 a 4 cigarros por dia, aumenta a chance de infarto não fatal e de doença coronária fatal em 2 vezes (Willet et al, 1987). Além disso Wilson et al (1999) demonstraram que o número de fatores de risco tradicionais está significativamente associado à extensão e à gravidade da doença arterial coronária.

Observações mais recentes no entanto indicam que aproximadamente $35 \%$ dos pacientes com DAC não têm fatores de risco convencionais (Favarato e da Luz, 1998). Outros fatores de risco cogitados incluem Proteína C Reativa ultra-sensível elevada, LP(a) (lipoproteína (a)) elevada, processos infecciosos (Chlamydia e H.pylori por exemplo) e hiperhomocisteinemia.

Nosso interesse no presente estudo é o HDL-C baixo, um fator de risco já conhecido e cada vez mais valorizado. Analisamos especificamente sua relação com a função endotelial e a cinética de lípides. Para dar uma visão mais abrangente do papel do HDL-C segue-se uma síntese sobre suas funções fisiológicas e sua importância fisiopatológica.

\section{Metabolismo do HDL-C e Transporte Reverso do Colesterol}

Uma gama de partículas de densidade de 1.063 a $1.125 \mathrm{~g} / \mathrm{ml}$ é denominada HDL-C ou lipoproteína de alta-densidade (O'Conell e Genest, 2001); são compostas por proteínas, em especial as apolipoproteínas A-I e 
A-Il e uma monocamada de fosfolípides, em especial fosfatidilcolina, com pequena quantidade de colesterol livre, apresentando em seu interior ésteres de colesterol e triglicérides.

Parte do HDL-C é sintetizado pelo fígado; a Apo (apolipoproteína) A-I lá produzida se associa a fosfolípides formando o pré- $\beta$ HDL-C, discóide; outra parte é originada no plasma a partir de componentes de superfície de lipoproteínas ricas em triglicérides liberados durante a remodelação intravascular mediada pela lípase lipoprotéica (LPL) (von Eckardstein et al, 2001; Deckelbaum et al, 1986). O HDL-C recém formado, pobre em lípides remove colesterol e fosfolípides de membranas celulares de tecidos periféricos, células endoteliais em especial (Savion, Kotev-Emeth, 1989), por intermédio do ABCA1 ("cassete" transportador de ligantes de adenosina trifosfato A1 ou "ATP-binding cassette transporter A1"). A deficiência de ABCA1 resulta na diminuição ou na ausência de HDL-C em humanos e animais (Attie et al, 2001), sendo seu exemplo mais conhecido a doença de Tangier e hipoalfalipoproteinemia familiar, ambas associadas à doença coronariana precoce.

O colesterol adquirido pelo HDL-C é então esterificado pela lecitina colesterol acil transferase (LCAT), proteína secretada pelo fígado e localizada na superfície do HDL-C, com a partícula de HDL-C modificando sua forma para esférica, ficando o colesterol estereficado no núcleo hidrofóbico e os fosfolípides e o restante do colesterol não estereficado na superfície. Este HDL-C, agora denominado HDL-C 3, continua crescendo vindo a tornar-se o HDL-C 2 ao receber mais colesterol livre, que é também 
estereficado pela LCAT; entretanto neste estágio o transporte do colesterol não mais ocorre por intermédio do $A B C A 1$, mas sim por difusão passiva ou intermédio do SR-B1 (receptor "scavenger" B1) (Phillips et al, 1998).

O HDL-C 2 realiza trocas de colesterol e triglicérides (TG) com as partículas de LDL-C e VLDL-C por intermédio da proteína de transferência de colesterol éster (CETP) plasmática; ele também recebe colesterol livre e fosfolípides de VLDL-C, hidrolisadas pela lípase lipoprotéica (LPL), por intermédio da proteína de transferência de fosfolípides (PLTP). Essa relação do HDL-C com as demais lipoproteínas, realizada pelas CETP e PLTP, é fundamental para a remoção do excesso de colesterol periférico, tanto para o uso no metabolismo quanto para sua reciclagem, e tem impacto no tamanho, na composição e nas concentrações de HDL-C, regenerando sua função para continuidade do processo de transporte reverso direto do colesterol (Wang e Briggs, 2004). Esse processo permite também um mecanismo de transporte reverso indireto do colesterol com as LDL-C e as VLDL-C que receberam este excesso de colesterol éster sendo captadas no fígado por receptores de LDL (Gotto Jr e Brinton, 2004).

A degradação do HDL-C no fígado ocorre pela retirada de colesterol éster mediada pelo SR-B1 e pela hidrólise dos triglicérides, pela lípase hepática $(\mathrm{HL})$. A Apo A-I restante é reciclada para formação de novas partículas de HDL-C (von Eckardstein et al, 2001; Attie et al, 2001). Além disso outra lípase, a endotelial (EL), parece regular as concentrações e função do HDL-C por hidrolisar seus fosfolípides (McCoy et al, 2002). Outra via de degradação do HDL-C é o clearence renal de Apo A-I pelo complexo 
cubulina/megalina, amplamente expresso no rim (von Eckardstein et al, 2001). A Figura 1 sintetiza o transporte reverso do colesterol.

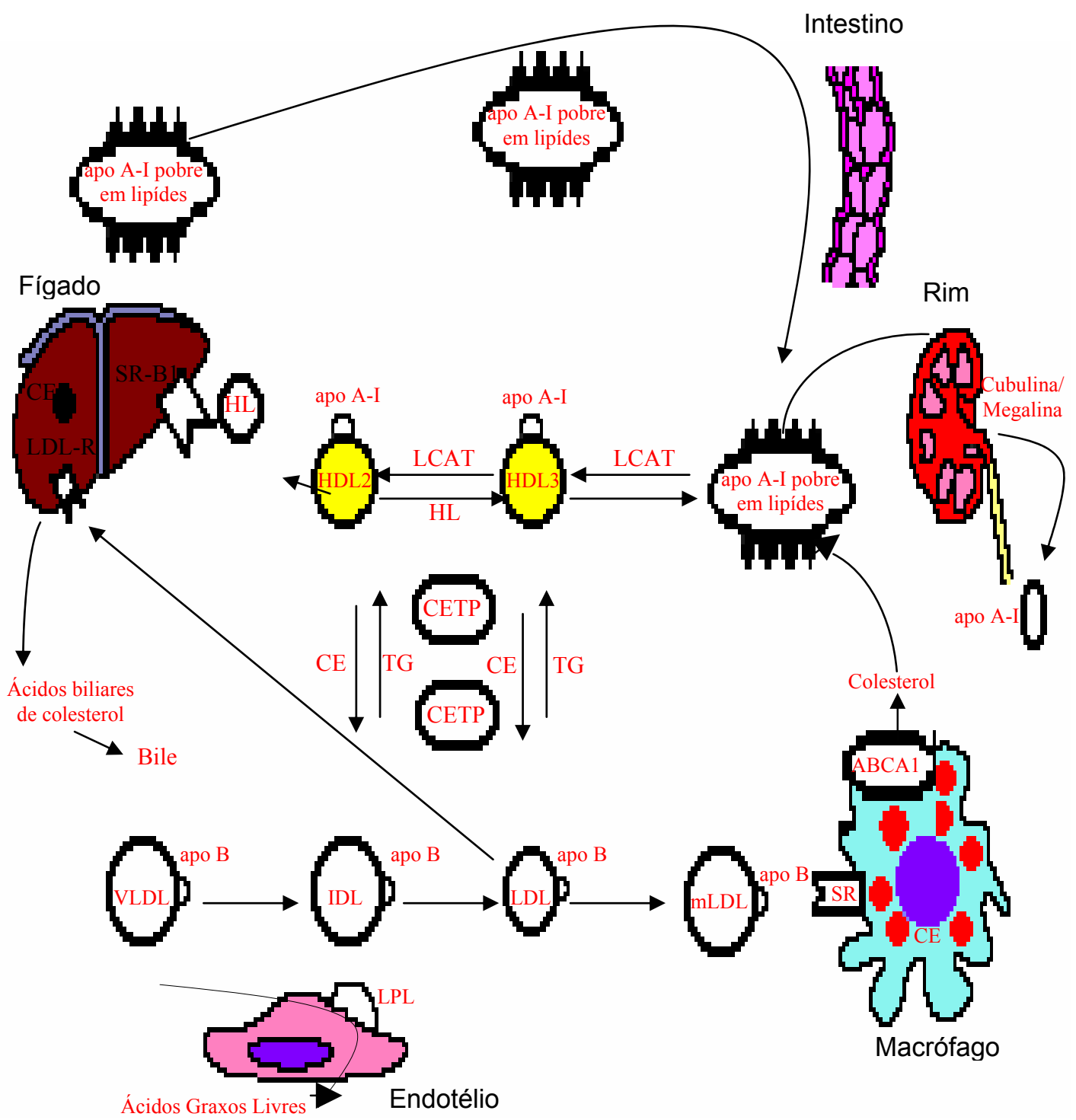

Figura 1: TRANSPORTE REVERSO DO COLESTEROL (TRC). O colesterol livre sai dos tecidos periféricos, dos macrófagos por exemplo, por intermédio do "cassete" transportador de ligante de adenosina (ABCA1) indo para a lipoproteína de alta densidade (HDL) nascente rica em apo-AI. Quando a lecitina colesteroacil transferase (LCAT) esterifica a lecitina desta HDL há a formação de HDL2 maduro que troca colesterol éster (CE) por triglicérides com as demais lipoproteínas, isto é mediado pela proteína de transferência de colesterol éster (CETP); estes triglicérides são posteriormente hidrolisados pela lípase hepática (HL). O CE restante na HDL2 é removido do plasma pelo receptor "scavenger" B1 (SR-B1) no fígado (TRC "direto") resultando numa partícula de apo AI pobre em lípides susceptível a filtração glomerular e endocitose pelos receptores cubulina/megalina no rim. O CE transferido para VLDL, IDL e LDL (lipoproteínas densidades muito baixa, intermediária e baixa respectivamente) é retirado no fígado pelos receptores de LDL (LDL-R). No fígado o colesterol é excretado pela bile. $\mathrm{mLDL}=$ LDL modificada

Adaptado de Gotto Jr. e Brinton, J Am Coll Cardiol, 43: 7192004. 
Como dito antes, o ABCA1 media a transferência de colesterol e fosfolípides das células periféricas para o HDL-C "jovem" ou "nascente", ainda com poucos lípides, realizando o primeiro estágio do transporte reverso do colesterol. Um de seus mecanismos de ação é a modificação da distribuição lipídica na membrana celular facilitando o acoplamento da Apo A-I à sua superfície (Chambenoit et al, 2001). Além das mutações que diminuem a expressão do ABCA1 e as concentrações de HDL, como na doença de Tangier e na hipoalfalipoproteinamia (Marcil et al, 1999; Remaley et al, 1999; Mott et al, 2000),também já foi descrito polimorfismo que parece estar associado à elevação de ambos, ABCA1 e HDL-C (Wang et al, 2000), demonstrando sua correlação direta. Além deste, outros ABCs relacionamse ao metabolismo lipídico, o ABCG1, parece mediar o efluxo de colesterol e fosfolípides de macrófagos para o HDL-C3 (Klucken et al, 2000), e os ABCG5 e ABCG8, têm papel no efluxo dos esteróis da dieta da luz do enterócito de volta ao lúmen intestinal e do fígado aos canais biliares (Berge et al, 2000; Yu et al 2002).

Em relação às demais enzimas e proteínas citadas que atuam no metabolismo do HDL-C e no transporte reverso do colesterol, sabemos por exemplo que a LCAT também esterifica o colesterol associado a Apo B no LDL-C (Furbee, 2002) e que a deficiência dela parece aumentar o risco de aterosclerose e coronariopatia (Funke, 1993). É sabido também que o SRB1 é uma proteína de membrana induzida pela ativação de PPARs (receptor ativado de proliferador de peroxissoma) a e y (Chinetti, 2000) que se liga tanto ao LDL-C quanto ao HDL-C, porém por estruturas diferentes; de forma 
interessante, pequenas elevações em suas concentrações se relacionam a inibição da aterosclerose, enquanto grandes elevações não demonstram este papel (Ueda et al, 2000). Já a EL que é aumentada pelo estresse de cisalhamento e por citocinas como a interleucina-6 (IL-6) e o fator de necrose tumoral- $\alpha$ (TNF- $\alpha$ ), quando expressada em cobaias diminuiu significativamente as concentrações de HDL-C e Apo A-I (Jaye et al, 1999). Sobre a $\mathrm{HL}$ sabe-se que sua deficiência em humanos causa hipertrigliceridemia e elevação das concentrações de HDL-C, porém das partículas de HDL grandes e ricas em triglicérides Demant et al, 1988).

Ainda sobre as enzimas e proteínas citadas que atuam no metabolismo do HDL-C e no transporte reverso do colesterol, a LPL tem papel primordial no transporte reverso do colesterol por realizar a hidrólise de triglicérides do VLDL-C provendo componente de superfície para a produção de HDL-C (Wang e Briggs, 2004); pórem, quando sua atividade está elevada nos macrófagos e na parede vascular ela é aterogênica, já quando elevada nos demais sítios é benéfica e anti-aterogênica (Babaev et al, 1999). Por outro lado, a CETP media a transferência de triglicérides do VLDL-C para o LDL-C e o HDL-C, bem como a de colesterol éster do LDL-C para o VLDL-C e o HDL-C; sua neutralização por anti-corpos reduz as concentrações de LDL-C e de VLDL-C e aumenta as concentrações de HDLC em animais (Evans et al, 1994; Zuckerman e Evans, 1995). Já a PLTP que media a troca e transferência de fosfolípides entre VLDL-C e HDL-C, quando diminuída em animais, associa-se a concentrações reduzidas de HDL (Jiang et al, 1999; Qin et al, 2000). O melhor conhecimento do 
melhor conhecimento do metabolismo destas enzimas e proteínas poderá gerar terapêuticas para elevar as concentrações de HDL-C.

\section{Outros Papéis Fisiológicos do HDL-C}

Além de atuar no transporte reverso do colesterol o HDL-C tem papel importante em múltiplos processos metabólicos. Por exemplo, o HDL-C atua em diversos níveis nos mecanismos inflamatórios, como por exemplo, na modulação de expressão de citocinas, em especial na inibição do NFKappa-B (fator nuclear Kappa B) (Cockerill et al, 1994; Oconell e Genest, 2001). Outra função do HDL-C é aumentar as concentrações de PGI2 (prostaglandina-12) tanto por prolongar sua meia vida, quanto por incrementar sua produção por diversos mecanismos (Yui et al, 1988; Pomerantz et al, 1985; Tamagaki, 1996). Além disso, Sampietro et al (2002) demonstraram que indivíduos com HDL-C e Apo A-I baixos apresentam concentrações elevadas de proteína C reativa, questionando se o HDL-C reduzido, por si mesmo, já não é uma condição pró-inflamatória.

Por outro lado, foi demonstrado que indivíduos com concentrações de HDL-C permanentemente baixas apresentam disfunção endotelial e maior oxidação de $L D L-C$. Experimentalmente observou-se que a LDL-C oxidada transloca a eNOS (sintase de óxido nítrico endotelial) das cavéolas para o compartimento interno da membrana, e o HDL-C tem capacidade de reverter este fenômeno (Toikka et al, 1999; Uittenbogaard et al, 2000). Grande parte 
do efeito anti-oxidante do HDL se deve a paraoxonase, ou PON1, enzima específica do HDL, associada a Apo A-I que é responsável pela hidrólise de peróxidos lipídicos e destruição de moléculas inflamatórias, ou de lipoproteínas que podem alterar o metabolismo do HDL-C; recentemente propriedades similares têm sido descritas em outros membros da família das paraoxonases, a PON2 e a PON3. Sabe-se também que variantes menos ativas da PON1, como a PON1 192 se associam a maior incidência de coronariopatia (Mackness et al, 2002).

Sabe-se também que o HDL-C possui papel fundamental no controle da hemostasia. Como visto antes, o HDL-C aumenta a produção de eNOS e conseqüentemente de NO (óxido nítrico). O NO aumenta o GMPc (guanosina 5'monofosfato cíclico) das plaquetas, diminuindo sua ativação. Por outro lado, o HDL-C aumenta a síntese de PGI2 por aumento de AMPc (adenosina 5'monofosfato cíclico), e isto gera diminuição da disponibilidade do cálcio do citosol, o que leva a menor ativação das vias da ciclooxigenase e da proteína $\mathrm{C}$ quinase, com conseqüente menor ativação plaquetária por diminuição na formação de tromboxane (TX) A2 e não exposição de receptores de superfície, como as glicoproteínas (gp) lb e Ilb/Illa (Chen, Mehta, 1994; Sugatani et al, 1996; Naqvi et al, 1999). Concomitantemente o HDL-C diminui a concentração do fator de von Willebrand, aumenta a atividade das proteínas $\mathrm{C}$ e $\mathrm{S}$, e reverte a ação da LDL-glicada na diminuição de t-PA (ativador de plasminogênio tecidual) e aumento de PAl-1 (inibidor de ativador de plasminogênio-1) (Rosenson e Lowe, 1998; Griffin et al, 1999; Ren e Shen, 2000). 
Demonstrou-se também que o HDL-C pode prevenir a apoptose gerada pela LDL-C oxidada e por TNF (fator de necrose tecidual), seja por ação direta, seja por supressão de caspases (Suc et al, 1997; Sugano et al, 2000).

Uma forma direta de analisar os efeitos do HDL-C é a infusão endovenosa de HDL-C reconstituído. Utilizando esta técnica, Pajkrt et al (1996 e 1997) pré-trataram pacientes com HDL-C reconstituído antes de infundir uma endotoxina, e encontraram uma inibição das lipopolissacaridases, tanto por ligação direta, quanto por inibição da expressão de CD14 nos monócitos, com diminuição dos sintomas da endotoxemia. Tais efeitos provavelmente se deveram à diminuição importante na liberação de TNF e interleucinas 6 e 8, ao aumento na expressão de CD11b/CD18 nos granulócitos, à redução na agregação plaquetária estimulada por colágeno, e à diminuição na ativação da coagulação pelas lipossacaridases.

McDonald et al (2003), entretanto, não conseguiram demonstrar em roedores o mesmo benefício durante choque endotóxico. Não houve diminuição do TNF-alfa e as cobaias evoluíram com hipotensão. Porém, eles demonstraram diminuição nas lesões teciduais renais, pulmonares, hepáticas e intestinais, bem como nas concentrações de P-selectina, e de molécula de adesão intracelular-1 (ICAM-1) no glomérulo renal; isso sugere que um dos mecanismos de benefício do HDL-C é relacionado à inibição da expressão de moléculas de adesão. 
No mesmo sentido Dimayuga et al (1999) demonstraram que a infusão de HDL-C reconstituída diminuiu a formação de neo-íntima em carótidas lesadas por balão, em camundongos ApoE (-/-), com alimentação rica em colesterol. Tal efeito aparentemente se deveu à menor expressão de VCAM-1 (molécula de adesão vascular-1) e à diminuição na infiltração de monócitos/macrófagos.

Já Angelin et al (2002) observaram em humanos que a infusão de HDL-C reconstituído aumenta a excreção fecal de colesterol sob a forma de esteróides, o que demonstra estimulação do transporte reverso de colesterol, o qual é um mecanismo anti-aterogênico a médio prazo. Em paralelo a isto, Spieker et al (2002) observaram, também em humanos, que a infusão aguda de HDL-C reconstituído em homens hipercolesterolêmicos normalizou disfunção endotelial por aumento da biodisponibilidade de NO, o que demonstra que mecanismos rápidos também estão envolvidos nos efeitos protetores do HDL-C.

Como visto, os mecanismos de ação do HDL-C são diversos e portanto sua participação nos mecanismos de aterosclerose e eventos cardiovasculares é de importância fundamental.

\section{HDL-C e Doenças Cardiovasculares}

Diversas causas, além das genéticas, concorrem para produzir concentrações baixas de HDL-C, como o tabagismo, dieta com mais de $60 \%$ 
das calorias provenientes de carboidratos e diversas drogas como betabloqueadores, progestágenos e anabolizantes. Além disso destaca-se sua participação na síndrome plurimetabólica que inclui obesidade, hipertrigliceridemia, sedentarismo, resistência insulínica e diabetes do tipo 2 (Gotto Jr. e Briton, 2004).

Inúmeros estudos analisaram o papel do HDL-C nas doenças cardiovasculares, em diferentes circunstâncias. No Cooperative Lipoprotein Phenotyping Study, a prevalência de coronariopatia obstutiva foi de $8 \%$ nos poetadores de HDL-C acima de $45 \mathrm{mg} / \mathrm{dl}$ e de $18 \%$ naqueles que se mostrou inferior a $25 \mathrm{mg} / \mathrm{dl}$ (Castelli et al, 1977). Recentemente no estudo PROCAM (Assman et al, 2002) propôs-se um escore para cálculo de risco de evento cardiovascular agudo levando em conta além dos fatores de risco tradicionais, por exemplo, HAS, HF, concentrações de LDL-C, idade, tabagismo e diabetes, também trigliceridemia e concentrações de HDL-C. Neste estudo o HDL-C baixo aparece como quarto fator de risco mais importante, à frente de HAS, HF, DM e hipertrigliceridemia. Além disso, concentrações baixas de HDL-C são reconhecidas pela "American Heart Association", em seu "National Cholesterol Education Program Adult Treatment Panel III" (2001) como preditores de eventos coronários.

É sabido que os japoneses têm menor mortalidade por DAC que americanos e australianos. Analisando-se populações de crianças dos 3 países, notou-se que as japonesas tem as concentrações de HDL-C maiores que as australianas e as americanas; esta poderia ser uma das causas para explicar a diferença na mortalidade (Dwyer et al, 1997). Analisando ainda 
outra população japonesa notou-se também que as concentrações de HDLC são inversamente proporcionais a incidência de DAC em homens de meia idade (Kitamura et al, 1994).

Seguindo por 13 anos pacientes com DAC comprovada por estudo angiográfico, Miller et al (1992) encontrou como único fator preditor de eventos cardiovasculares subseqüentes, concentrações baixas de HDL-C. Em estudo de angiografia seriada, com ultra-som coronário, von Birgelen et al (2003) demonstraram uma relação inversa das concentrações de HDL-C com mudanças no tamanho das placas ateroscleróticas no tronco de artéria coronária esquerda. Já Sha e Amin (1992), demonstraram que concentrações baixas de HDL-C estavam fortemente associadas a maior índice de re-estenose coronária pós-angioplastia, num período de 9 meses. Mais recentemente, Johansen et al (2001) também encontraram concentrações baixas de HDL-C como um dos fatores de re-estenose após 6 meses de angioplastia.

A pravastatina utilizada em coronariopatas diabéticos com LDL-C normal ou baixo diminuiu o número de eventos em 44\%; aparentemente por aumentar as concentrações de HDL-C e diminuir as concentrações de triglicérides (Sacks et al, 2002).

Avaliando pacientes coronários com HDL-C e LDL-C baixos, tratados com gemfibrozil, o estudo VA-HIT (Bloomenfeld Rubins et al, 2001; Robins et al, 2001) demonstrou que a elevação das concentrações de HDL-C está relacionada a menor incidência de eventos coronários e AVC, mesmo sem ação significativa nas concentrações de LDL-C. No mesmo sentido, o estudo 
LOCAT (Frick et al, 1997) seguiu indivíduos com HDL-C baixo submetidos à cirurgia de revascularização coronária aleatorizados para gemfibrozil ou placebo. O grupo tratado desenvolveu menor progressão angiográfica da doença coronária e menor formação de lesões nos enxertos, com uma redução de apenas $4,5 \%$ nas concentrações de LDL-C, contra uma diminuição de $36 \%$ nos triglicérides e um aumento de $21 \%$ no HDL-C.

Concentrações reduzidas de HDL-C mostraram-se importante fator preditor de mortalidade em pacientes submetidos à revascularização miocárdica. Tais dados foram demonstrados em diversos estudos, de diferentes países como a Suécia (Linden et al, 1994) e os E.U.A. (Cleveland) (Foody et al, 2000). No Brasil, no InCor HC/FMUSP, isto foi demonstrado pelo Dr. Magalhães em sua tese de doutoramento (2003). Seguindo 165 pacientes revascularizados durante 6,3 anos, ele observou que aqueles com concentrações reduzidas de HDL-C ( $<35 \mathrm{mg} / \mathrm{dl}$ ) apresentavam mortalidade aproximadamente 3 vezes maior que os com HDL-C normal: 20,8\% contra $6,3 \%$. Além disso, mais de $70 \%$ dos óbitos em pacientes com HDL-C baixo tiveram causa cardiovascular. No grupo com HDL-C normal nenhum paciente faleceu por causa cardiovascular.

O Coronary Drug Project Research Group documentou mortalidade maior nos indivíduos com HDL-C baixo após infarto do miocárdio. Além disso, mostrou nos pacientes tratados com niacina, uma redução no número de re-infartos, bem como diminuição tardia na mortalidade, 9 anos após a descontinuação da droga (1975; Berge et al, 1982 ; Canner et al, 1986). 
Estudos com associação de niacina com outros hipolipemiantes, como CLAS II (Cashin-Hemphill, 1990) e o HATS (Brown, 2001), demonstraram diminuição de eventos cardiovasculares e/ou regressão angiográfica da aterosclerose. Todos estes estudos também se associaram a alterações positivas do perfil lipídico, em especial a elevação das concentrações de HDL-C.

No entanto, esses estudos clínicos que consistentemente documentaram a associação HDL-C baixo e eventos ateroscleróticos não esclareceram os mecanismos pelos quais o HDL-C baixo causa a doença arterial coronária.

\section{HDL-C, função endotelial e risco cardiovascular}

Uma alteração precoce e contínua na aterosclerose é a disfunção endotelial caracterizada, por exemplo, pela perda da capacidade de relaxamento do vaso mediado por fluxo e/ou por acetilcolina. Tal disfunção está presente desde as fases iniciais da formação de placas, até a instabilização da placa aterosclerótica e seus eventos cardiovasculares resultantes (Ludmer et al, 1986; Celermajer et al, 1992; Adams e Celermajer, 1999; Swaidi et al, 2000; Schächinger et al, 2000; Halcox et al, 2002; da Luz e Uint, 2003).

Celermajer et al (1994) demonstraram, estudando 500 indivíduos clinicamente saudáveis, uma correlação da diminuição da DMF (dilatação 
mediada por fluxo) com hipercolesterolemia, tabagismo, pressão arterial elevada, sexo masculino, idade e história familiar de doença vascular precoce; ou seja, com os mesmos fatores de risco que tradicionalmente levam a aterosclerose. Além disso, vários outros estudos também relacionaram a disfunção endotelial aos mesmos fatores de risco, e ainda dislipidemia mista, sedentarismo, menopausa e hiperhomocisteinemia (Jodoin et al, 1999; Cohen et al, 2000; Dupuis, 1999; Malik et al, 2001; Celermajer et al, 1993; Celermajer et al, 1996; Raitakari et al, 1999; Celermajer et al, 1994; Kimura et al, 1999; Takase et al, 1996; Clarkson et al, 1997; Clarkson et al, 1999; Perregaux et al, 1999; Higashi et al, 2001; Saitta et al, 2001; Woo et al, 1999).

A disfunção endotelial apresenta valor prognóstico para eventos cardiovasculares em pacientes com precordialgia típica e atípica, bem como para eventos cardíacos em pacientes com lesões coronárias inferiores à $40 \%$, ou mesmo sem lesões. Além disso, marca uma pior evolução após cirurgia vascular e transplante cardíaco (da Luz e Favarato, 2003).

A avaliação não invasiva da função endotelial com ultassom de altaresolução, vem se mostrando mais prática que a invasiva, por apresentar menores riscos e custos. Como dito, quando normal ela possui um excelente valor preditivo negativo para presença de doença arterial coronária (Kuvin et al, 2001).

Em suma, a disfunção endotelial associa-se a fatores de risco cardiovasculares, sendo precursora e marcadora de prognóstico da doença aterosclerótica; sua detecção é possível por métodos invasivos e não- 
invasivos. O tratamento da disfunção endotelial deve ser um alvo terapêutico por si mesmo, e deve ser dirigido à reversão da causa básica desta, ou seja, dos fatores de risco.

$H D L-C$ e função endotelial

Em estudo com indivíduos normais e hipertensos leves, Toikka et al (1999) relacionaram concentrações baixas de HDL-C com disfunção endotelial e aumento na oxidação de LDL-C. Tais dados são reforçados por Li et al (2000) e Zhang et al (2000), que demonstraram que a FMD apresenta correlação direta com os valores de HDL-C em indivíduos normais e coronariopatas, porém em vigência de outros fatores de risco.

Além disso, como mencionado anteriormente, Spieker et al (2002) demonstraram normalização da disfunção endotelial com infusão aguda de HDL-C reconstituído em homens hipercolesterolêmicos.

No único estudo encontrado sobre terapêutica oral da disfunção endotelial causada pelo HDL-C baixo, Kuvin et al(2002) demonstraram que 0 uso de niacina elevava as concentrações de HDL-C e melhorava a função endotelial em pacientes coronariopatas com outros fatores de risco. Com adição de HDL-C à cultura de células vasculares, houve uma maior expressão da eNOS. Eles concluíram que esta maior expressão da eNOS provocada pelo HDL-C contribuiria para o aumento da vasodilatação no experimento clínico. Não foram encontrados, entretanto, estudos em 
pacientes sem outros fatores de risco, que não o HDL-C baixo, tampouco foram encontrados estudos em prevenção primária.

Outro aspecto relacionado ao HDL-C diz respeito ao fluxo de partículas lipídicas no plasma. Técnicas desenvolvidas pelo Dr. Raul Maranhão, do InCor-HC/FMUSP, permitem tais estudos, como será visto a seguir.

\section{Cinética de Quilomícrons e seus Remanescentes}

Os remanescentes de quilomícrons (RQM) são lipoproteínas formadas no espaço intravascular de tecidos extra-hepáticos como resultado do catabolismo dos quilomícrons (QM) pela ação da lípase lipoprotéica. As principais transformações dos quilomícrons são a perda de $85 \%$ do conteúdo de triglicérides, a perda de Apo A-I e Apôs C e a aquisição de Apo E . Os remanescentes são rapidamente removidos da circulação sanguínea pelo fígado através de receptores específicos que reconhecem sua Apo E (Cooper et al, 1997).

Após a ligação ao receptor, ocorre a captação da partícula pelos hepatócitos, por endocitose. Os remanescentes transportam para o fígado o colesterol plasmático originário da dieta, que pode ser utilizado na síntese de membranas celulares, na síntese de outras lipoproteínas de origem hepática ou ser excretado na bile, na forma de ácidos biliares (Brown et al, 1981). 
Quando a cinética de quilomícrons está alterada, em especial na remoção dos remanescentes, há lipemia pós-prandial que está relacionada à doença coronária (Zilversmith et al, 1973; Maranhão et al, 1996; Martins et al, 1995; Roche, Gibney, 2000) e dislipidemias (Sposito et al, 2002; Santos et al, 2001). Maior tempo de permanência dos remanescentes de quilomícrons na circulação pode levar à deposição de colesterol na parede arterial, o que pode colaborar com o processo aterogênico (Mamo et al, 1994). Não foram porém encontrados estudos com esta técnica em pacientes com HDL-C baixo isoladamente. Assim procuramos analisar aqui também estes aspectos menos conhecidos de uma possível função da partícula de HDL-C.

Para o tratamento das concentrações baixas do HDL-C a droga escolhida foi niacina, cujas características principais são a seguir descritas.

\section{Niacina}

A niacina, ou ácido nicotínico, é tida como o agente farmacológico com maior capacidade de elevar o HDL-C. Os mecanismos de ação da niacina ainda não estão totalmente elucidados; porém sabe-se que ela altera as concentrações lipídicas inibindo a síntese de lipoproteínas e diminuindo a produção de partículas de VLDL-C no fígado por inibição da mobilização de ácidos graxos livres, o que diminui a concentração plasmática de triglicérides, remanescentes de VLDL-C e IDL-C, e aumenta o tamanho e diminui a densidade das partículas de LDL-C. Outro mecanismo de ação da 
niacina é diminuir a taxa de catabolismo fracional da Apo A-I, diminuíndo sua captação pelo fígado e conseqüente degradação, o que aumenta o HDL-C plasmático; isto a difere das demais drogas disponíveis que aumentam a taxa de transporte desta (Jin et al, 1997; Gotto Jr. e Briton, 2004). Os principais efeitos colaterais da niacina são rubor facial, alterações do trânsito intestinal, hiperglicemia, hiperuricemia e alterações hepáticas (III Diretrizes Brasileiras sobre Dislipidemias e Diretriz de Prevenção da Aterosclerose, Sociedade Brasileira de Cardiologia, 2001).

A niacina é apresentada em 3 diferentes formulações, com algumas características peculiares. A cristalina, primeira formulação disponível, apresenta baixa tolerabilidade pela alta incidência de "flushes", com rubor facial e sensação de calor intensos e freqüentes. A de liberação estendida $\left(\right.$ Niaspan $\left.^{\mathrm{R}}\right)$, mais recente, apesar de boa tolerabilidade e potência, apresenta custo elevado e não está disponível em nosso país. A formulação de liberação lenta, a escolhida, apesar de elevar menos as concentrações de HDL-C (cerca de 10 a 15\%) que as formulações cristalina e de liberação estendida, não tem os problemas de tolerabilidade da formulação cristalina, e apresenta custo acessível e fácil acesso em nosso país.

Vimos então que o HDL-C apresenta diversos papéis biológicos na modulação do tônus vascular, da hemostasia, da coagulação e da inflamação entre outras ações. Vimos também que o HDL-C baixo se relaciona diretamente à doença aterosclerótica em suas diversas formas; porém, até o presente momento não encontramos mecanismos que expliquem de forma inequívoca como o HDL-C baixo causa tal doença. 
Nossa hipótese é que concentrações baixas de HDL-C acarretem disfunção endotelial e diminuição da remoção de remanescentes de quilomícrons e que o tratamento desta dislipidemia possa reverter estes efeitos. 


\section{Objetivos}

Avaliando homens adultos saudáveis com HDL-C baixo, tivemos por objetivos:

a) Determinar se concentrações reduzidas de HDL-C se associam à disfunção endotelial avaliada por DMF com ultra-som de altaresolução.

b) Determinar se concentrações baixas de HDL-C acarretam menor remoção dos remanescentes de quilomícrom, avaliada por clearence de quilomícrons artificiais.

c) Em havendo disfunção endotelial e diminuição na remoção de remanescentes de quilomícrons, determinar se o tratamento com niacina de liberação lenta é capaz de revertê-las. 


\section{Casuística e métodos}

\section{Casuística}

Características dos pacientes

Foram selecionados indivíduos adultos do sexo masculino, com concentrações de HDL-C iguais ou inferiores a $40 \mathrm{mg} / \mathrm{dl}$ e com idade até 70 anos. Estes não deviam apresentar outros fatores de risco para aterosclerose, ou seja: hipertensão arterial sistêmica, tabagismo, diabetes melito e hereditariedade.

Além disso as concentrações dos demais lípides deveriam estar entre as toleráveis segundo as III Diretrizes Brasileiras sobre Dislipidemias e Diretriz de Prevenção da Aterosclerose, Sociedade Brasileira de Cardiologia (2001), por exemplo, colesterol total inferior a $240 \mathrm{mg} / \mathrm{dl}$, LDL-c inferior a 160 $\mathrm{mg} / \mathrm{dl}$ e triglicérides inferior ou igual a $200 \mathrm{mg} / \mathrm{dl}$.

Os indivíduos do grupo controle apresentavam os mesmos critérios de inclusão e exclusão excetuando os valores de HDL-C que deveriam ser superiores a $40 \mathrm{mg} / \mathrm{dl}$.

Utilizamos as recomendações das IV Diretrizes Brasileiras de Hipertensão Arterial (2002) para diagnóstico de hipertensão arterial, ou seja, pressão arterial sistólica (PAS) acima de $139 \mathrm{mmHg}$, e pressão arterial diastólica (PAD) acima de $89 \mathrm{mmHg}$. 
Para diagnóstico de diabetes mellitus utilizamos o valor limite de 126 $\mathrm{mg} / \mathrm{dl}$ para glicemia de jejum conforme preconizado no Report of the Expert Committee on the Diagnosis and Classification of Diabetes Mellitus (2003).

Como história familiar precoce de aterosclerose consideramos novamente os critérios contidos nas III Brasileiras Sobre Dislipidemias e Diretriz de Prevenção da Aterosclerose, Sociedade Brasileira de Cardiologia (2001), ou seja, de aterosclerose em parentes de primeiro grau com idade inferior a 55 anos, se do sexo masculino, e inferior a 65 anos se do sexo feminino.

Foram analisados 30 pacientes com HDL-C baixo e 11 controles.

\section{Métodos}

Reatividade Vascular

Foi empregado um método não invasivo para testar a reatividade das artérias sistêmicas, usando ultra-som de alta resolução conforme descrito por Celermajer (1992), e normatizado por Correti et al nos "Guidelines for the ultrasound assessment of endothelial-dependent flow-mediated vasodilatation of brachial artery" de 2002 .

Este método contrasta as mudanças do diâmetro da artéria braquial em resposta ao aumento de fluxo por hiperemia reativa (HR) (dilatação 
mediada por fluxo - DMF) e nitrato sublingual (dilatação mediada por nitrato $-\mathrm{DMN})$.

A capacidade da luz dos vasos sangüíneos em responder a estímulos físicos e químicos confere habilidade para regular o tônus e ajustar o fluxo sangüíneo. Muitos vasos respondem a um aumento de fluxo , ou mais precisamente ao estresse de cisalhamento ou "shear stress", com dilatação. Este fenômeno é chamado de dilatação mediada pelo fluxo ou DMF. O principal mediador da DMF é o óxido nítrico (NO) derivado do endotélio como descrito por Meredith et al (1996) e Celermajer et al (1998).

O mecanismo preciso para explicar esta DMF não está bem esclarecido. Conforme descrito nos trabalhos de Cooke et al (1991), Miura et al (2001) e Olesen et al (1988), a membrana da célula endotelial contém canais iônicos, por exemplo, os canais de potássio cálcio-ativados, que se abrem em resposta ao estresse de cisalhamento. Os canais de potássio abertos hiperpolarizam as células endoteliais, aumentando a entrada de cálcio. O cálcio ativa a sintase do óxido nítrico endotelial, e portanto, gera NO e aumenta a DMF. A dilatação arterial mediada pelo fluxo mostrou ser dependente da função endotelial intacta, o que não ocorre com nitrato.

Para avaliação da vasodilatação endotélio-independente utilizamos nitrato (DMN). O nitrato orgânico é convertido em óxido nítrico. O NO reage com radicais sulfidrila, transformando-se em S-nitrosotiol, e estimulam a enzima guanilato-ciclase, resultando na produção de GMP cíclico. O GMP cíclico é um potente inibidor da entrada de cálcio do espaço extracelular para o intracelular e da captação de cálcio pelo retículo sarcoplasmático. 
Conseqüentemente, ocorre relaxamento da musculatura lisa vascular por inibição do sistema actino-miosina, levando ao efeito vasodilatador independentemente da função endotelial.

Os efeitos colaterais mais comuns dos nitratos são a cefaléia, resultante da dilatação brusca de estruturas vasculares cerebrais, e a hipotensão arterial, que ocorre menos freqüentemente. Estes foram facilmente monitorizáveis por questionamento verbal e pela aferição seriada da PA. Quando ocorreram cefaléia foi tratada com analgésicos usuais, e a hipotensão é revertida com posição supina e hidratação oral.

\section{Estudos com Ultra-som}

Usamos ultra-som de alta resolução para medir mudanças no diâmetro da artéria braquial em resposta a um fluxo aumentado e nitrato. Mudanças no diâmetro desta foram avaliadas por imagens de ultra-som modo bidimensional (ATL modelo APOGEE 800 plus, equipado com transdutor linear $7,5-12 \mathrm{MHz}$, e software para imagem bidimensional e doppler, e monitorização eletrocardiográfica (ECG)) (Figura 2), em ambiente com temperatura controlada variando de $20^{\circ}$ a $25^{\circ} \mathrm{C}$. O método foi realizado em Laboratório Pesquisa da Unidade Clínica de Aterosclerose, do InCor HC/FMUSP, equipado para estudos clínicos. 
Figura 2:

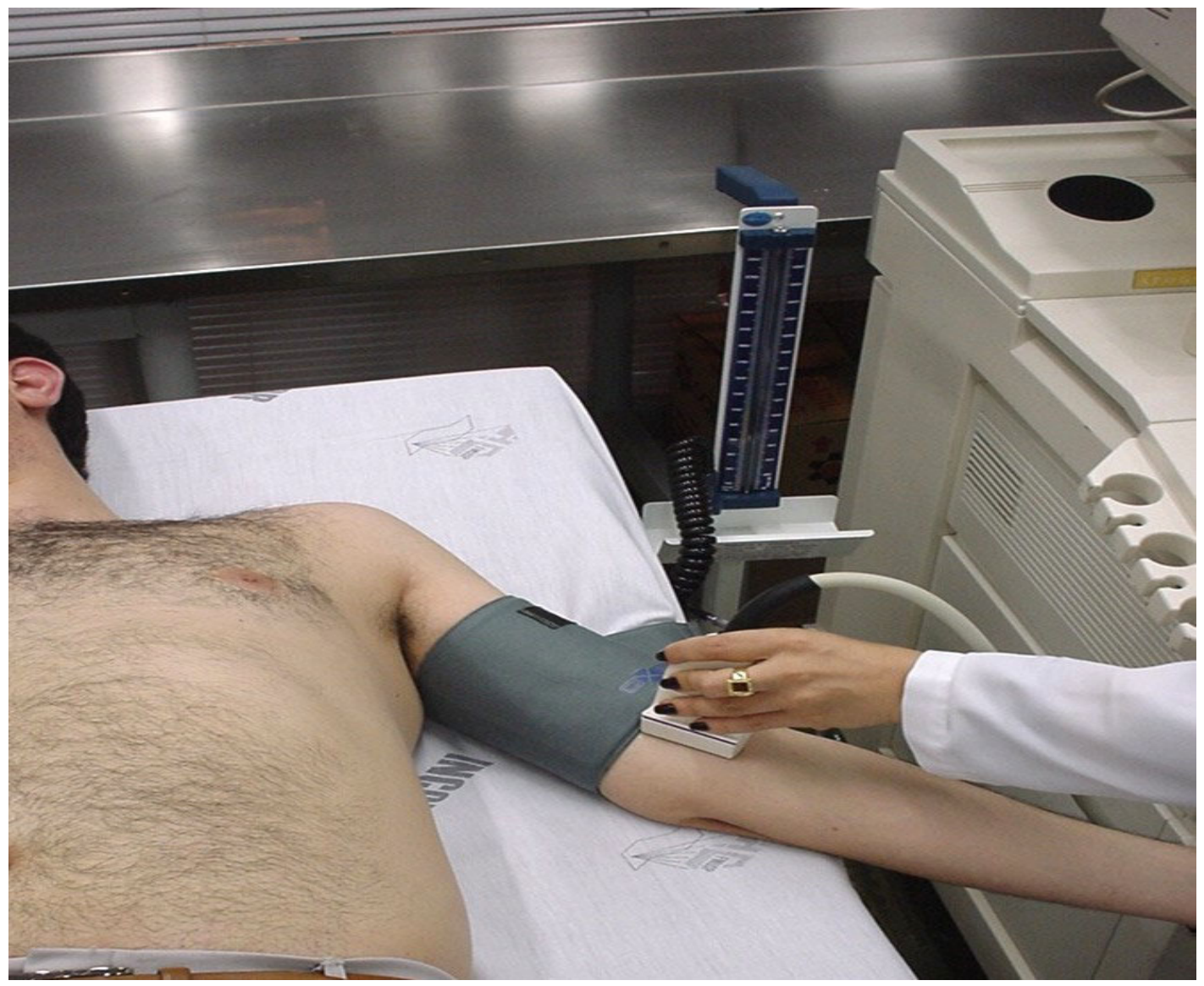

Paciente com manguito e transdutor posicionados para realização do exame de reatividade vascular

Todos os pacientes foram examinados após jejum de 12 horas. Nenhum deles usava qualquer medicação de rotina ou medicação esporádica nas últimas 96 horas. No laboratório o paciente ficou em posição supina por 15 min antes do início do exame, e permaneceu nesta posição até o final do exame. As medidas foram feitas antes e após a HR, e antes e após o nitrato. Quanto ao membro superior usado para esta avaliação, não existe relato na literatura qual lado deve ser usado. Optou-se pelo membro superior esquerdo. A prega do cotovelo foi utilizada como marca anatômica 
para sempre obtermos a mesma imagem da artéria. A artéria braquial acima desta é medida em secção longitudinal (Figura 2).

O centro do vaso foi identificado através da imagem mais clara entre as paredes anterior e posterior do vaso, e o Doppler posicionado a $60^{\circ}$, em relação ao centro do vaso. A profundidade e o ganho foram otimizados para identificar a luz e as paredes do vaso durante cada estudo. A avaliação da função endotélio-dependente por DMF foi realizada em duplicata, em dias separados, visando aumentar a confiabilidade do método. Houve diferença sempre inferior a $1 \%$ entre as medidas. A DMN foi realizada apenas $1 \mathrm{vez}$ em cada momento. A HR induz o aumento do fluxo por insuflação de um torniquete pneumático com manguito ao redor do braço até a pressão de $250 \mathrm{mmHg}$, mantida por 5 minutos, seguido de desinsuflação do mesmo. Isto gera isquemia e conseqüente dilatação dos vasos de resistência via mecanismos auto-regulatórios, e, com a subseqüente desinsuflação do manguito, induz um breve aumento de fluxo na artéria braquial para acomodar os vasos de resistência dilatados. O aumento de fluxo causa dilatação da artéria braquial (Figura 3). Após desinsuflar o manguito, monitorizamos os 5 primeiros fluxos (Figura 4) e o diâmetro da artéria por um período entre o $15^{\circ}$ e o $120^{\circ}$ segundo.

Outras medidas de diâmetro e fluxo foram feitas durante o primeiro dia de exames para a avaliação da função endotélio-independente. Foi analisada a mesma artéria braquial na mesma posição, e no mesmo ponto, após repouso de 20 minutos da hiperemia reativa. Repetiu-se as aferições após administração de $5 \mathrm{mg}$ de dinitrato de isossorbida via sublingual, 
sendo calculada porcentagem de dilatação da artéria. $O$ nitrato não foi administrado a pacientes hipotensos ou com bradicardia clinicamente significativa; estes pacientes foram excluídos do protocolo. Os pacientes com diâmetro da artéria braquial menor que $2,5 \mathrm{~mm}$ e maior que $5 \mathrm{~mm}$ foram excluídos por ser de difícil mensuração e a vasodilatação ser menor, respectivamente.

Figura 3:

\section{DIÂMETRO DA ARTÉRIA BRAQUIAL}

Repouso

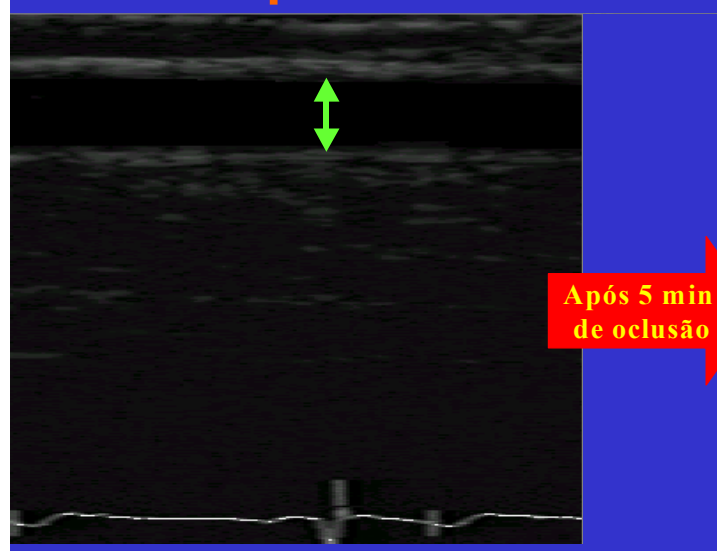

Hiperemia Reativa

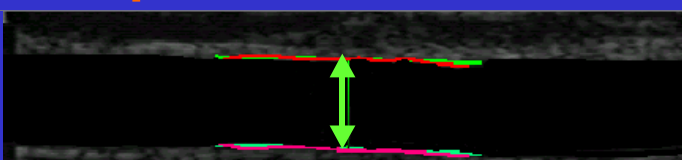

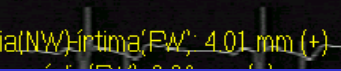

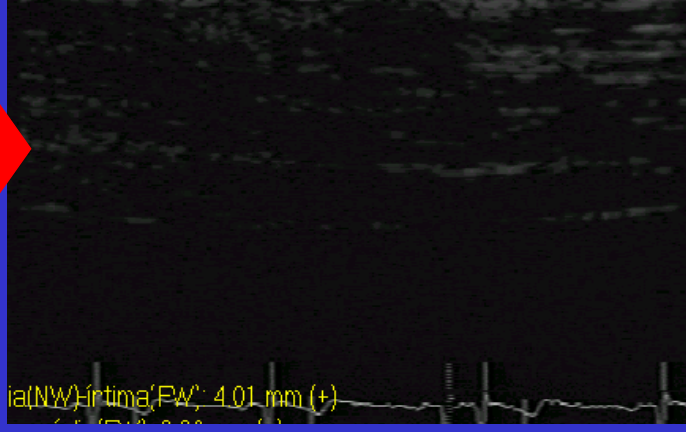

Variação de diâmetro da artéria braquial após a hiperemia reativa. 
Figura 4:

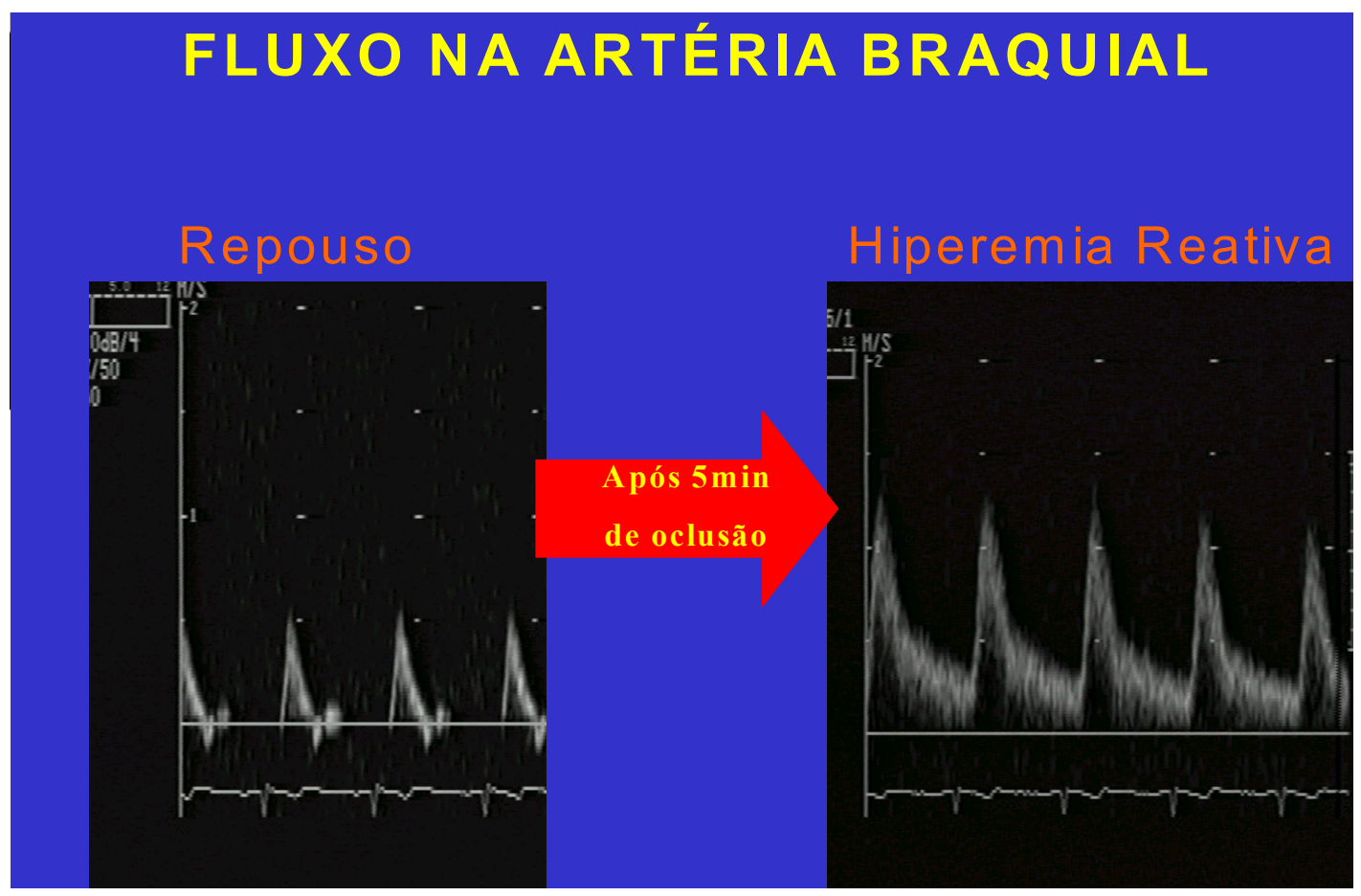

Aumento do fluxo da artéria braquial após hiperemia reativa.

O diâmetro da artéria braquial foi medido no corte longitudinal com a visualização da luz-intima da parede anterior até a posterior. A análise da imagem foi realizada entre a média-adventícia da parede anterior até a posterior, por um software que permitiu medir um segmento da artéria e calcular a média, conforme demonstrado por Gutierrez et al (2002) (Figura 5). As imagens foram adquiridas em 3 ciclos cardíacos e expressas em média, coincidente com a onda R do ECG (diâmetro mínimo). 


\section{Figura 5:}

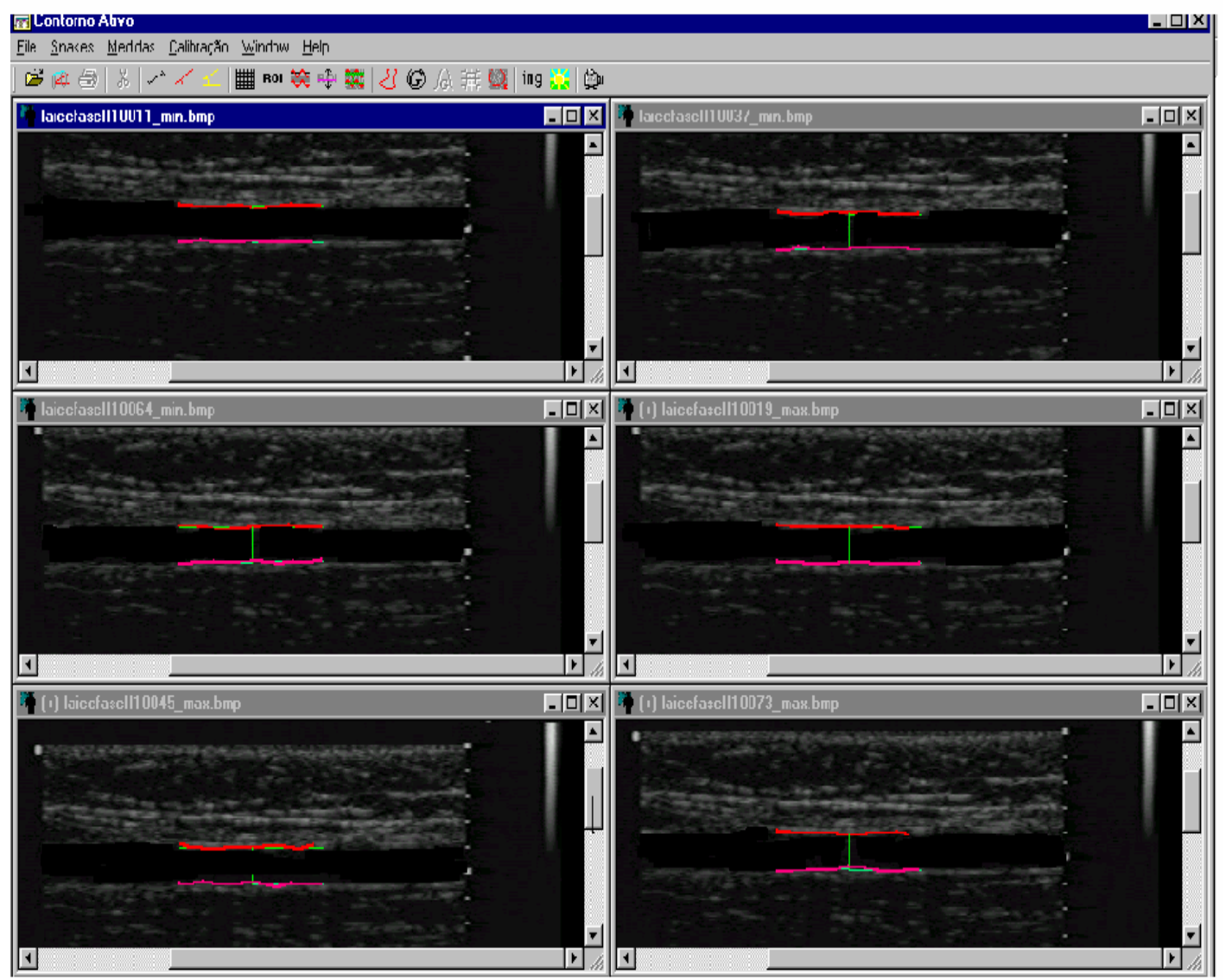

Avaliação computadorizada do diâmetro da artéria braquial.

As DMF e DMN foram expressas em porcentagem de mudança do diâmetro da artéria braquial após estímulo em relação ao diâmetro basal, conforme formula abaixo:

(Diâmetro após intervenção- Diâmetro pré-intervenção)x100

DMF ou DMN =

Diâmetro pré-intervenção 
O valor de normalidade da DMF para função endotelial é igual ou superior a $8 \%$ nos homens. Já o da DMN é igual ou superior a $10 \%$. Os diâmetros e fluxos foram medidos diretamente da gravação em videoteipe VHS. A precisão da análise da reatividade da artéria braquial é altamente dependente das imagens ultrassonográficas.

Todos estes procedimentos foram feitos em 1 ou 2 ocasiões diferentes, isto é, na época da inclusão e após o tratamento com niacina ou placebo, nos pacientes pertinentes.

Sorensen et al (1995) descrevem que a variação das medidas em períodos longos não é significativa, o que permite que medidas realizadas com até meses de intervalo possam ser comparadas. Para assegurar adequada reprodutibilidade do método, cerca de 150 indivíduos foram estudados para treinamento. A variabilidade entre medidas do diâmetro arterial, neste laboratório, foi inferior a $1,5 \%$ entre dois observadores e de $1 \%$ intraobservador, mesmo quando analisadas repetidamente por outros 2 observadores. Estes dados estão de acordo com os critérios para assegurar a reprodutibilidade do método conforme o Intersocietal Commission for the Accreditation of Vascular Laboratories.

\section{Análises Laboratoriais}

As dosagens séricas foram realizadas pelo laboratório de análises clínicas do InCor - HC/FMUSP pelos seguintes métodos:

a) Colesterol total pelo método enzimático colorimétrico (CHOD/PAP), 
descrito por Alain et al (1974),

b) HDL-C colesterol pela separação da fração HDL-C colesterol com $\mathrm{MgCl} 2$ e ácido fosfotengstênico e determinação colorimétrica enzimática, descrito por Assman et al (1983),

c) Triglicérides pelo método colorimétrico enzimático (GPO/PAP) com fosfato de glicerol oxidado e 4-aminoantipirina, descrito por McGowon et al (1983),

d) LDL colesterol calculada pela formula de Friedwald et al (1972), isto é, $\quad$ LDL colesterol $=$ (colesterol total $-\mathrm{HDL}-\mathrm{C}$ colesterol $)-$ Triglicérides/5, somente aplicável para valores de triglicérides ate $400 \mathrm{mg} / \mathrm{dl}$, o que, como já mencionado, era critério de inclusão.

e) Glicose pelo método enzimático com hexoquinase, descrito por Neeley et al (1972),

f) Aspartato aminotransferase (AST) pelo método da International Federation of Clinical Chemistry (IFCC), porém sem piridoxal-5', como descrito por Bergmeyer et al (1986),

g) Alanina aminotransferase (ALT) pelo método da International Federation of Clinical Chemistry (IFCC), porém sem piridoxal-5', como descrito por Bergmeyer 2 et al (1986),

h) Ácido úrico, pelo método enzimático colorimétrico, descrito por Siedel 
Medidas antropométricas

Massa corpórea em quilogramas $(\mathrm{Kg})$, peso em metros $(\mathrm{m})$ e circunferência abdominal $(\mathrm{CA})$ em centímetros $(\mathrm{cm})$ foram aferidos com balança digital acoplada a aparelho para aferição manual de altura, e com fita métrica. O índice de massa corpórea, dado pela massa dividida pelo quadrado da altura, foi calculado.

Cinética de Lípides

A cinética de lípides foi avaliada por determinação das taxas de remoção fracional de triglicérides e colesterol éster remanescentes do clearence de emulsão artificial de quilomícrons, por análise compartimental.

Redgrave e Maranhão (1985) desenvolveram a emulsão artificial de estrutura e composição lipídica semelhante à dos quilomícrons da linfa. A emulsão é composta de trioleína (69\%), lecitina (23\%), oleato de colesterol $(6 \%)$ e colesterol (2\%). Seu comportamento metabólico é semelhante ao dos quilomícrons naturais (Maranhão et al., 1986; Hirata et al, 1987; Oliveira et al, 1988).

Os quilomícrons artificiais consistem numa emulsão lipídica, sem apolipoproteína, o que pode ser aparente contradição porque, os componentes protéicos são de fundamental importância na modulação do seu metabolismo, assim como das outras classes de lipoproteínas. No 
entanto, em experimentos in vitro Redgrave e Maranhão (1985) demonstraram que, em contato com o plasma, apolipoproteínas das lipoproteínas plasmáticas são transferidas para as partículas da emulsão que, assim, adquirem toda a gama de apolipoproteínas existentes no quilomícrom natural; a única exceção é a Apo B, que é pouco solúvel, portanto, não passível de troca entre as partículas. No entanto a Apo B-48, que é essencial para a síntese do quilomícrom pela célula absortiva da mucosa intestinal, não participa de nenhum processo metabólico importante, tanto no compartimento intravascular quanto na captação da partícula pela célula parenquimatosa hepática (Shaeffer et al., 1978). Uma vez provido da Apo Cll, o quilomícrom artificial sofre a ação da lipase de lipoproteína, quando injetado no meio plasmático, conforme demonstrado em ratos (Hirata et al., 1987). Isto resulta em hidrólise da maior parte dos seus triglicérides e geração de partícula remanescente. A presença da Apo E, adsorvida a esta partícula, possibilita a sua captação, principalmente pelo fígado, através de receptores específicos que reconhecem a Apo E. Portanto, os triglicérides são removidos das partículas durante a lipólise, enquanto os ésteres de colesterol tendem a permanecer nelas até sua remoção final, Isto se reflete em remoção plasmática do componente triglicéride mais rápida que a do éster de colesterol (Redgrave e Maranhão, 1985).

Os exames foram coletados no Laboratório da Unidade Clínica de Aterosclerose do Incor - HC por biomédica, e processados no Laboratório de Lípides do InCor - HC/FMUSP. 
Material utilizado no preparo da emulsão lipídica artificial

Os lipídeos puros, trioleína, colesterol, colesterol oleato e fosfatidilcolina (lecitina de ovo) foram adquiridos da Sigma Chemical Co. (St. Louis, EUA). Os isótopos radioativos, glicerol tri $\left[9,10(n)-{ }^{3} \mathrm{H}\right]$ oleato $\left({ }^{3} \mathrm{H}-\mathrm{TG}\right)$ e colesteril [1-14] oleato $\left({ }^{14} \mathrm{C}-\mathrm{CE}\right)$ foram obtidos da Amersham International (Amersham, Reino Unido).

As emulsões foram preparadas através de irradiação ultrassônica em meio aquoso salino, utilizando-se disruptor de células, Branson Cell Disruptor (Branson Ultrasonics Corp, mod .B450). As emulsões obtidas foram submetidas a duas etapas de ultracentrifugação, utilizando-se ultracentrífuga da marca Sorvall rotor TH641 modelo OTD Comb, Wilmington, EUA. Após o preparo, a emulsão foi esterilizada em filtros da marca Millipore , SP de porosidade de 0,22 $\mu$.

Materiais utilizados nos estudos cinéticos

As amostras de sangue foram centrifugadas em centrífuga da marca Sorvall modelo RT7, Wilmington, EUA. A radioatividade presente em alíquotas do plasma é determinada em solução de cintilação PPO:DMPOPOP (TritonX-100: Tolueno; 5g:0,5g:333ml:667ml), marca Merck, Rio de Janeiro, Brasil usando um Beta-contador marca Packard, modelo 1660TR, EUA. A heparina sódica (Liquemine) utilizada como anticoagulante nas amostras colhidas dos participantes do estudo foi obtida do Laboratório Roche. 
Preparo da emulsão artificial de quilomícrons

Uma mistura de lípides é seca através de fluxo de nitrogênio na composição que se segue: $2 \%$ de colesterol, $23 \%$ de lecitina, $6 \%$ de oleato de colesterol e 69 \% de trioleína (Lípides Frios) juntamente com os lípides radioativos colesteril $\left[1-{ }^{14} \mathrm{C}\right]$ oleato e glicerol tri $\left[9,10(n)-{ }^{3} \mathrm{H}\right]$ oleato. A mistura foi mantida durante 12 horas em dessecador a vácuo para completa evaporação dos solventes orgânicos residuais. Acrescentou-se à mistura já evaporada, $6.0 \mathrm{ml}$ de solução salina densidade 1,101g/ml, pH 7,0.

As emulsões foram preparadas através de irradiação ultrassônica das misturas em meio aquoso salino, utilizando-se disruptor de células, durante 40 minutos com uma potência de 70-80 watts, sob fluxo de nitrogênio em uma temperatura que varia de $50-55^{\circ} \mathrm{C}$. As emulsões obtidas foram submetidas a duas etapas de ultracentrifugação em gradiente descontínuo de densidade, para purificação, ou seja obtenção de partículas homogêneas, com a densidade e o tamanho desejados. Na primeira etapa, acrescentou-se ao volume das emulsões obtidas por irradiação ultrassônica, soluções salinas com densidades $1,065 \mathrm{~g} / \mathrm{ml}, 1,020 \mathrm{~g} / \mathrm{ml}$ e 1,006 g/ml, nesta ordem. As emulsões foram centrifugadas a 12.000 rotações por minuto, a $22^{\circ} \mathrm{C}$ por 15 minutos. Ao término da ultracentrifugação, foram desprezados $0,5 \mathrm{ml}$ do sobrenadante e o restante do volume foi submetido à segunda etapa de purificação ,através de ultracentrifugação a 36.000 rpm, à mesma temperatura durante 25 minutos. Após o término da ultracentrifugação foram retirados $3,0 \mathrm{ml}$ do sobrenadante contendo a fração das partículas utilizadas no 
estudo, e foi submetida à esterilização em filtros com poros de 0,22 $\mu$, de diâmetro e armazenada em frasco estéril, à temperatura ambiente.

\section{Estudos cinéticos}

A emulsão de quilomícrom artificial foi injetada endovenosamente em pacientes que estavam em jejum por 12 horas. Os pacientes foram submetidos à cateterização venosa, mantida com soro fisiológico (0,9\%). Foram injetados 100 $\mu \mathrm{l}$ da emulsão artificial contendo $148 \mathrm{kBq}(4 \mu \mathrm{Ci})$ de ${ }^{3} \mathrm{H}$ e $74 \mathrm{kBq}(2 \mu \mathrm{Ci}) \mathrm{de}{ }^{14} \mathrm{C}$.

Amostras de sangue foram coletadas em intervalos regulares préestabelecidos (2,4,6,10,15,20,30,45 e 60 minutos), mantendo-se a cateterização venosa com soro fisiológico. A radioatividade presente em alíquotas do plasma foi determinada em solução de cintilação usando um Beta-contador. A taxa fracional de remoção (TFR) dos lipídeos é calculada através do estudo de Análise Compartimental que foi realizada de acordo com o modelo proposto por Redgrave et al (1987). Tal como descrito anteriormente, o catabolismo intravascular do quilomícrom é um processo bifásico, envolvendo a hidrólise dos triglicérides do quilomícrom pela lipase da lipoproteína e a captação dos remanescentes, principalmente pelo fígado , por meio de receptores.

Foram analisadas as amostras de todos os grupos antes e após o tratamento, quando pertinente. As contagens da radioatividade obtidas foram utilizadas para o cálculo de decaimento plasmático e dos parâmetros dos componentes marcados na emulsão. 
A dose radiológica injetada foi avaliada de acordo com as normas da "International Comission on Radiological Protection" (ICRP) (Sowby , 1985). O parâmetro "Annual Limit for Intake" (ALI) de radionuclídeo é definido como a quantidade de radio isótopo que induz a uma dose equivalente de $50 \mathrm{mSv}$. Para componentes orgânicos marcados $\operatorname{com}{ }^{14} \mathrm{C}$ ou ${ }^{3} \mathrm{H}$, os valores de $\mathrm{ALI}$ são $9 \times 10^{7}$ e $3 \times 10^{9} \mathrm{~Bq}$, respectivamente. No presente estudo, a dose injetada foi de ${ }^{14} \mathrm{C}$ foi de $22,2 \times 10^{4} \mathrm{~Bq}$, o que equivale a $\left.22,2 \times 10^{4} \mathrm{~Bq} / 9 \times 10^{7} \mathrm{~Bq}\right) \times 50 \mathrm{mSv}=$ $0,1233 \mathrm{mSv}$. Para ${ }^{3} \mathrm{H}$, a dose injetada foi de $44,4 \times 10^{4} \mathrm{~Bq}$, portanto a dose equivale a $\left(44.4 \times 10^{7} \mathrm{~Bq} / 3 \times 10^{9} \mathrm{~Bq}\right) \times 50 \mathrm{mSv}=0,0074 \mathrm{mSv}$.

A dose equivalente incorporada no corpo inteiro em conseqüência da exposição aos lípides radioativos foi estimada em $0,04 \mathrm{mSv}$, conforme avaliado pelo método MIRD - Medical Internal Radiological Dosimetry (Smith, 1977). Em conformidade com as normas de proteção radiológica (Comissão Nacional de Energia Nuclear, 1988), este valor é muito inferior ao máximo permitido. A dose de radiação induzida pela injeção dos radioisótopos é menor que a obtida com a maioria dos procedimentos radiológicos, sendo cerca de 10 vezes menor que a dose induzida por uma radiografia de crânio.

Análise dos dados cinéticos

Foi utilizado o modelo de análise compartimental do programa computacional AnaComp versão 4.1, desenvolvido por Mesquita (Mesquita, 1994), para a análise de cinética de emulsões. A cinética da emulsão foi 
avaliada através das remoções plasmáticas de seus componentes lipídicos radioativos, pelo fato dos mesmos apresentarem cinéticas diferentes.

Assim, como no metabolismo dos quilomícrons naturais, os triglicérides da emulsão são hidrolisados durante o metabolismo, enquanto que o éster de colesterol permanece no interior da partícula até a captação da mesma pelo fígado . A curva de remoção plasmática dos ${ }^{3} \mathrm{H}$-triglicérides $\left({ }^{3} \mathrm{H}-\mathrm{TG}\right)$ representa a cinética das moléculas de triglicérides. Embora a curva apresente as mesmas características da curva de remoção do ${ }^{14} \mathrm{C}-\mathrm{CE}$, o seu decaimento é mais rápido devido à ação da lipase de lipoproteína. A cinética do ${ }^{3} \mathrm{H}-\mathrm{TG}$ é representada por três compartimentos: os triglicérides na partícula, tal como foi injetada na circulação sanguínea (compartimento 3), as partículas remanescentes (compartimento 4) e os ácidos graxos livres, derivados da hidrólise dos triglicérides (compartimento 5).

A curva de remoção plasmática do ${ }^{14} \mathrm{C}$-colesterol esterificado $\left({ }^{14} \mathrm{C}\right.$-CE $)$ reflete a cinética do colesterol esterificado e apresenta um perfil biexponencial com um rápido decaimento inicial seguido de outro mais lento. Esse perfil levou à adoção de um modelo com dois compartimentos (Figura 6) que representam o colesterol esterificado dos quilomícrons no espaço intravascular, tal como foi injetado (compartimento 1) ou na partícula remanescente, resultante do processo de lipólise (compartimento 2).

Para representar a remoção das partículas foram utilizados os parâmetros denominadas taxas de remoção fracional (TRF), em $\mathrm{min}^{-1}$, dos lípides marcados, calculados pela média ponderada das respectivas taxas fracionais de transferências $(\mathrm{k})$. 
Figura 6:

${ }^{14} \mathrm{C}-\mathrm{CE}$

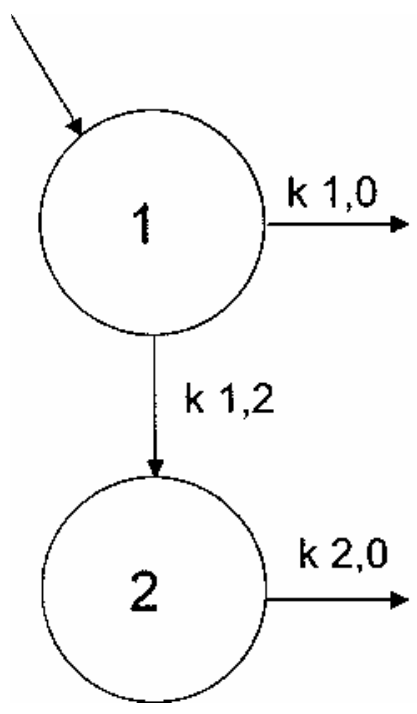

${ }^{3} \mathrm{H}-\mathrm{TG}$

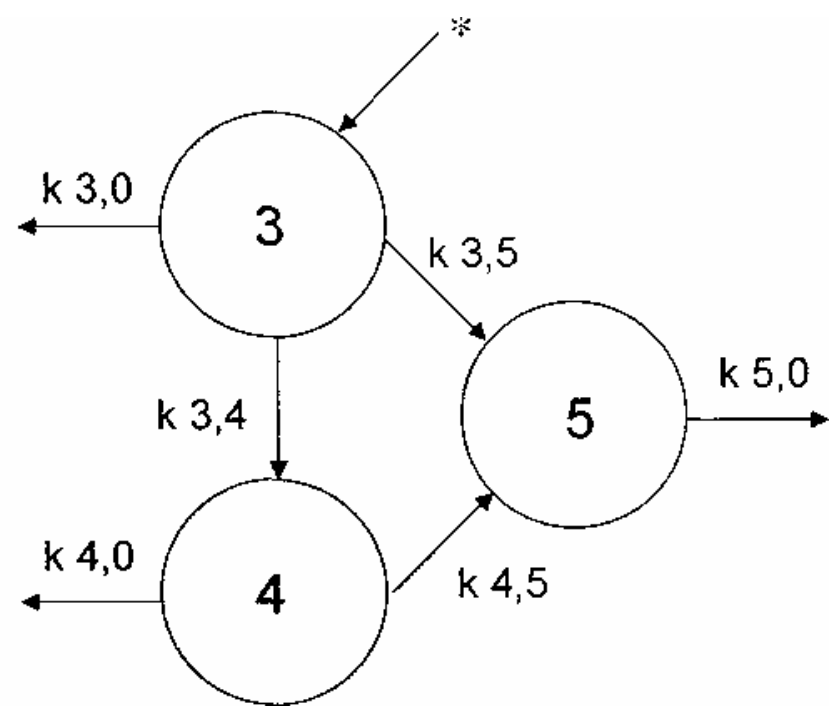

Modelo compartimental utilizado para demonstrar a cinética plasmática dos quilomícrons artificiais (Mesquita, 1994), adaptado de Brandizzi, LIV. 2002 - Metabolismo de Quilomícrons em pacientes portadores de doença arterial coronária. Dissertação de Mestrado - IPEN/USP.

\section{Tratamento}

Foi utilizada para tratamento a niacina de liberação lenta "No flush niacin" ; da marca Solaray, lote 070603 , fabricados por Nutraceutical Corp. Park City UT 84060 USA, e adquiridos em filiais do grupo Natural Quality Store em São Paulo. Cada comprimido era composto por 500mg de niacina, $125 \mathrm{mg}$ de inositol, gelatina, arroz integral concentrado, estearato de magnésio e amêndoa, concentrado, cera e gel de aloe Vera.

O placebo foi o placebo HC número 1 fabricado no HC/FMUSP. 
Inicialmente todos os pacientes do grupo Niacina tomaram uma cápsula com 500mg de niacina de liberação lenta 3 vezes ao dia, totalizando 1,5 g de droga/dia durante 3 meses. Mimetizando a prescrição do outro grupo, foi prescrito ao grupo Placebo um comprimido de placebo 3 vezes ao dia.

\section{Protocolo}

A avaliação, em todos os indivíduos, constou de exame físico completo, e perfil laboratorial dos parâmetros anteriormente mencionados. Todos os pacientes foram esclarecidos quanto ao procedimento e assinaram um termo de consentimento pós-informação. O protocolo foi aprovado pela Comissão Científica do InCor sob o número 1978/01/166.

O protocolo foi realizado através de estudo aleatorizado duplo-cego.

Dividimos inicialmente os pacientes em 2 grupos: Controle e HDL-C Baixo. No $1^{\circ}$ dia o paciente chegava ao Laboratório pela manhã em jejum de 12 horas, para coleta de sangue exigidos no perfil laboratorial; a coleta era realizada no membro superior direito, e em seguida era deitado na maca em que seriam realizados os exames de ultra-som. Após repouso, em decúbito horizontal em ambiente tranqüilo e refrigerado, por um período de $15 \mathrm{~min}$, efetuava-se medidas de pressão arterial com aparelho Onrom no membro superior direito, coincidindo com as medidas efetuadas pelo método ultrassonográfico (pré-HR, pós-HR, antes do nitrato, após 5 minutos do uso do nitrato). 
No segundo dia o paciente, novamente em jejum, vinha diretamente ao laboratório de pesquisa, onde após novos 15 minutos de repouso nas condições já mencionadas, era repetido o exame de DMF, mas não o de DMN. Em seguida o paciente era levado à sala de repouso do mesmo laboratório, onde realizava o exame de cinética de lípides.

\section{Grupo Controle}

Formado por 11 indivíduos não idosos, sem fatores de risco cardiovascular, submetidos à duas avaliações de DMF, uma de DMN, uma de cinética de quilomícrons artificiais, além da dosagem de perfil bioquímico.

Grupo HDL-C Baixo

Formado por 30 indivíduos submetidos inicialmente à duas avaliações de DMF, uma de DMN, uma de cinética de quilomícrons artificiais, além da dosagem de perfil bioquímico. Este grupo foi subdividido em outros 3 grupos.

Primeiramente foi extraído um grupo de 8 pacientes que apresentaram DMF normal, denominado não tratamento, por não ser submetido a tratamento ou novas avaliações.

Os 22 pacientes restantes foram divididos aleatoriamente em grupos Placebo e Niacina, denotando o tratamento a eles oferecido. Os grupos foram constituídos de 11 indivíduos cada .

Os pesquisadores que procediam os exames ou analisavam os 
resultados destes não sabiam em que grupos estavam alocados os indivíduos, caracterizando um estudo duplo-cego. Um médico informado sobre o que cada indivíduo utilizava ficou à disposição para análise e, se fosse necessário, tratamento de efeitos colaterais.

Como mencionado, inicialmente todos os pacientes do grupo Niacina tomaram uma cápsula com 500 mg de niacina de liberação lenta 3 vezes ao dia, totalizando $1,5 \mathrm{~g}$ de droga/dia durante 3 meses. Mimetizando a prescrição do outro grupo, foi prescrito aos pacientes do grupo Placebo um comprimido de placebo 3 vezes ao dia. A aleatorização foi feita com moeda, jogando "cara ou coroa" .

A análise dos dados da cinética de lípides foi o único parâmetro aferido por pesquisador que conhecia a aleatorização dos pacientes. A realização e a análise dos dados de DMF e DMN, entretanto, foi realizada por 2 pesquisadores sem esta informação e sem contato entre si, que obtiveram leitura semelhantes, com variação intra e interobservador inferior a 1\%, validando o método. A dosagem dos parâmetros lipídicos foi realizada na rotina do laboratório de análises clínicas, sem que os técnicos conhecessem a aleatorização, e os valores foram colocados no banco de dados apenas após todos os demais parâmetros já terem sido analisados e o estudo ter sido aberto. Os parâmetros bioquímicos dos pacientes de ALT, AST, ácido úrico e glicemia (repetidos também no $2^{\circ}$ mês) eram abertos aos pesquisadores informados sobre a aleatorização para possível interrupção do tratamento se necessário, o que não ocorreu.

Uma sumarização do protocolo pode ser vista no esquema abaixo: 
Esquema 1: Sumarização do protocolo do estudo.

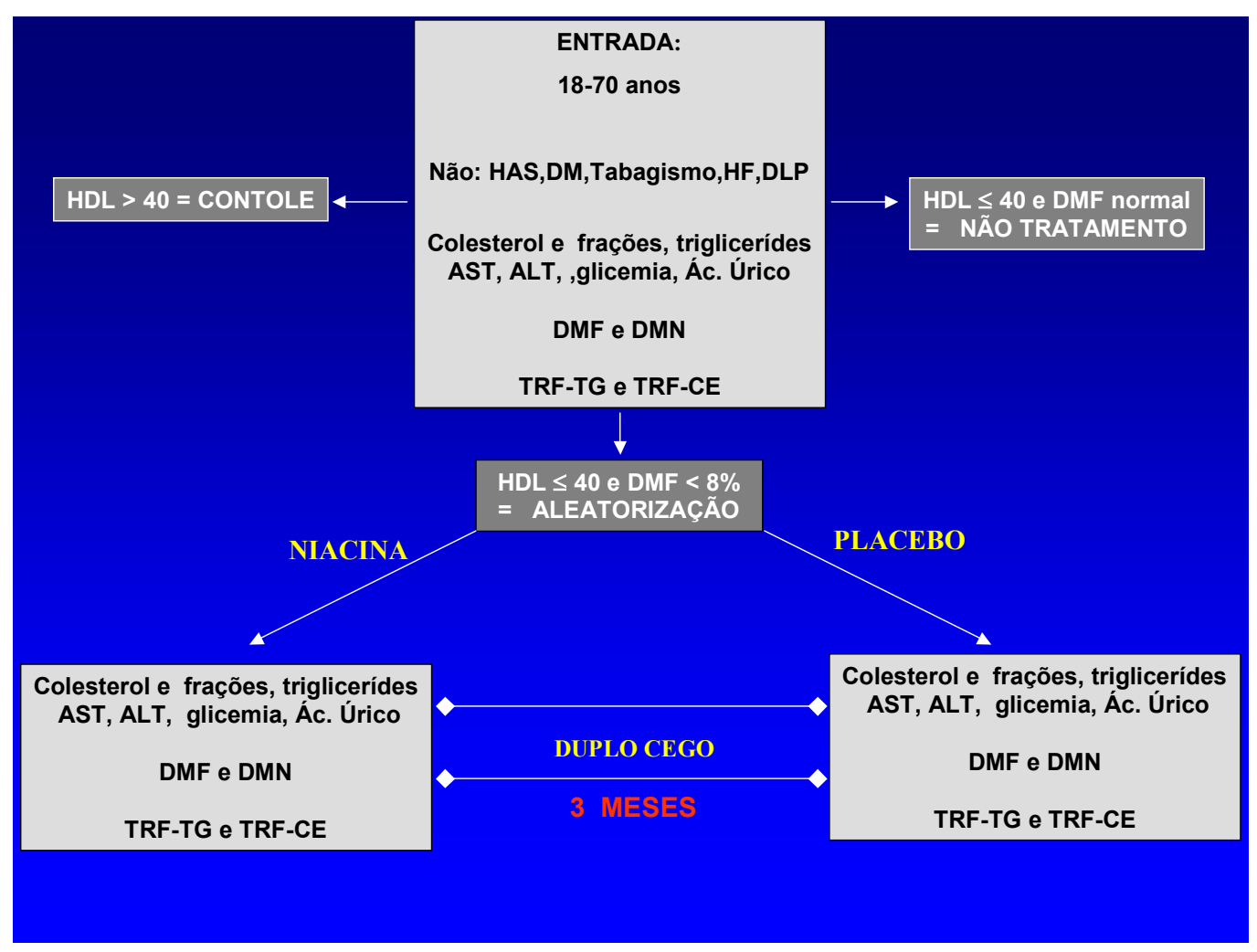

Análise de dados

O tamanho amostral necessário para se detectar uma diferença maior ou igual ao maior desvio-padrão entre um par de medidas da variável dilatação da artéria, com nível de significância a=0,05 e poder estatístico 1$b=0,80$, é de $n=7$ pacientes, em cada grupo. Sendo então o tamanho dos grupos e subgrupos satisfatório. 
Os dados com distribuição normal foram comparados utilizando análise de variância, ou quando comparando os efeitos do tratamento, análise de variância repetida. Na ausência desta distribuição utilizou-se os testes não paramétricos de Kruskal-Wallis, com teste de Dunn se necessário, para comparação entre os grupos, e Wilcoxon para comparações entre o mesmo grupo pré e pós-tratamento.

Foi realizada análise de correlação entre variáveis utilizando-se o coeficiente de correlação de Pearson.

O programa utilizado para análise dos dados foi o SAS versão 6.11 fabricado por SAS Institute Inc.. 


\section{Resultados}

\section{Características Basais dos Pacientes}

\section{Dados Demográficos}

Idade e altura foram similares em ambos os grupos. Os pacientes do grupo HDL-C Baixo porém, apesar de normais, eram mais pesados que os do grupo Controle, tendo conseqüentemente maiores IMC e circunferência abdominal. (Tabela 1).

Tabela 1: Perfil demográfico basal dos dois grupos.

\begin{tabular}{lllc}
\hline & Controle $(\mathbf{n = 1 1 )}$ & HDL-C Baixo $(\mathbf{n = 3 0})$ & $\mathbf{p}$ \\
\hline Idade (anos) & $35,6+/-8,7$ & $35,1+/-11,9$ & $\mathrm{NS}$ \\
Peso (Kg) & $68,9+/-8,1$ & $78,1+/-13,7$ & 0,01 \\
Altura (m) & $1,75+/-0,1$ & $1,71+/-0,6$ & $\mathrm{NS}$ \\
MC & $22,4+/-1,4$ & $26,4+/-3,7$ & 0,0001 \\
C.Abdo. (cm) & $81,5+/-6,8$ & $89,6+/-9,3$ & 0,02 \\
PAS (mmHg) & $118,8+/-10,1$ & $122,7+/-9,7$ & $\mathrm{NS}$ \\
PAD (mmHg) & $77,2+/-8,1$ & $77,5+/-6,6$ & $\mathrm{NS}$ \\
\hline IMC = Indice de Massa Corporal & C.Abdo = Circunferência Abdominal \\
PAS = Pressão Arterial Sistólica & PAD =Pressão Arterial Diastólica
\end{tabular}


Dados Laboratoriais

Como esperado, os pacientes do grupo HDL-C Baixo apresentaram concentrações mais baixas de HDL-C que os pacientes do grupo Controle. As concentrações de Colesterol Total e LDL-C foram semelhantes em ambos os grupos. Porém, as concentrações basais de glicemia e triglicérides foram mais altos no grupo HDL-C Baixo que no grupo controle, apesar dos valores de ambos serem compatíveis com a normalidade (Tabela 2).

Tabela 2: Dados Laboratoriais Basais dos dois grupos.

\begin{tabular}{|c|c|c|c|}
\hline & Controle $(n=11)$ & HDL-C Baixo $(n=30)$ & $\mathbf{p}$ \\
\hline Glicose & $89,9+/-7,8$ & $96,2+/-8,6$ & $<0,05$ \\
\hline Colesterol Total & $174,3+/-34,4$ & $165,5+/-27,3$ & NS \\
\hline HDL-C & $50,6+/-11,7$ & $34,3+/-4,6$ & $<0,001$ \\
\hline LDL-C & $107,9+/-31,4$ & $108,4+/-25,1$ & NS \\
\hline Triglicérides & $78,9+/-35,1$ & $113,1+/-43,9$ & $<0,02$ \\
\hline
\end{tabular}

Reatividade Vascular Basal

Os pacientes do grupo HDL-C Baixo apresentaram uma menor Dilatação Mediada por Fluxo, ou seja, apresentaram uma pior função endotelial em relação ao grupo Controle. Porém, não houve diferença em relação à Dilatação Mediada por Nitrato, denotando uma função integra da camada muscular em ambos os grupos (Gráfico 1). 
Gráfico 1: COMPARAÇÃO DOS VALORES DE REATIVIDADE VASCULAR, DMF E DMN, ENTRE OS GRUPOS CONTROLE E

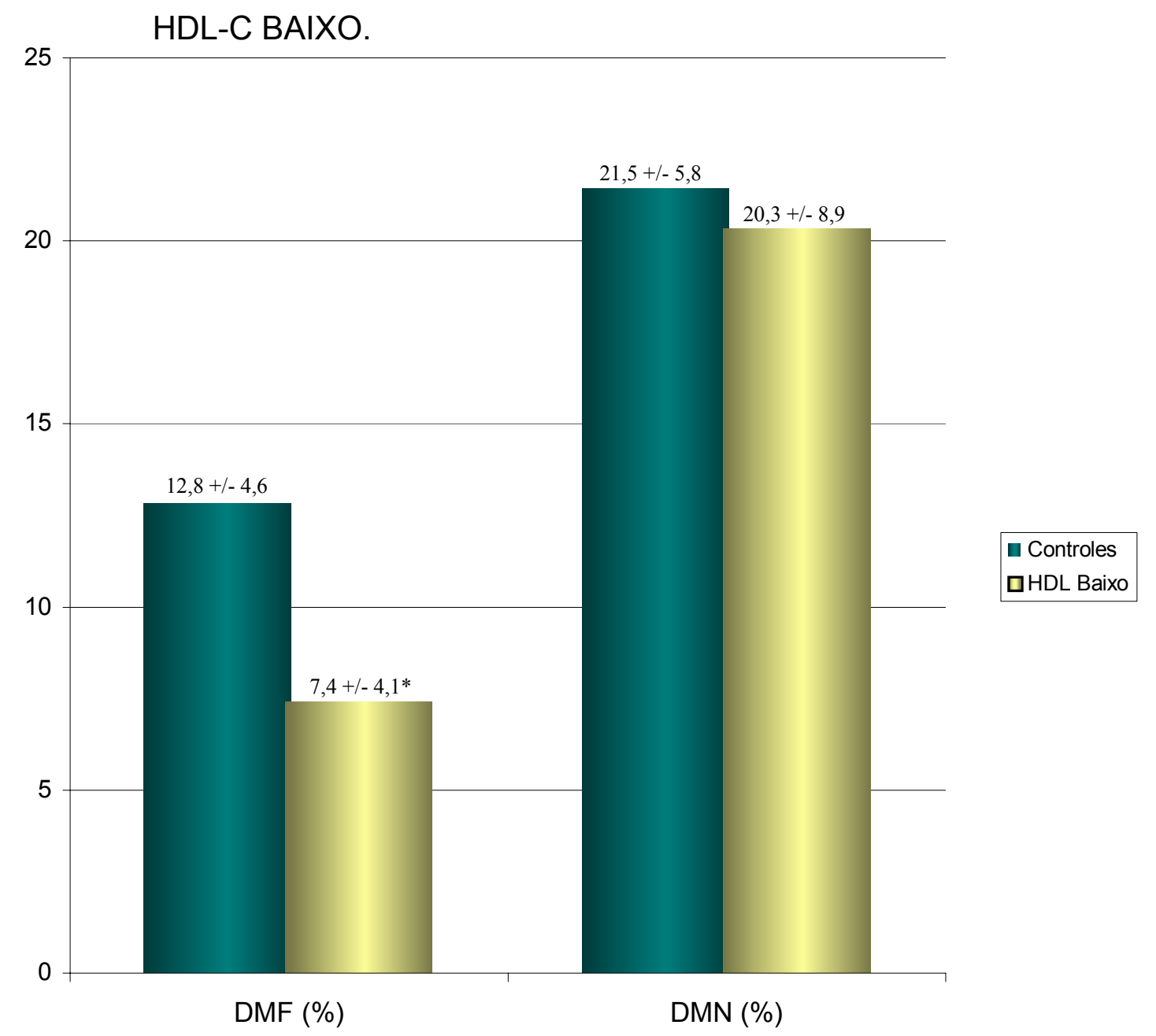

${ }^{*} \boldsymbol{p}<0,001$ em relação ao grupo Controle

DMF = Dilatação Mediada por Fluxo, e DMN = Dilatação Mediada por Nitrato Valores em \%

Dados de Cinética de Quilomícrons Artificiais

Os indivíduos do Grupo HDL-C Baixo apresentaram uma lentificação na remoção do colesterol éster dos remanescentes de quilomícrons, demonstrada pela menor TRF-CE em relação aos controles. A TRF-TG, foi 
similar em ambos os grupos, mostrando uma lipólise normal em ambos os grupos (Gráfico 2).

Gráfico 2: $\quad$ COMPARAÇÃO DOS VALORES DAS TAXAS DE REMOÇÃO FRACIONAL DE TRIGLICÉRIDES E DE COLESTEROL ÉSTER ENTRE OS GRUPOS CONTROLE E HDL-C BAIXO.

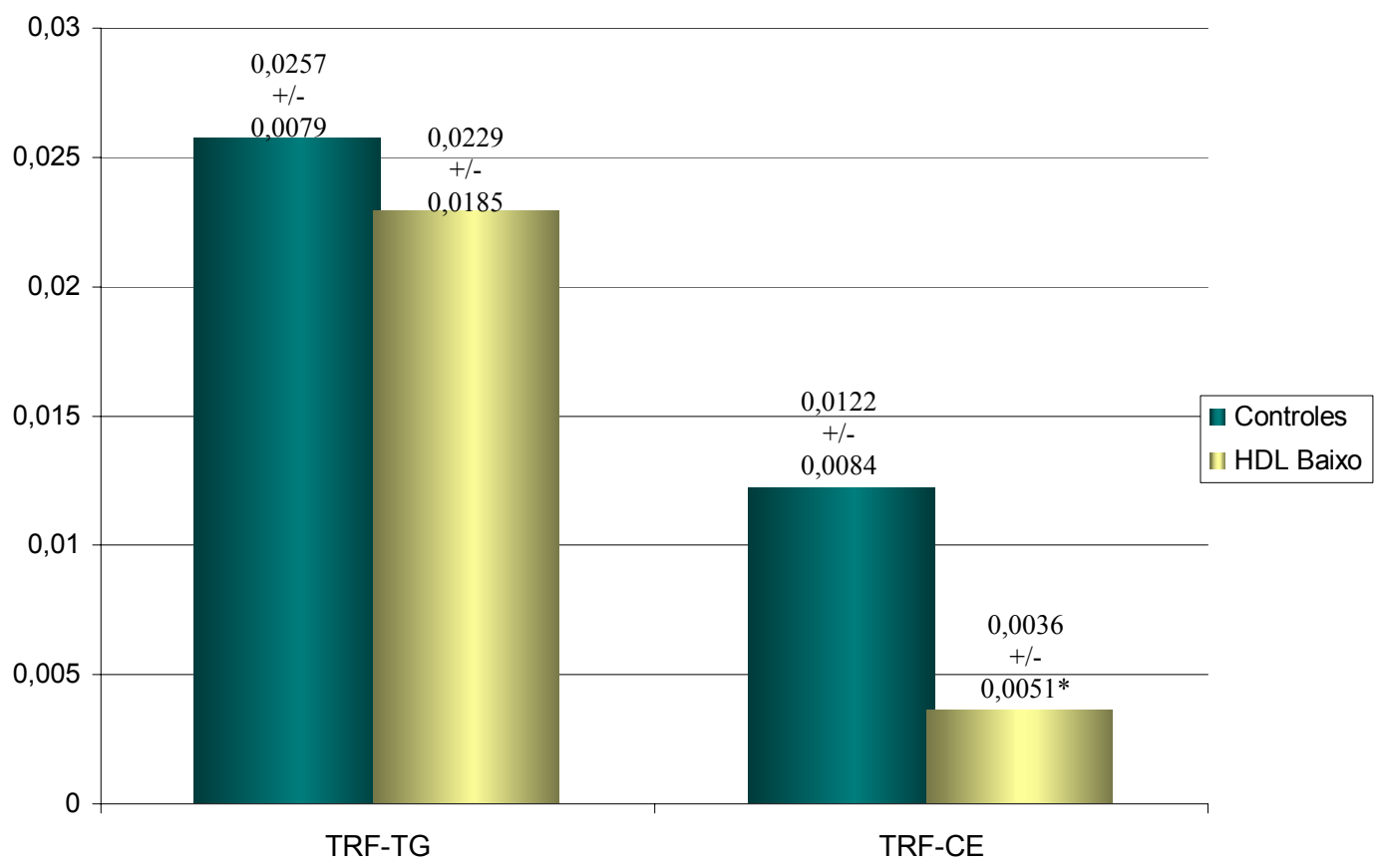

${ }^{*} \mathbf{p}<\mathbf{0 , 0 0 8}$ em relação ao grupo Controle

TRF-TG = Taxa de Remoção Fracional de Triglicérides

TRF-CE = Taxa de remoção Fracional de Colesterol Éster.

Valores em $\min ^{-1}$ 
Análise de correlação

Foi realizada análise de correlação entre as variáveis DMF, DMN, TRF-TG, TRF-CE, idade, peso, IMC, glicose, colesterol total, HDL-C, LDL-C, triglicérides, pressão arterial sistólica e pressão arterial diastólica considerando significativo um $R$ igual ou superior a 0,5 se o $p$ fosse menor que 0,05 . Não foram encontradas correlações significativas entre essas variáveis.

\section{Efeitos do Tratamento}

Os pacientes do grupo HDL-C baixo foram divididos em 2 grupos conforme sua reatividade vascular. Os 8 pacientes com a DMF normal não foram seguidos; já os 22 com DMF menor que $8 \%$ foram aleatorizados em 2 grupos de 11 pacientes cada, e receberam placebo ou niacina por 3 meses.

Dados Laboratoriais - Lípides

Os pacientes dos grupos Placebo e Niacina apresentavam concentrações basais de HDL-C e Triglicérides similares. Porém, apesar da aleatorização, os pacientes do grupo Placebo apresentavam concentrações laboratoriais basais menores de Colesterol Total e LDL-C que o grupo 
Niacina.Após o tratamento não houve alterações significativas nos valores dos lípides em ambos os grupos.

Tabela 3: Valores de Colesterol Total e LDL-C nos grupos Placebo e Niacina antes e após o tratamento.

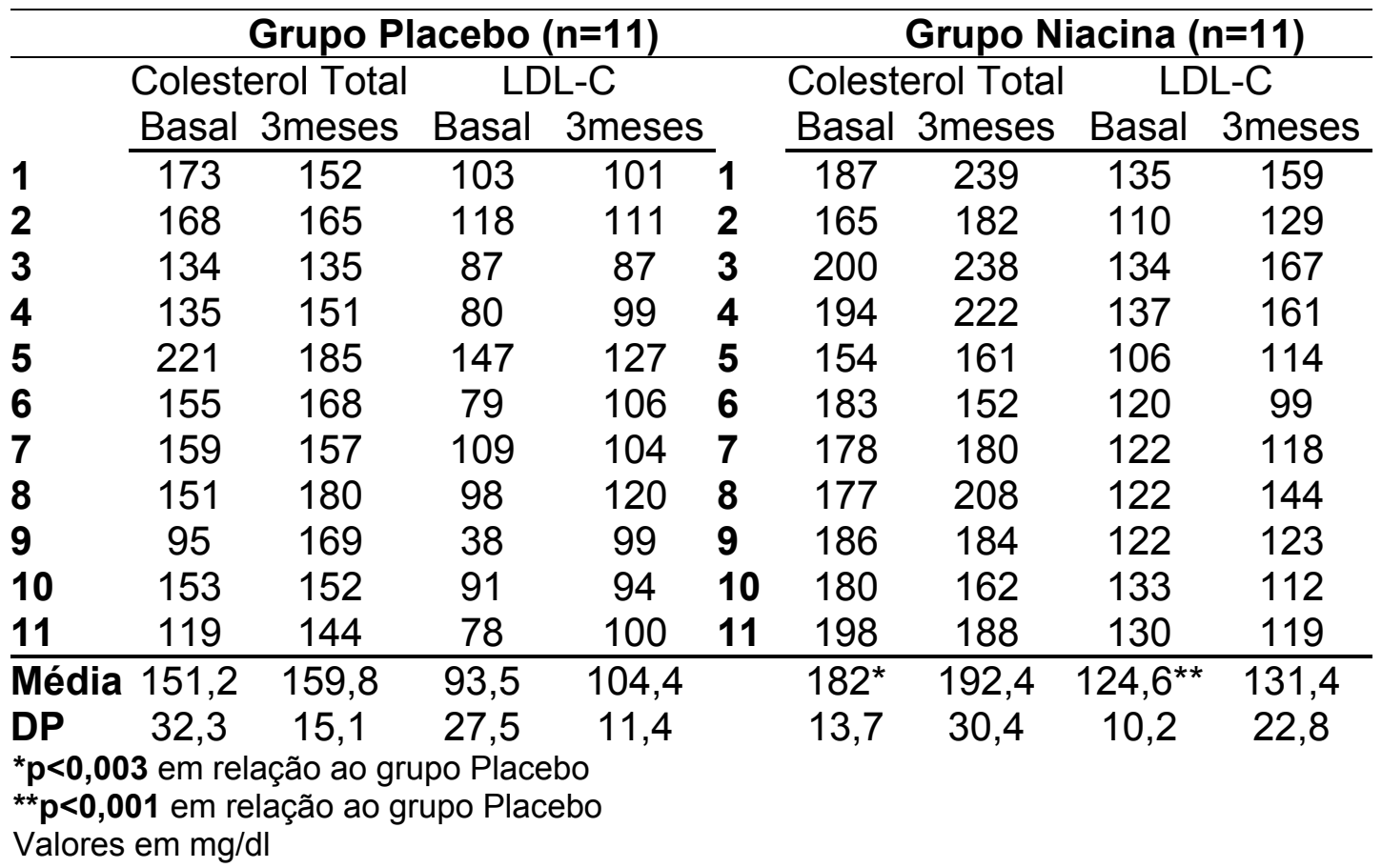

Tabela 4: Valores de HDL-C e Triglicérides nos grupos Placebo e Niacina antes e após o tratamento.

\begin{tabular}{|c|c|c|c|c|c|c|c|c|c|}
\hline & \multicolumn{5}{|c|}{ Grupo Placebo $(n=11)$} & \multicolumn{4}{|c|}{ Grupo Niacina $(n=11)$} \\
\hline & \multicolumn{2}{|c|}{ HDL-C } & \multicolumn{3}{|c|}{ Triglicérides } & \multicolumn{2}{|c|}{ HDL-C } & \multicolumn{2}{|c|}{ Triglicérides } \\
\hline & Basal & 3 meses & Basal & 3meses & & Basal & 3 meses & Basal & 3meses \\
\hline 1 & 39 & 35 & 157 & 80 & 1 & 40 & 49 & 60 & 153 \\
\hline 2 & 37 & 41 & 63 & 67 & 2 & 36 & 38 & 96 & 74 \\
\hline 3 & 29 & 31 & 88 & 85 & 3 & 35 & 38 & 157 & 166 \\
\hline 4 & 38 & 38 & 83 & 72 & 4 & 32 & 34 & 126 & 134 \\
\hline 5 & 40 & 36 & 170 & 109 & 5 & 24 & 27 & 120 & 100 \\
\hline 6 & 37 & 42 & 193 & 102 & 6 & 37 & 34 & 128 & 93 \\
\hline 7 & 38 & 39 & 59 & 68 & 7 & 30 & 33 & 128 & 144 \\
\hline 8 & 40 & 43 & 66 & 83 & 8 & 35 & 35 & 101 & 143 \\
\hline 9 & 27 & 33 & 149 & 183 & 9 & 36 & 37 & 141 & 119 \\
\hline 10 & 27 & 27 & 175 & 157 & 10 & 34 & 38 & 65 & 62 \\
\hline 11 & 26 & 27 & 74 & 84 & 11 & 38 & 36 & 152 & 165 \\
\hline Média & 34,4 & 35,6 & 116,1 & 99,1 & & 34,3 & 36,3 & 115,8 & 123,0 \\
\hline DP & 5,8 & 5,6 & 52,2 & 37,8 & & 4,4 & 5,3 & 32,2 & 36,1 \\
\hline
\end{tabular}


Reatividade Vascular

Os pacientes do grupo Niacina apresentaram normalização da DMF após o tratamento, o que não ocorreu com os pacientes do grupo Placebo (Tabelas 5 e 6, e Gráficos 3 e 4). Um caso que exemplifica bem esta melhora é o paciente RABS, como se vê no gráfico 5 .

Já a DMN se manteve normal em ambos os grupos, variando não significativamente no grupo Placebo de $22,7+/-9,5 \%$ para $19,1+/-6,3 \%$, e no grupo Niacina de $17,7+/-9 \%$ para $21,7+/-9,5$.

Tabela 5: Valores de DMF e DMN no grupo Placebo antes e após o tratamento.

\begin{tabular}{|c|c|c|c|c|}
\hline \multirow{2}{*}{$\begin{array}{l}\text { Placebo } \\
11 \text { pacientes }\end{array}$} & \multicolumn{2}{|c|}{ DMF } & \multicolumn{2}{|c|}{ DMN } \\
\hline & Basal & 3 meses & Basal & 3 meses \\
\hline 1 & 6,15 & 6,14 & 18,13 & 12,02 \\
\hline 2 & 1,43 & 2,33 & 8,00 & 9,66 \\
\hline 3 & 6,85 & 7,30 & 43,23 & 22,68 \\
\hline 4 & 7,27 & 7,55 & 14,24 & 30,84 \\
\hline 5 & 4,48 & 5,90 & 28,37 & 21,16 \\
\hline 6 & 7,66 & 8,05 & 23,72 & 20,11 \\
\hline 7 & 1,61 & 3,84 & 28,93 & 27,32 \\
\hline 8 & 5,21 & 5,97 & 26,16 & 16,86 \\
\hline 9 & 6,25 & 2,34 & 20,16 & 18,67 \\
\hline 10 & 5,45 & 7,13 & 24,31 & 16,11 \\
\hline 11 & 4,93 & 6,06 & 14,32 & 15,05 \\
\hline Média & 5,21 & 5,69 & 22,69 & 19,13 \\
\hline DP & 2,07 & 2,00 & 9,45 & 6,27 \\
\hline
\end{tabular}

DMF=Dilatação Mediada por Fluxo DMN=Dilatação Mediada por Nitrato Valores em \% 
Tabela 6: Valores de DMF e DMN no grupo Niacina antes e após o tratamento.

\begin{tabular}{lccccc}
\hline Niacina & \multicolumn{2}{c}{ DMF } & & \multicolumn{2}{c}{ DMN } \\
\cline { 2 - 3 } \cline { 5 - 5 } \cline { 5 - 5 } pacientes & Basal & 3 meses & & Basal & 3 meses \\
\hline $\mathbf{1}$ & 6,83 & 15,80 & & 20,11 & 27,69 \\
$\mathbf{2}$ & 6,63 & 10,53 & & 33,67 & 11,11 \\
$\mathbf{3}$ & 6,47 & 12,53 & & 9,54 & 36,68 \\
$\mathbf{4}$ & 5,23 & 15,92 & & 10,00 & 18,27 \\
$\mathbf{5}$ & 6,78 & 8,99 & & 26,72 & 38,99 \\
$\mathbf{6}$ & 7,44 & 10,09 & & 9,96 & 15,74 \\
$\mathbf{7}$ & 1,95 & 4,86 & & 12,04 & 14,21 \\
$\mathbf{8}$ & 3,98 & 10,95 & & 13,69 & 24,74 \\
$\mathbf{9}$ & 6,46 & 14,17 & & 16,58 & 22,82 \\
$\mathbf{1 0}$ & 2,28 & 11,25 & & 10,95 & 11,85 \\
$\mathbf{1 1}$ & 5,76 & 7,35 & & 31,42 & 16,86 \\
\hline Média & 5,44 & $11,13^{*}$ & & 17,70 & 21,72 \\
DP & 1,89 & 3,40 & & 9,01 & 9,52
\end{tabular}

DMF=Dilatação Mediada por Fluxo DMN=Dilatação Mediada por Nitrato

Valores em \%

${ }^{*} \mathrm{p}<0,001$

Gráfico 3: VARIAÇÃO DA DMF COM O TRATAMENTO COM PLACEBO.

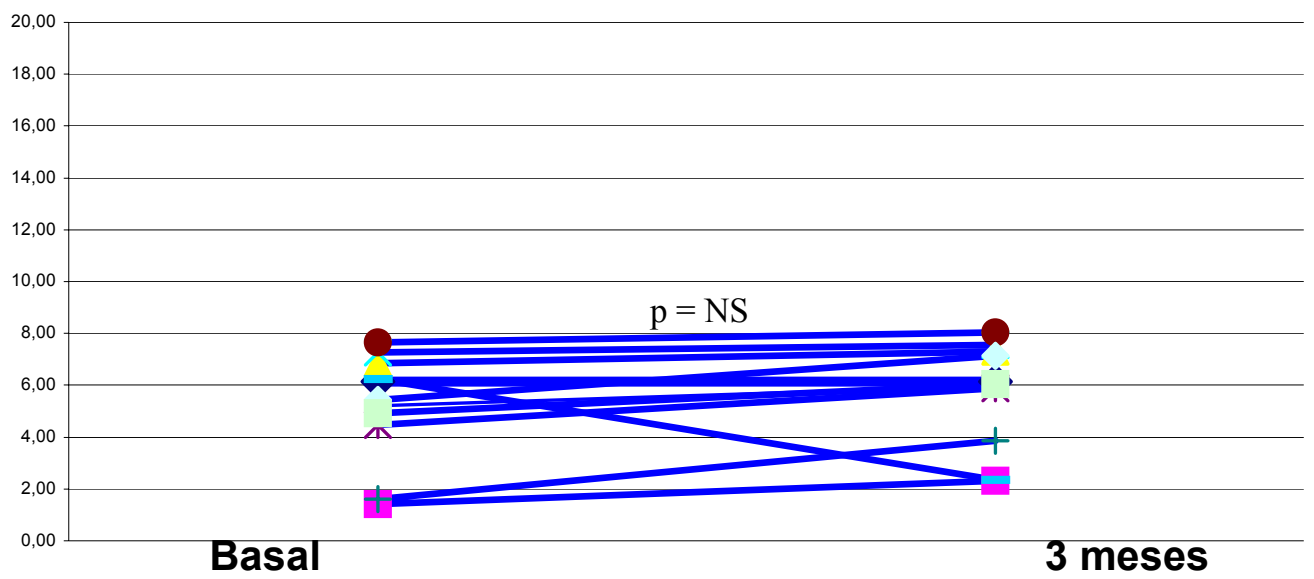

DMF = Dilatação Mediada por Fluxo

NS = Não Significativo

Valores em \% 
Gráfico 4: VARIAÇÃO DA DMF COM O TRATAMENTO COM NIACINA.

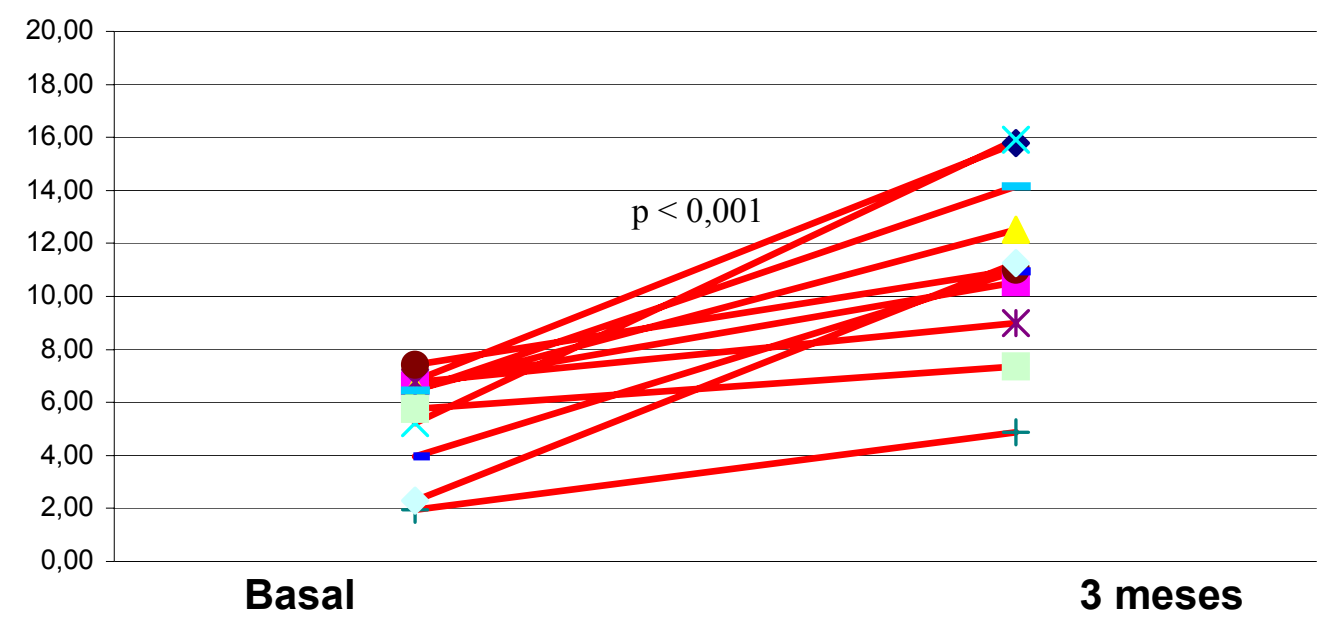

DMF = Dilatação Mediada por Fluxo

Valores em \%

Gráfico 5:EXEMPLO DE CASO ( PACIENTE RABS) MOSTRANDO A VARIAÇÃO DA DMF E DA DMN COM O TRATAMENTO COM NIACINA.

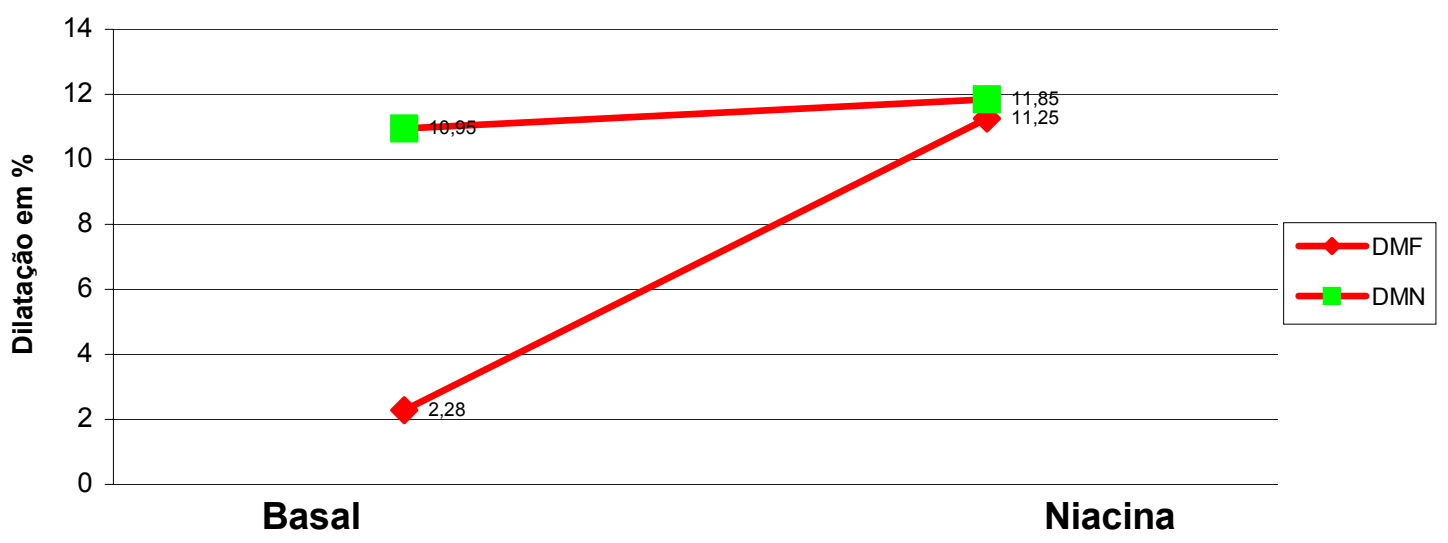


Cinética de Quilomícrons Artificiais

Da mesma forma que as concentrações lipídicas não se alteraram, tampouco se alterou a cinética de quilomícrons artificiais (Tabela 7).

Tabela 7:Valores de TRF-TG e TRF-CE nos grupos Placebo e Niacina antes e após o tratamento.

\begin{tabular}{lccc}
\hline & Placebo $(\mathbf{n}=11)$ & & Niacina $(\mathbf{n}=11)$ \\
\cline { 2 - 2 } TRF-TG Basal & $0,0232+/-0,0260$ & & $0,0198+/-0,0126$ \\
TRF-TG 3 m & $0,0169+/-0,0134$ & & $0,0196+/-0,0187$ \\
TRF-CE Basal & $0,0044+/-0,0062$ & & $0,0012+/-0,0022$ \\
TRF-CE 3 m & $0,0015+/-0,0026$ & & $0,0050+/-0,0072$
\end{tabular}

TRF-TG = Taxa de Remoção Fracional de Triglicérides

TRF-CE = Taxa de Remoção Fracional de Colesterol Éster

Valores em $\min ^{-1}$

Efeitos Colaterais - Dados Clínicos e Laboratoriais

A niacina e o placebo foram muito bem tolerados, não havendo nescessidade de se descontinuar o tratamento de nenhum dos pacientes. Os efeitos colaterais clínicos ocorreram em apenas um paciente do grupo Placebo e outro do grupo Niacina que apresentavam dispepsia e cefaléia, respectivamente, a ingesta da medicação.

Laboratorialmente, diferentemente do esperado, houve uma diminuição nas concentrações glicêmicas dos pacientes de ambos os grupos em relação ao basal. As concentrações de ácido úrico, AST e ALT não se alteraram (Tabelas 8 e 9). 
Tabela 8: Efeitos do tratamento com placebo nas concentrações séricas de glicose, ácido úrico, AST e ALT.

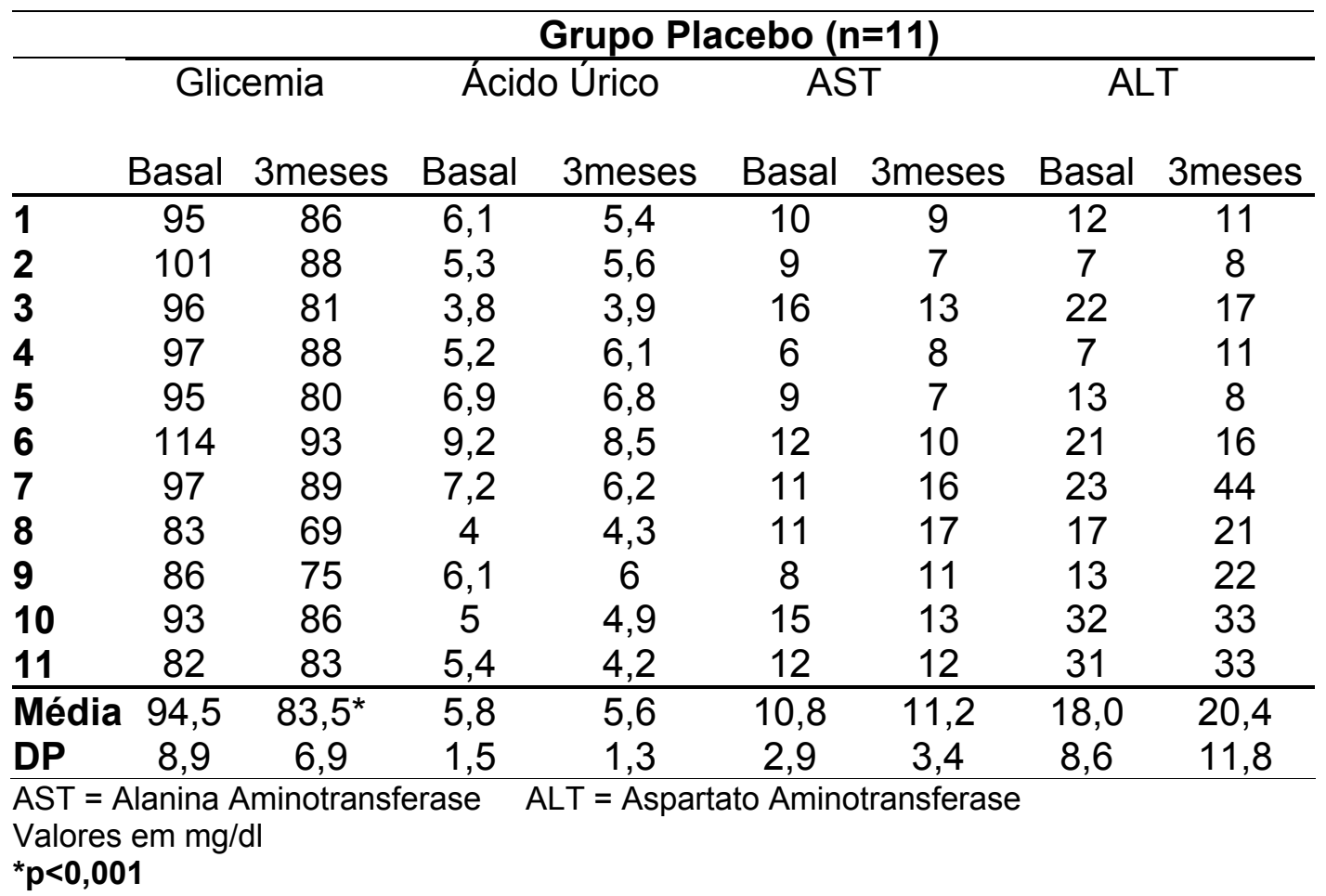

Tabela 9: Efeitos do tratamento com niacina nas concentrações séricas de glicose, ácido úrico, AST e ALT.

\begin{tabular}{|c|c|c|c|c|c|c|c|c|}
\hline & \multicolumn{8}{|c|}{ Grupo Niacina $(n=11)$} \\
\hline & \multicolumn{2}{|c|}{ Glicemia } & \multicolumn{2}{|c|}{ Ácido Úrico } & \multicolumn{2}{|c|}{ AST } & \multicolumn{2}{|c|}{ ALT } \\
\hline & Basal & 3 meses & Basal & 3 meses & Basal & 3 meses & Basal & 3 meses \\
\hline 1 & 90 & 92 & 5,7 & 6,7 & 11 & 13 & 24 & 25 \\
\hline 2 & 97 & 90 & 6,3 & 6,4 & 10 & 10 & 15 & 12 \\
\hline 3 & 93 & 86 & 4,6 & 5,2 & 9 & 9 & 11 & 13 \\
\hline 4 & 97 & 94 & 6,3 & 6,2 & 13 & 14 & 28 & 31 \\
\hline 5 & 100 & 93 & 6 & 5,5 & 9 & 10 & 10 & 8 \\
\hline 6 & 101 & 89 & 4,2 & 4,4 & 8 & 8 & 12 & 10 \\
\hline 7 & 106 & 81 & 6,9 & 6,8 & 14 & 13 & 28 & 28 \\
\hline 8 & 100 & 87 & 7,9 & 7,4 & 9 & 11 & 17 & 17 \\
\hline 9 & 93 & 75 & 6,3 & 5,6 & 12 & 13 & 11 & 14 \\
\hline 10 & 99 & 83 & 6 & 4,6 & 9 & 9 & 10 & 11 \\
\hline 11 & 95 & 82 & 7,2 & 6,6 & 11 & 9 & 27 & 19 \\
\hline Média & 97,4 & $86,5^{*}$ & 6,1 & 5,9 & 10,5 & 10,8 & 17,5 & 17,1 \\
\hline DP & 4,5 & 5,9 & 1,1 & 1,0 & 1,9 & 2,1 & 7,7 & 7,8 \\
\hline
\end{tabular}




\section{DISCUSSÃO}




\section{Discussão}

Os principais achados deste estudo foram:

a. indivíduos com o HDL-C baixo têm diminuição significativa da reatividade vascular endotélio dependente; b. indivíduos com o HDL-C baixo têm diminuição na remoção de colesterol éster de partícula artificial lipídica; c. houve restauração da função endotelial nos indivíduos que tomaram niacina sem haver alterações significativas nos lípides, inclusive nas concentrações de HDL-C. d. não houve modificações da cinética de lípides com niacina de liberação lenta.

Vários pontos do estudo merecem discussão, como será visto à seguir.

\section{Valores Basais - Comparação entre os grupos}

Os resultados dos pacientes do grupo HDL-C Baixo foram similares ao grupo Controle em relação à idade, altura, colesterol total, LDL-C, pressão arterial, DMN e TRF-TG; no entanto HDL-C, DMF e TRF-CE foram menores no grupo HDL-C Baixo, enquanto glicemia, triglicérides, peso, IMC e circunferência abdominal foram maiores. Tentando relacionar os valores dos triglicérides e da glicemia com os dados de peso, IMC e circunferência abdominal, nota-se que os dados de glicemia parecem ser casuais, pois não 
se repetem nos pacientes seguidos; nem no grupo Niacina, tampouco no Placebo; sendo estes no seguimento similares ao grupo placebo .

Além disso as concentrações glicêmicas e de triglicérides foram em média não somente normais, mas dentro da faixa desejável, com os valores médios de glicemia inferiores a $100 \mathrm{mg} / \mathrm{dl}$ e os valores médios de triglicérides muito inferiores a $150 \mathrm{mg} / \mathrm{dl}$.

Pelas diferenças encontradas entre os dois grupos seria possível imaginar que a síndrome plurimetabólica fosse freqüente nos pacientes do grupo HDL-C baixo, e que esta pudesse ser responsável pela disfunção endotelial encontrada. Entretanto, utilizando-se os critérios do ATP III (pelo menos 3 dos seguintes: 1 -Circunferência abdominal $>102 \mathrm{~cm} ; 2-\mathrm{TG} \geq 150$ $\mathrm{mg} / \mathrm{dl} ;$ 3- HDL 40 mg/dl; 4- PAS $\geq 130$ e/ou PAD $\geq 85$ mmHg; e 5- Glicemia de jejum $\geq 110 \mathrm{mg} / \mathrm{dl}$ ) encontramos apenas 4 pacientes que se enquadram nestes critérios, dois dos quais com função endotelial normal. Além disso, se o critério para elevação da pressão fosse o da Organização Mundial da Saúde (OMS), PAS $\geq 140$ e/ou PAD $\geq 90 \mathrm{mmHg}$, apenas dois pacientes seriam considerados portadores da síndrome plurimetabólica, um dos quais com a DMF normal; os demais critérios da OMS para síndrome plurimetabólica não poderiam ser aplicados a esses pacientes pois demandariam teste oral de tolerância à glicose, avaliação da relação cinturaquadril e dosagem de microalbuminúria e clearence de creatinina não realizados nestes pacientes.

Além disso, os estudos que tentam relacionar a síndrome plurimetabólica à disfunção endotelial têm encontrado resultados díspares; 
por exemplo Thomas et al (2004) encontraram correlação entre ambas, diferentemente de Wendelhag et al (2002). Mesmo analisando separadamente os critérios da síndrome plurimetabólica os resultados permanecem díspares, havendo porém maior tendência a se valorizar a hiperglicemia, como no estudo de Thomas et al (2004), e a resistência insulínica, como nos estudos de Balletshofer et al (2000) e de Campia et al (2004); a primeira ausente e a segunda não aferida o que não em nossos pacientes. Mesmo os dados relacionados à obesidade são contraditórios, com Accini et al (2001) e Aggoun (2002) encontrando, e Joseph et al (2002) não encontrando relação entre disfunção endotelial e obesidade. Mesmo os estudos que encontram esta relação a associam à resistência insulínica ou à glicemia, como por exemplo Raitakari et al (2004). Um estudo recente (Jonkers et al, 2002) demonstrou que as concentrações de triglicérides per se não se associam à disfunção endotelial, a não ser quando associadas à resistência insulínica e, além disso, trabalhos que analisam a função endotelial em pacientes hipertrigliceridêmicos geralmente denominam hipertrigliceridemia leve valores maiores que $300 \mathrm{mg} / \mathrm{dl}$, (Lundman et al, 2001). Em suma, avaliando nossos pacientes em relação a síndrome plurimetabólica notamos que pelos critérios possíveis de utilização, os do ATP III, apenas 4 deles se enquadram na síndrome, e que metade destes têm função endotelial preservada. Isto corrobora a idéia de que a relação da síndrome metabólica com a função endotelial não é perfeita e se deve muito mais à disglicemia que aos demais fatores, e que a provável causa da 
disfunção endotelial em nossos pacientes realmente são as concentrações de HDL-C.

Ou seja, em nossos dados demonstramos que concentrações baixas de HDL-C relacionam-se à pior função endotelial, demonstrada pela menor Dilatação Mediada por Fluxo. Este achado poderia em parte explicar a elevada susceptibilidade de pacientes com HDL-C baixo ao desenvolvimento precoce de aterosclerose, mesmo na ausência de outros fatores de risco. Como a disfunção endotelial é um fenômeno inicial na aterosclerose, o HDLC baixo poderia ser visto como um fator desencadeante de todo processo. Estudos prévios já haviam relacionado concentrações baixas de HDL-C à disfunção endotelial, porém em geral em pacientes coronariopatas ou com outros fatores de risco (Toikka et al, 1999; Li et al, 2000; Zhang et al, 2000; Kuvin et al, 2002).

Quanto à Cinética de Quilomícrons Artificiais nota-se que a Taxa de Remoção Fracional de Colesterol Éster dos pacientes com HDL-C baixo foi muito diminuída em relação ao grupo Controle. Isso identifica uma lentificação na remoção de remanescentes de quilomícrons, sendo este outro possível mecanismo pelo qual as concentrações baixas de HDL-C geram a aterosclerose.

Vários estudos têm relacionado alterações na cinética de quilomícrons artificiais, em especial na remoção dos remanescentes, à doença coronária (Maranhão et al, 1996; Martins et al, 1995) e ao aumento do LDL-C e dos triglicérides (Sposito et al, 2002; Santos et al, 2001). Porém não foram encontrados estudos com esta técnica em pacientes com HDL-C baixo 
isoladamente. Entretanto, foram encontrados estudos analisando a lipemia pós-prandial em indivíduos com HDL-C baixo e normotrigliceridêmicos (Couillard et al, 2000; Cohen, Grundy, 1992); em ambos, diferentemente de nosso estudo, não se verificou associação do HDL-C baixo com a lipemia pós-prandial. Estes estudos diferem do nosso por utilizarem outras técnicas para avaliação de lipemia pós-prandial; Couillard et al avaliaram apenas a trigliceridemia pós-prandial, enquanto Cohen e Grundy utilizaram a técnica de sobrecarga lipídica com retinil palmitato que depende da absorção deste pelo trato gastro-intestinal; a metodologia utilizada em nosso estudo tem como vantagem, em relação aos demais métodos, a característica de não depender da quantidade de gordura absorvida pelo paciente, que é variável entre indivíduos e mesmo em um mesmo indivíduo em momentos diferentes, tal diferença pode ao menos em parte explicar o fato de termos encontrado diferenças na permanência de remanescentes.

Cabe ressaltar que os remanescentes de quilomícrons são direta e indiretamente aterogênicos. Diretamente, pela interação com a parede vascular levando a um maior estresse oxidativo, por lesão endotelial causada por constituintes como lisofosfatidilcolina e oxiesteróis, por efeitos pró-trombóticos e por estimulação da produção endotelial de moléculas de adesão. Indiretamente, por sua influência na composição de outras lipoproteínas como o HDL-C e o LDL-C (Wilhelm e Cooper, 2003). As alterações encontradas no metabolismo destes remanescentes nos pacientes com HDL-C baixo são um mecanismo inequívoco de aterogênese. 
Em suma, vários estudos demonstraram a importância do HDL-C baixo nas doenças cardiovasculares, como o PROCAM que o classificou como fator de risco maior que hipertensão e diabetes. Em nosso meio, Magalhães (2003) demonstrou o HDL-C baixo como marcador de mortalidade após cirurgia de revascularização miocárdica, porém não demonstraram seus mecanismos de ação. Este estudo sugere a disfunção endotelial e a alteração na cinética de quilomícrons, como dois desses mecanismos.

Resultados do tratamento - Niacina X Placebo

Reatividade Vascular e Lípides Séricos

Como visto, os pacientes tratados com niacina apresentaram normalização da função endotelial; diferentemente dos tratados com placebo, apesar de terem colesterol total e LDL-C maiores. Apesar disso não houve melhora nas concentrações de lípides. Tal dado foi interessante já que o único estudo encontrado com niacina para o tratamento de disfunção endotelial (Kuvin et al, 2002) demonstrou, em pacientes coronariopatas com HDL-C baixo, o aumento das concentrações de HDL-C e a melhora da função endotelial, demonstrando também, em culturas de células endoteliais humanas expostas ao HDL-C, o aumento na expressão da eNOS; sugerindo 
que a melhora na função endotelial foi devida ao aumento do HDL-C. Em nosso estudo, no entanto, não encontramos esta associação.

Diversos possíveis motivos para a não elevação das concentrações de HDL-C podem ser invocados. A falta de aderência ao tratamento está descartada pois os pacientes eram solicitados a trazer os frascos com os comprimidos restantes, sendo possível confirmar diretamente a aderência, além disso é possível confirmar indiretamente a aderência pela melhora ocorrida na DMF dos pacientes do grupo Niacina, diferentemente do que ocorreu ao grupo Placebo. Dois outros fatores seriam o tempo de tratamento e a quantidade da droga administrada. Porém, diversos estudos demonstraram que o período de 8 a 12 semanas é suficiente para melhora do perfil lipídico e que $1,5 \mathrm{~g} /$ dia é dose suficiente para tal; entre estes estudos podemos citar dois estudos realizados nesta instituição pelo Dr. Sposito e colaboradores (1999 e 2001) utilizando apenas 1 g/dia de niacina de liberação lenta, o que praticamente descarta estas possibilidades.

Outra possibilidade para o efeito benéfico da niacina sobre a DMF é seu efeito nas concentrações das sub-frações de HDL-C, o que não foi aferido na presente investigação; em estudo recente de associação de niacina com lovastatina comparada a sinvastatina e a atorvastatina (Bays et al, 2003) demonstrou-se um aumento muito maior das concentrações de HDL-C 2 nos pacientes que utilizaram a niacina, sendo que estudos prévios sugerem que esta sub-fração seja mais cardioprotetora que o HDL-C 3 (Cheung et al, 1991; Griffin et al, 1988). Outra possibilidade poderia ser o aumento do conteúdo de Apo A-I do HDL-C gerado pela niacina ao diminuir 
a taxa de catabolismo fracional da Apo A-I, diminuíndo sua captação pelo fígado , como demonstrado por Sakai et al (2001); a Apo A-I parece ser responsável pela maior quantidade de eNOS gerada pelo HDL-C já que Rämet et al (2003) demonstraram que os efeitos da HDL-C e da Apo A-I isolada não diferiam em relação ao aumento da eNOS.

Outra hipótese seria o melhor funcionamento do HDL-C por alterações da atividade das proteínas e enzimas a ele relacionadas, o que não foi dosado em nosso estudo. Por exemplo, sabe-se que polimorfismos de paroxonase (PON1) e de proteína de transferência de colesterol éster (CETP) estão relacionados ao aumento da espessura íntima-média da carótida (Leus et al, 2000; Kakko et al, 2000); porém não foram encontrados estudos que avaliassem o efeito da niacina sobre estas. Ainda sobre a PON1, sabe-se que ela diminui a peroxidação do LDL-C; sabe-se também que o LDL-C oxidado leva a uma pior função endotelial (Heitzer et al, 1996); um aumento da atividade da PON1 poderia diminuir a oxidação do LDL-C e melhorar a função endotelial. Em relação à proteína de transferência de fosfolípides (PLTP), níveis baixos de atividade de PLTP se relacionam a concentrações baixas de Apo A-I em pacientes com HDL-C baixo e DAC. Por outro lado a PLTP previne a disfunção endotelial por aumentar a oferta de alfa-tocoferol às células endoteliais (Desrumaux et al, 1999); porém, em estudo recente, Cheung et al (2001) demonstraram que a terapêutica com niacina associada a sinvastatina não se associa a alterações na PLTP.

Estudos mais recentes forneceram dados importantes sobre a atuação da niacina na inflamação. Assim, foi descrito o efeito da niacina 
bloqueando a transcrição de NF-Kappa B na fibrose pulmonar ( Gurujeyalaksmi et al, 2000; Giri, 2003). Além disso também foram descritos os efeitos da niacina na via de AMPc/proteína quinase $A$ e na estimulação da formação da prostaglandina D2, cujo metabólito 15-deoxi-delta $(12,14)$ prostaglandina $\mathrm{J} 2$ foi recentemente identificado como $\mathrm{o}$ mais potente ativador endógeno de PPAR gama; a niacina estimulou, em monócitos, a translocação e a transcrição de PPAR gama, bem como a transcrição de CD36 e ABCA1; o efeito sobre o CD36 foi bloqueado pela inibição da ciclooxigenase; e o sobre o ABCA1 pela inibição da proteína quinase $A$ (Rubic et al, 2004).

Em síntese, os efeitos da niacina sobre a reatividade vascular parecem ser pleiotrópicos, já que esta não alterou as concentrações lipídicas; descarta-se a falta de aderência e tempo ou dose inadequados para o efeito. Alterações nas sub-frações e no conteúdo do HDL-C poderiam explicar estes efeitos, bem como a atividade das proteínas e enzimas relacionadas ao $\mathrm{HDL}$, ou mesmo os efeitos anti-oxidantes ou antiinflamatórios, porém estes dados não foram avaliados no presente estudo.

\section{Cinética de Quilomícrons Artificiais}

Em relação à utilização de niacina na avaliação da cinética de quilomícrons foi encontrado apenas um estudo do Laboratório de Lípides do InCor (Dr. Raul C. Maranhão) que utilizou etofibrato, droga híbrida que combina niacina com clofibrato em pacientes coronariopatas com perfil 
lipídico bastante diverso do nosso grupo (colesterol total de $240 \pm 41 \mathrm{mg} / \mathrm{dl}$, LDL-C maior que $130 \mathrm{mg} / \mathrm{dl}$, em média $162 \pm 38 \mathrm{mg} / \mathrm{dl}$, HDL-C $39 \pm 7 \mathrm{mg} / \mathrm{dl} \mathrm{e}$ triglicérides $188 \pm 42 \mathrm{mg} / \mathrm{dl}$ ), havendo melhora da lipólise e da remoção de remanescentes de quilomícrons (Sposito et al, 2001). Neste mesmo sentido Santos et al. (2001), igualmente no Laboratório de Lípides do InCor, demonstraram que o gemfibrozil melhorou a lipólise e a remoção de remanescentes de quilomícrons em pacientes com hipertrigliceridemia endógena. Estes dados podem sugerir que a melhora com o etofibrato se deveu ao componente fibrato da droga e não à niacina, o que estaria em acordo com este estudo; entretanto não se pode descartar que o efeito positivo da niacina ou do fibrato se deva à ação nos demais lípides, que estavam elevados, e não no HDL-C; isto explicaria a ausência de resposta à niacina em nosso estudo. Não foram, entretanto, encontrados estudos utilizando apenas niacina.

Foram também encontrados estudos clínicos e experimentais com estatina (Santos et al, 2000; Sposito, 2003) e probucol (Mamo et al, 1993), todos com respostas favoráveis; no entanto em todos havia associação de fatores de risco .

No presente estudo, dicotomizando a resposta em melhora ou não da TRF-CE, os pacientes do grupo Placebo apresentaram comportamento homogêneo, não havendo melhora em nenhum; já os pacientes do grupo Niacina se comportaram de forma heterogênea com quatro pacientes apresentando melhora significativa da TRF-CE que se tornou compatível com a média do grupo Controle; tal dado sugere que esta alteração na 
cinética de lípides relacionada ao HDL-C baixo possa ter múltiplas causas com alguns pacientes respondendo e outros não a determinados tratamentos; assim a combinação de terapêuticas pode ser um caminho, como demonstrado por O'Keffe et al (1995); no estudo a associação de pravastatina e niacina diminuiu a lipemia pós-prandial e a presença de remanescentes, porém a pravastatina sozinha não apresentou tal efeito.

Outra consideração é que, apesar de haver estudos relacionando a hipertrigliceridemia pós-prandial à pior reatividade vascular (Lundman et al, 1997; Gaenzer et al, 2001) e a hipetrigliceridemia pós-prandial à presença de remanescentes (Geurian et al, 1992), podendo se supor que a presença de remanescentes estaria relacionada à pior reatividade vascular, esta relação não se mostrou válida em nosso estudo. De fato, apesar de inicialmente a reatividade vascular e a cinética de quilomícrons parecerem se relacionar, após o tratamento a primeira se normalizou e a segunda não.

\section{Efeitos Colaterais}

Como visto os pacientes de ambos os grupos não apresentaram alterações laboratoriais importantes em relação ao lípides; tal também é verdadeiro para as aminotransferases hepáticas e para o ácido úrico; isto é importante pois um fator limitante de qualquer terapia são os efeitos colaterais. A literatura mostra a hepatite medicamentosa e a gota como efeitos colaterais, ainda que raros, temidos no uso de niacina. Apesar da 
amostra reduzida e do tempo exíguo de uso, não observamos quaisquer modificações.

Em relação a hiperglicemia e ao desenvolvimento de diabetes, possíveis com a niacina, nossos pacientes tiveram o efeito oposto com diminuição dos valores de glicemia de jejum, tanto nos pacientes do grupo Niacina, quanto nos pacientes do grupo Placebo.

A niacina foi portanto tão bem tolerada quanto o placebo em nosso estudo. 


\section{Limitações}

Apesar de estatisticamente adequado este foi um estudo breve e com poucos pacientes, podendo haver efeitos benéficos ou adversos não observados por isto. Por exemplo, as alterações da TRF-CE com o uso de niacina talvez se mostrassem significativas em uma amostra maior. Neste mesmo sentido, outra limitação foi a impossibilidade de encontrar um grupo de pacientes com HDL-C baixo que fosse totalmente similar ao grupo Controle. Em relação à estas limitações salientamos a dificuldade de encontrar indivíduos saudáveis com HDL-C baixo sem outras alterações lipídicas ou outros fatores de risco cardiovascular.

\section{Relevância}

O HDL-C baixo é conhecidamente aterogênico, porém seus mecanismos de ação ainda não estão totalmente elucidados. Estes dados permitem identificar a disfunção endotelial e a deficiência na remoção de remanescentes de quilomícrons como mecanismos facilitadores de aterosclerose em indivíduos com HDL-C baixo.

Além disso, sugere-se a presença de efeito pleiotrópico da niacina de liberação lenta corrigindo a disfunção endotelial sem agir em lípides; possivelmente mecanismos anti-inflamatórios ou anti-oxidantes e a ação nas sub-frações de HDL-C ou na disponibilidade de óxido nítrico expliquem tais achados. 


\section{Conclusões}

Este estudo demonstrou que:

a) Concentrações baixas de HDL-C associaram-se com disfunção endotelial, caracterizada por menor DMF.

b) Concentrações baixas de HDL-C associaram-se também com menores taxas de remoção fracional de colesterol éster de quilomícrons artificiais, ou seja, associam-se a uma maior permanência de remanescentes de quilomícrons no plasma.

c) O uso de niacina de liberação lenta corrigiu a disfunção endotelial sem agir nas concentrações lipídicas ou na cinética de lípides. 


\section{Bibliografia}

ACCINI, J.L.; SOTOMAYOR, A.; TRUJILLO, F.; BARRERA, J.G.; BAUTISTA, L.; LOPEZ-JARAMILLO, P. Colombian study to assess the use of noninvasive determination of endothelium-mediated vasodilatation (CANDEV). Normal values and factors associated. Endothelium, v.8, p.15766, 2001.

ADAMS, M.R.; CELERMAJER, D.S. Detection of presymptomatic atherosclerosis: a current perspective. Clin. Sci. (Lond), v.97, p.615-24, 1999.

AGGOUN, Y.; TOUNIAN, P.; DABBAS-TYAN, M.; MASSIH, T.A.; GIRARDET, J.P.; RICOUR, C.; SIDI, D.; BONNET, D. Arterial rigidity and endothelial dysfunction in obese children. Arch. Mal. Coeur Vaiss, v.95, p.631-5, 2002.

ALLAIN, C.C.; PONN, L.S.; CHAN, C.S.G.; RICHMOND, W.; FU, P.C. Enzymatic determination of total serum cholesterol. Clin. Chem., v. 20, p.470-5, 1974 .

ANGELIN, B.; PARINI, P.; ERIKSSON, M. Reverse cholesterol transport in man: promotion of fecal steroid excretion by infusion of reconstituted HDL-C. Atheroscler. Suppl., v.3, p.23-30, 2002. 
ASSMANN, G.; CULLEN, P.; SCHULTE, H. Simple scoring scheme for calculating the risk of acute coronary events based on the 10-year follow-up of the prospective cardiovascular Munster (PROCAM) study. Circulation, v.105, p.3101-5, 2002.

ASSMANN, G.; SCHRIEWER,H.; SCHMITZ, G. Quantification of highdensity lipoprotein cholesterol by precipitin with phosphotungstic acid / MgCl2. Clin. Chem., v. 29, p. 2026-30, 1983.

ATTIE, A.D.; KASTELEIN, J.P.; HAYDEN, M.R. Pivotal role of ABCA1 in reverse cholesterol transport influencing HDL levels and susceptibility to atherosclerosis. J. Lipid Res., v.42, p.1717-26, 2001.

BABAEV, V.R.; FAZIO, S.; GLEAVES, L.A.; CARTER, K.J.; SEMENKOVICH, C.F.; LINTON, M.F. Macrophage lipoprotein lipase promotes foam cell formation and atherosclerosis in vivo. J. Clin. Invest., v.103, p.1697-705, 1999.

BALLETSHOFER, B.M.; RITTIG, K.; ENDERLE, M.D.; VOLK, A.; MAERKER, E.; JACOB, S.; MATTHAEI, S.; RETT, K.; HARING, H.U. Endothelial dysfunction is detectable in young normotensive first-degree relatives of subjects with type 2 diabetes in association with insulin resistance. Circulation, v.101, p.1780-4, 2000. 
BAYS, H.E.; DUJOVNE, C.A.; MCGOVERN, M.E.; WHITE, T.E.; KASHYAP, M.L.; HUTCHESON, A.G.; CROUSE, J.R. ADvicor Versus Other CholesterolModulating Agents Trial Evaluation. Comparison of once-daily, niacin extended-release/lovastatin with standard doses of atorvastatin and simvastatin (the ADvicor Versus Other Cholesterol-Modulating Agents Trial Evaluation [ADVOCATE]). Am. J. Cardiol., V.91, p.667-72, 2003.

BERGE, K.G.; CANNER, P.L. Coronary Drug Project: experience with niacin. Coronary Drug Project Research Group. Eur. J. Clin. Pharmacol., v.40, p.S49-S51, 1982.

BERGE, K.E.; TIAN, H.; GRAF, G.A.; YU, L.; GRISHIN, N.V.; SCHULTZ, J.; KWITEROVICH, P.; SHAN, B.; BARNES, R.; HOBBS, H.H. Accumulation of dietary cholesterol in sitosterolemia caused by mutations in adjacent $A B C$ transporters. Science., v.290, p.1771-5, 2000.

BERGMEYER, H.U.; HORDER, M.; REJ, R. International Federation of Clinical Chemistry (IFCC) Scientific Committee, Analytical Section: approved recommendation (1985) on IFCC methods for the measurement of catalytic concentration of enzymes. Part 2. IFCC method for aspartate aminotransferase. J. Clin. Chem. Clin. Biochem., v.24, p.497-510, 1986. 
BERGMEYER, H.U.; HORDER, M.; REJ, R. International Federation of Clinical Chemistry (IFCC) Scientific Committee, Analytical Section: approved recommendation (1985) on IFCC methods for the measurement of catalytic concentration of enzymes. Part 3. IFCC method for alanine aminotransferase. J. Clin. Chem. Clin. Biochem., v.24, p.481-95, 1986.

BLOOMFIELD RUBINS, H.; DAVENPORT, J.; BABIKIAN, V.; BRASS, L.M.; COLLINS, D.; WEXLER, L.; WAGNER, S.; PAPADEMETRIOU, V.; RUTAN, G.; ROBINS, S.J.: VA-HIT Study Group. Reduction in stroke with gemfibrozil in men with coronary heart disease and low HDL-C cholesterol: The Veterans Affairs HDL-C Intervention Trial (VA-HIT). Circulation, v.103, p.2828-33, 2001.

BRANDIZZI, L.I.V. Metabolismo de Quilomícrons em pacientes portadores de doença arterial coronariana. Dissertação de Mestrado IPEN/USP, 2002.

BROWN, B.G.; ZHAO, X.Q.; CHAIT. A.; FISHER, L.D.; CHEUNG, M.C.; MORSE, J.S.; DOWDY, A.A.; MARINO, E.K.; BOLSON, E.L.; ALAUPOVIC, P.; FROHLICH, J.; SERAFINI, L.; HUSS-FRECHETTE, E.; WANG, S.; DEANGELIS, D.; DODEK, A.; ALBERS J.J. Simvastatin and Niacin, Antioxidant Vitamins, or the Combination for the Prevention of Coronary Disease. N. Engl. J. Med., v.345, p.1583-92, 2001. 
BROWN, M.S.; KOVANEN, P.T.; GOLDSTEIN, J.L. - Regulation of plasma cholesterol by lipoprotein receptors. Science, v.212, p.628-35,1981.

CAMPIA, U.; SULLIVAN, G.; BRYANT, M.B.; WACLAWIW, M.A.; QUON, M.J.; PANZA, J.A. Insulin impairs endothelium-dependent vasodilation independent of insulin sensitivity or lipid profile. Am. J. Physiol. Heart Circ. Physiol., v.286, p.H76-H82, 2004.

CANNER, P.L.; BERGE, K.G.; WENGER, N.K.; STAMLER, J.; FRIEDMAN, L.; PRINEAS, R.J.; FRIEDEWALD, W. Fifteen year mortality in Coronary Drug Project patients: long-term benefit with niacin. J. Am. Coll. Cardiol., v.8, p.1245-55, 1986.

CASHIN-HEMPHILL, L.; MACK, W.J.; POGODA, J.M.; SANMARCO, M.E.; AZEN, S.P.; BLANKENHORN, D.H. Beneficial effects of colestipol-niacin on coronary atherosclerosis. A 4-year follow-up. JAMA, v.264 p.3013-7, 1990.

CASTELLI, W.P.; DOYLE, J.T.; GORDON, T.; HAMES, C.G.; HJORTLAND, M.C.; HULLEY, S.B.; KAGAN, A.; ZUKEL, W.J. HDL cholesterol and other lipids in coronary heart disease. The cooperative lipoprotein phenotyping study. Circulation, v.55, p.767-72, 1977.

CELEMAJER, D.S.; SORENSEN, K.E.; GOOCH, V.M. Non-invasive detection of endothelial dysfunction in children and adults at risk of atherosclerosis. Lancet, v. 340, p. 1111-5, 1992. 
CELERMAJER, D.S.; SORENSEN, K.E.; GEORGAKOPOULOS, D.; BULL, C.; THOMAS, O.; ROBINSON, J.; DEANFIELD, J.E. Cigarette smoking is associated with dose-related and potentially reversible impairment of endothelium-dependent dilation in healthy young adults. Circulation, v.88, p.2149-55, 1993.

CELERMAJER, D.S.; SORENSEN, K.E.; BULL, C.; ROBINSON, J.; DEANFIELD, J.E. Endothelium-dependent dilation in the systemic arteries of asymptomatic subjects relates to coronary risk factors and their interaction. $\mathbf{J}$. Am. Coll. Cardiol., v.24, p.1468-74, 1994.

CELERMAJER, D.S.; SORENSEN, K.E.; SPIEGELHALTER, D.J.; GEORGAKOPOULOS, D.; ROBINSON, J.; DEANFIELD, J.E. Aging is associated with endothelial dysfunction in healthy men years before the agerelated decline in women. J. Am. Coll. Cardiol., v. 24, p. 471-6, 1994.

CELERMAJER, D.S.; ADAMS, M.R.; CLARKSON, P.; ROBINSON, J.; MCCREDIE, R.; DONALD, A.; DEANFIELD, J.E. Passive smoking and impaired endothelium-dependent arterial dilatation in healthy young adults. N. Engl. J. Med., v.1334, p.150-4, 1996.

CELEMAJER, D.S. Testing endothelial function using ultrasound. J. Cardiov. Pharmacology., v. 32, p.S29-S32, 1998. 
CHAMBENOIT, O.; HAMON, Y.; MARGUET, D.; RIGNEAULT, H.; ROSSENEU, M.; CHIMINI, G. Specific docking of apolipoprotein A-I at the cell surface requires a functional ABCA1 transporter. J. Biol. Chem., v.276, p. 9955-60, 2001.

CHEN, L.Y.; MEHTA, J.L. Inhibitory effect of high-density lipoproteins on platelet function is mediated by increase in nitric oxide synthase activity in platelets. Life Sci., v.55, p.1815-21, 1994.

CHEUNG, M.C.; WOLFBAUER, G.; KENNEDY, H.; BROWN, B.G.; ALBERS, J.J. Plasma phospholipid transfer protein activity in patients with low HDL and cardiovascular disease treated with simvastatin and niacin. Biochim. Biophys. Acta., v.1537, p.117-24, 2001.

CHEUNG, M.C.; BROWN, B.G.; WOLF, A.C.; ALBERS, J.J. Altered particle size distribution of apolipoprotein A-I-containing lipoproteins in subjects with coronary artery disease. J. Lipid. Res., v.32, p.383-94, 1991.

CHINETTI, G.; FRUCHART, J.C.; STAELS, B. Peroxisome proliferatoractivated receptors (PPARs): nuclear receptors at the crossroads between lipid metabolism and inflammation. Inflamm, Res., v.49, p.497-505, 2000. 
CLARKSON, P.; CELERMAJER, D.S.; POWE, A.J.; DONALD, A.E.; HENRY, R.M.; DEANFIELD, J.E. Endothelium-dependent dilatation is impaired in young healthy subjects with a family history of premature coronary disease. Circulation, v.96, p.3378-83, 1997.

CLARKSON, P.; MONTGOMERY, H.E.; MULLEN, M.J.; DONALD, A.E.; POWE, A.J.; BULL, T.; JUBB, M. WORLD, M.; DEANFIELD, J.E. Exercise training enhances endothelial function in young men. J. Am. Coll. Cardiol., v.33, p.1379-85, 1999.

COCKERILL, G.W.; RYE, K.A.; GAMBLE, J.R.; VADAS, M.A.; BARTER, P.J. High-density lipoproteins inhíbit cytokíne-índuced expression of endothelial cell adhesion molecules, Arterioscl. Thromb. Vasc. Biol., v.15, p.1987-94, 1995.

COHEN, J.D.; DRURY, J.H.; OSTDIEK, J.; FINN, J.; BABU, B.R.; FLAKER, G.; BELEW, K.; DONOHUE, T.; LABOVITZ, A. Benefits of lipid lowering on vascular reactivity in patients with coronary artery disease and average cholesterol levels: a mechanism for reducing clinical events? Am. Heart J., v.139, p.734-8, 2000. 
COLLINS, R.; PETO, R.; MACMAHON, S.; HEBERT, P.; FIEBACH, NH.; EBERLEIN, K.A.; GODWIN, J.; QIZILBASH, N.; TAYLOR, J.O.; HENNEKENS, C.H. Blood pressure, stroke, and coronary heart disease. Part 2, Short-term reductions in blood pressure: overview of randomised drug trials in their epidemiological context. Lancet, v.335, p.827-38, 1995.

COMISSÃO NACIONAL DE ENERGIA NUCLEAR (CNEN). Diretrizes Básicas de Radioproteção. São Paulo, 1988 [Norma 3.01].

COOKE, J.P.; ROSSITCH, E. JR; ANDON, N.A.; LOSCALZO, J.; DZAU, V.J. Flow activates na endothelial potassium channel to release na endogenous nitrovasodilatador. J. Clin. Invest., v. 88, p. 1663-71, 1991.

COOPER, A.D. Hepatic uptake of chylomicron remnants. J. Lipid Res., v.38, p.2173-92, 1997.

COOPER, R.; LIU, K.; STAMLER, J.; SCHOENBERGER, J.A.; SHEKELLE, R.B.; COLLETTE, P.; SHEKELLE, S. Prevalence of diabetes/hyperglycemia and associated cardiovascular risk factors in blacks and whites: Chicago Heart Association Detection Project in Industry. Am. Heart J., v.108, p.82733, 1984.

CORONARY DRUG PROJECT: Clofibrate and niacin in coronary heart disease. JAMA, v.231, p.360-81, 1975. 
CORRETTI, M.C.; ANDERSON, T.J.; BENJAMIN, E.J.; CELEMAJER, D.; CHARBONNEAU, F.; CREAGER, M.A .; DEANFIELD, J.; DREXLER, H.; GERHARD-HERMAN, M.; HERRINGTON, D.; VALLANCE, P.; VITA, J.; VOGEL, R. Guidelines for the ultrasound assessment of endothelialdependent flow-mediated vasodilatation of brachial artery. J. Am. Coll. Cardiol., v. 39, p. 257-65, 2002.

da LUZ, P.L., UINT, L. O endotélio na Aterosclerose: Interações Celulares e Vasomotricidde. In: da LUZ, P.L., LAURINDO F.R.M., CHAGAS A.C.P. Endotélio \& doenças cardiovasculares. $1^{\text {a }}$.Ed. São Paulo, Atheneu, 2003. p.133-60.

da LUZ, P.L., Favarato, D. A Disfunção Endotelial como ïndice Prognóstico e Alvo Terapêutico In: da LUZ, P.L., LAURINDO F.R.M., CHAGAS A.C.P. Endotélio \& doenças cardiovasculares. $1^{\mathrm{a}}$.Ed. São Paulo, Atheneu, 2003. p.203-20.

DECKELBAUM, R.J.; EISENBERG, S.; OSCHRY, Y.; GRANOT, E.; SHARON, I.; BENGTSSON-OLIVECRONA, G. Conversion of human plasma high density lipoprotein-2 to high density lipoprotein-3. Roles of neutral lipid exchange and triglyceride lipases. J. Biol. Chem., v.261, p.5201-8, 1986. 
DEMANT, T.; CARLSON, L.A.; HOLMQUIST, L.; KARPE, F.; NILSSONEHLE, P.; PACKARD, C.J.; SHEPHERD, J. Lipoprotein metabolism in hepatic lipase deficiency: studies on the turnover of apolipoprotein B and on the effect of hepatic lipase on high density lipoprotein. J. Lipid. Res., v.29, p.1603-11, 1988.

DESRUMAUX, C.; DECKERT, V.; ATHIAS, A.; MASSON, D.; LIZARD, G.; PALLEAU, V.; GAMBERT, P.; LAGROST, L. Plasma phospholipid transfer protein prevents vascular endothelium dysfunction by delivering alphatocopherol to endothelial cells. FASEB J., v.13, p.883-92, 1999.

DIMAYUGA, P.; ZHU, J.; OGUCHI, S.; CHYU, K.Y.; XU, X.O.; YANO, J.; SHAH, P.K.; NILSSON J; CERCEK, B. Reconstituted HDL-C containing human apolipoprotein A-I reduces VCAM-1 expression and neointima formation following periadvential cuff-induced carotid injury in apoE null mice. Biochim. Biophys. Res. Commun., v.264, p.465-8, 1999.

DOWNS, J.R.; CLEARFIELD, M.; WEIS, S.; WHITNEY, E.; SHAPIRO, D.R.; BEERE, P.A.; LANGENDORFER, A.; STEIN, E.A.; KRUYER, W.; GOTTO Jr., A.M. Primary prevention of acute coronary events with lovastatin in men and women with average cholesterol levels: results of AFCAPS/TexCAPS. Air Force/Texas Coronary Atherosclerosis Prevention Study. JAMA, v.279, p.1615-22, 1998. 
DUPUIS, J.; TARDIF, J.C.; CERNACEK, P.; THEROUX, P. Cholesterol reduction rapidly improves endothelial function after acute coronary syndromes. The RECIFE (reduction of cholesterol in ischemia and function of the endothelium) trial. Circulation, v.99, p.3227-33, 1999.

DWYER, T.; IWANE, H.; DEAN, K.; ODAGIRI, Y.; SHIMOMITSU, T.; BLIZZARD, L.; SRINIVASAN, S.; NICKLAS, T.; WATTIGNEY, W.; RILEY, M.; BERENSON, G. Differences in HDL-C cholesterol concentrations in Japanese, American, and Australian children. Circulation, v.96, p.2830-6, 1997.

EXECUTIVE SUMMARY OF THE THIRD REPORT OF THE NATIONAL CHOLESTEROL EDUCATION PROGRAM (NCEP) EXPERT PANEL ON DETECTION, EVALUATION, AND TREATMENT OF HIGH BLOOD CHOLESTEROL IN ADULTS (ADULTS TREATMENT PANEL III). JAMA, v.285, p.2486-97, 2001.

EVANS, G.F.; BENSCH, W.R.; APELGREN, L.D.; BAILEY, D.; KAUFFMAN, R.F.; BUMOL, T.F.; ZUCKERMAN, S.H. Inhibition of cholesteryl ester transfer protein in normocholesterolemic and hypercholesterolemic hamsters: effects on HDL subspecies, quantity, and apolipoprotein distribution. J. Lipid Res., v.35, p.1634-45, 1994. 
FAVARATO, D.; da LUZ, P.L. Aterosclerose não associada a hipercolesterolemia. Rev. Soc. Cardiol. Estado de São Paulo, v.8, p.35665, 1998.

FOODY, J.A.M.; FERDINAND, F.D.; PEARCE, G.L.; LYTLE, B.W.; COSGROVE, D.M.; SPRECHER, D.L. A. HDL-C cholesterol level predicts survival in men after coronary artery bypass graft surgery. Circulation, v.102, p.III90-4, 2000.

FRICK, M.H.; SYVANNE, M.; NIEMINEN, M.S.; KAUMA, H.; MAJAHALME, S.; VIRTANEN, V.; KESANIEMI, Y.A.; PASTERNACK, A.; TASKINEN, M.R. Prevention of the angiographic progression of coronary and vein-graft atherosclerosis by gemfibrozil after coronary bypass surgery in men with low levels of HDL-C cholesterol. Lopid Coronary Angiography Trial (LOCAT) Study Group. Circulation, v.96, p.2137-43, 1997.

FRIEDWALD, W.T.; LEVY, R.J.; FREDRICKSON, D.S.. Estimation of the concentration of low-density lipoprotein cholesterol in plasma without use of the preparative ultra centrifuge. Clin. Chem., v. 18, p. 499-502, 1972.

FUNKE $H$, VON ECKARDSTEIN A, PRITCHARD PH, HORNBY AE, WIEBUSCH H, MOTTI C, HAYDEN MR, DACHET C, JACOTOT B, GERDES $U$. Genetic and phenotypic heterogeneity in familial lecithin: cholesterol acyltransferase (LCAT) deficiency. Six newly identified defective alleles further contribute to the structural heterogeneity in this disease. J. Clin. Invest., v..91, p.677-83, 1993. 
FURBEE Jr., J.W.; FRANCONE, O.; PARKS, J.S. In vivo contribution of LCAT to apolipoprotein B lipoprotein cholesteryl esters in LDL receptor and apolipoprotein E knockout mice. J. Lipid Res., v.43, p.428-37, 2002.

GAENZER, H.; STURM, W.; NEUMAYR, G.; KIRCHMAIR, R.; EBENBICHLER, C.; RITSCH, A.; FOGER, B.; WEISS, G.; PATSCH, J.R. Pronounced postprandial lipemia impairs endothelium-dependent dilation of the brachial artery in men. Cardiovasc. Res., v.52, p.509-16, 2001.

GEURIAN, K.; PINSON, J.B.; WEART, C.W. The triglyceride connection in atherosclerosis. Ann. Pharmacother., v.26, p.1109-17, 1992.

GIRI, S.N. The combined treatment with taurine and niacin blocks the bleomycin-induced activation of nuclear factor-kappaB and lung fibrosis. Adv. Exp. Med. Biol., v.526, p.381-94, 2003.

GOTTO Jr., A.M.; BRINTON, E.A. Assessing low levels of high-density lipoprotein cholesterol as a risk factor in coronary heart disease: a working group report and update. J. Am. Coll. Cardiol., v.43, p.717-24, 2004.

GRIFFIN, B.A.; SKINNER, E.R.; MAUGHAN, R.J. Plasma high density lipoprotein subfractions in subjects with different coronary risk indices as assessed by plasma lipoprotein concentrations. Atherosclerosis, v.70, p.165-9, 1988. 
GURUJEYALAKSHMI, G.; WANG, Y.; GIRI, S.N. Taurine and niacin block lung injury and fibrosis by down-regulating bleomycin-induced activation of transcription nuclear factor-kappaB in mice. J. Pharmacol. Exp. Ther., v.293, p.82-90, 2000.

GRIFFIN, J.H.; KOJIMA, K., BANKA, C.L.; CURTISS, L.K.; FERNANDEZ, J.A. High-density lipoprotein enhancement of anti-coagulant activities of protein S and activated protein C. J. Clin. Invest., v.103, p.219-227, 1999.

GUTIERREZ, M.A.; PILON, P.E.; LAGE, S.G.; KOPEL, L.; CARVALHO, R.; FURUIE, S.S. Assessment of carotid diameter and wall thickness in ultrasound images using active contours improved by a multiresolution technique. Proc. SPIE, v. 4683, p. 248-55, 2002.

HALCOX ,J.P.; SCHENKE, W.H.; ZALOS, G.; MINCEMOYER, R.; PRASAD, A.; WACLAWIW, M.A.; NOUR, K.R.; QUYYUMI, A.A. Prognostic value of coronary vascular endothelial dysfunction. Circulation, v.106, p.653-8, 2002.

HEITZER, T.; YLA-HERTTUALA, S.; LUOMA, J.; KURZ, S.; MUNZEL, T.; JUST, H.; OLSCHEWSKI, M.; DREXLER, H. Cigarette smoking potentiates endothelial dysfunction of forearm resistance vessels in patients with hypercholesterolemia. Role of oxidized LDL. Circulation, v.93, p.1346-53, 1996. 
HIGASHI, Y.; SANADA, M.; SASAKI, S.; NAKAGAWA, K.; GOTO, C.; MATSUURA, H.; CHAYAMA, M.; OSHIMA, T. Effect of estrogen replacement therapy on endothelial function of peripheral resistance arteries in normotensive and hypertensive postmenopausal women. Hypertension, v. 37, p.651-7, 2001.

HIRATA, M.H.; OLIVEIRA, H.C.F.; QUINTÃO, E.C.R.; REDGRAVE, T.G.; MARANHÃO, R.C. The effects of Triton WR-1339, protamine sulfate and heparin on the plasma removal of emulsion models of chylomicrons and remnants in rats. Biochim. Biophys. Acta., v.917, p.344-6, 1987.

III DIRETRIZES BRASILEIRAS SOBRE DISLIPIDEMIAS E DIRETRIZ DE PREVENÇÃO DA ATEROSCLEROSE DO DEPARTAMENTO DE ATEROSCLEROSE DA SOCIEDADE BRASILEIRA DE CARDIOLOGIA. Arq. Bras. Cardiol., v.77, p.1-48 (Suppl. III), 2001.

IV DIRETRIZES BRASILEIRAS DE HIPERTENSÃO ARTERIAL ( 1 a 3 de fevereiro de 2002 - Campos do Jordão - SP).

JODOIN, I.; BUSSIERES, L.M.; TARDIF, J.C.; JUNEAU, M.. Effect of a short-term primary prevention program on endothelium-dependent vasodilation in adults at risk for atherosclerosis. Can. J. Cardiol., v.15, p.838, 1999. 
JAYE, M.; LYNCH, K.J.; KRAWIEC, J.; MARCHADIER, D.; MAUGEAIS, C.; DOAN, K.; SOUTH, V.; AMIN, D.; PERRONE, M.; RADER, D.J. A novel endothelial-derived lipase that modulates HDL metabolism. Nat. Genet., v.21, p.424-8, 1999.

JIANG, X.C.; BRUCE, C.; MAR, J.; LIN, M.; JI, Y.; FRANCONE, O.L.; TALL, A.R. Targeted mutation of plasma phospholipid transfer protein gene markedly reduces high-density lipoprotein levels. J. Clin. Invest., v.103, p.907-14, 1999.

JIN, F.Y.; KAMANNA, V.S.; KASHYAP, M.L. Niacin decreases removal of high-density lipoprotein apolipoprotein A-I but not cholesterol ester by Hep G2 cells. Implication for reverse cholesterol transport. Arterioscler. Thromb. Vasc. Biol., v.17, p.2020-8, 1997.

JOHANSEN, O.; ABDELNOOR, M.; BREKKE, M.; SELJEFLOT, I.; HOSTMARK, A.T.; ARNESEN, H. Predictors of restenosis after coronary angioplasty. A study on demographic and metabolic variables. Scand. Cardiovasc. J., v.35, p.86-91, 2001.

JONKERS, I.J.; VAN DE REE, M.A.; SMELT, A.H.; DE MAN, F.H.; JANSEN, H.; MEINDERS, A.E.; VAN DER LAARSE, A.; BLAUW, G.J. Insulin resistance but not hypertriglyceridemia per se is associated with endothelial dysfunction in chronic hypertriglyceridemia. Cardiovasc. Res., v.53, p.496$501,2002$. 
JOSEPH, L.J.; RYAN, A.S.; SORKIN, J.; MANGANO, C.; BRENDLE, D.C.; CORRETTI, M.C.; GARDNER, A.W.; KATZEL, L.I. Body fat distribution and flow-mediated endothelium-dependent vasodilation in older men. Int. J. Obes. Relat. Metab. Disord., v.26, p.663-9, 2002.

KAKKO, S.; TAMMINEN, M., PAIVANSALO, M.; KAUMA, H.; RANTALA, A.O.; LILJA, M.; REUNANEN, A.; KESANIEMI, Y.A.; SAVOLAINEN, M.J. Cholesteryl ester transfer protein gene polymorphisms are associated with carotid atherosclerosis in men. Eur. J. Clin. Invest., v.30, p.18-25, 2000.

KANNEL, W.B.; DAWBER, T.R.; KAGAN, A.; REVOTSKIE, N.; STOKES, J. 3rd. Factor of risk in the development of coronary heart disease: six years follow-up experience. The Framingham Study. Ann. Int. Med., v.55, p.33-50, 1961.

KIMURA, Y.; MATSUMOTO, M.; DEN, Y.B.; IWAI, K.; MUNEHIRA, J.; ATTORI, H.; HOSHINO, T.; YAMADA, K.; KAWANISHI, K.; TSUCHIYA, H. Impaired endothelial function in hypertensive elderly patients evaluated by high resolution ultrasonography. Can. J. Cardiol., v.15, p.563-8, 1999.

KINLAY, S.; LIBBY, P.; GANZ, P. Endothelial function and coronary heart disease. Curr. Opin. Lipidol., v.12, p.383-9, 2001. 
KITAMURA, A.; ISO, H.; NAITO, Y.; IIDA, M.; KONISHI, M.; FOLSOM, A.R.; SATO, S.; KIYAMA, M.; NAKAMURA, M.; SANKAI, T. High-density lipoprotein cholesterol and premature coronary heart disease in urban Japanese men. Circulation, v.89, p.2533-9, 1994.

KLUCKEN, J.; BUCHLER, C.; ORSO, E.; KAMINSKI, W.E.; PORSCHOZCURUMEZ, M.; LIEBISCH, G.; KAPINSKY, M.; DIEDERICH, W.; DROBNIK, W.; DEAN, M.; ALLIKMETS, R.; SCHMITZ, G. ABCG1 (ABC8), the human homolog of the Drosophila white gene, is a regulator of macrophage cholesterol and phospholipid transport. Proc. Natl. Acad. Sci. U.S.A., v.97, p.817-22, 2000.

KUVIN, J.T.; PATEL, A.R.; SLINEY, K.A.; PANDIAN, N.G.; RAND, W.M.; UDELSON, J.E.; KARAS, R.H. Peripheral vascular endothelial function testing as a noninvasive indicator of coronary artery disease. J. Am. Coll. Cardiol., v.38, p.1843-9, 2001.

KUVIN, J.T.; RAMET, M.E.; PATEL, A.R.; PANDIAN, N.G.; MENDELSOHN, M.E.; KARAS, R.H. A novel mechanism for the beneficial vascular effects of high-density lipoprotein cholesterol: enhanced vasorelaxation and increased endothelial nitric oxide synthase expression. Am. Heart J., v.144, p.165-72 2002. 
LEUS, F.R.; WITTEKOEK, M.E.; PRINS, J.; KASTELEIN, J.J.; VOORBIJ, H.A. Paraoxonase gene polymorphisms are associated with carotid arterial wall thickness in subjects with familial hypercholesterolemia. Atherosclerosis, v.149, p.371-7, 2000.

LI, X.P.; ZHAO, S.P.; ZHANG, X.Y.; LIU, L.; GAO, M.; ZHOU, Q.C. Protective effect of high-density lipoprotein on endothelium-dependent vasodilation. Int. J. Cardiol., v.73, p.231-6, 2000.

LIBBY, P.; RIDKER, P.M.; MASEN, A.. Inflammation and Atherosclerosis. Circulation, v.105, p.1135-43, 2002.

LINDEN, T.; BONDJERS, G.; KARLSSON, T.; WIKLUND, O. Serum triglycerides and HDL-C cholesterol--major predictors of long-term survival after coronary surgery. Eur. Heart J., v.15, p.747-52, 1994.

LOTUFO, P.A. Epidemiologia das doenças cardíacas no Brasil:histórico, situação atual e proposta de modelo teórico. Rev. Soc. Cardiol. Estado de São Paulo, v.5, p.541-7, 1996.

LUDMER, P.L.; SELWYN, A.P.; SHOOK, T.L.; WAYNE, R.R.; MUDGE, G.H.; ALEXANDER, R.W.; GANZ, P. Paradoxical vasoconstriction induced by acetylcholine in atherosclerotic coronary arteries. N. Engl. J. Med., v.315, p.1046-51, 1986. 
LUNDMAN, P.; ERIKSSON, M.; SCHENCK-GUSTAFSSON, K.; KARPE, F.; TORNVALL, P. Transient triglyceridemia decreases vascular reactivity in young, healthy men without risk factors for coronary heart disease. Circulation, v.96, p.3266-8, 1997.

LUNDMAN, P.; ERIKSSON, M.J.; STUHLINGER, M.; COOKE, J.P.; HAMSTEN, A.; TORNVALL, P. Mild-to-moderate hypertriglyceridemia in young men is associated with endothelial dysfunction and increased plasma concentrations of asymmetric dimethylarginine. J. Am. Coll. Cardiol., v.38, p.111-6, 2001.

LUSCHER, T.F. The endothelium and cardiovascular disease - A complex relation. N. Engl. J. Med., v.330, p.1081-3, 1994.

MACKNESS, M.I.; MACKNESS, B.; DURRINGTON, P.N. Paraoxonase and coronary heart disease. Atheroscler. Suppl., v.3, p.49-55, 2002.

MAGALHÃES, C.C. O HDL-C baixo é preditor de mortalidade cardiovascular na evolução clínica de pacientes de ambos os sexos submetidos à cirurgia de revascularização do miocárdio. Tese de Doutorado - InCor-HC/FMUSP, 2002. 
MALIK, J.; MELENOVSKY, V.; WICHTERLE, D.; HAAS, T.; SIMEK, J.; CESKA, R.; HRADEC, J. Both fenofibrate and atorvastatin improve vascular reactivity in combined hyperlipidaemia (fenofibrate versus atorvastatin trial FAT). Cardiovasc. Res., v.52, p.290-8, 2001.

MAMO, J.C.; WHEELER, J.R. Chylomicrons or their remnants penetrate rabbit thoracic aorta as efficiently as do smaller macromolecules, incluinding low-density lipoprotein, high-density lipoproteins,and albumin. Coron. Artery Dis., v.5, p.695-705, 1994.

MARANHÃO, R.C.; TERCYAK, A.M.; REDGRAVE, T.G. Effects of cholesterol content on the metabolism of protein-free emulsions models of lipoproteins. Biochim. Biophys. Acta, v.875, p.247-55, 1986.

MARANHAO, R.C.; FERES, M.C.; MARTINS, M.T.; MESQUITA, C.H.; TOFFOletTO, O.; VINAGRE, C.G.; GIANINNI, S.D.; PILEGGI, F. Plasma kinetics of a chylomicron-like emulsion in patients with coronary artery disease. Atherosclerosis, v.126, p.15-25, 1996.

MARCIL, M.; BROOKS-WILSON, A.; CLEE, S.M.; ROOMP, K.; ZHANG, L.H.; YU, L.; COLLINS, J.A.; VAN DAM, M.; MOLHUIZEN, H.O.; LOUBSTER, O.; OUELLETTE, B.F.; SENSEN, C.W.; FICHTER, K.; MOTT, S.; DENIS, M.; BOUCHER, B.; PIMSTONE, S.; GENEST Jr., J.; KASTELEIN, J.J.; HAYDEN, M.R. Mutations in the ABC1 gene in familial HDL deficiency with defective cholesterol efflux. Lancet, v.354, p.1341-6, 1999. 
MARTINS, M.C.; PILEGGI, F.; MARANHAO, R.C. Clearance of a chylomicron-like emulsion from plasma is delayed in patients with coronary artery disease. Braz. J. Med. Biol. Res., v.28, p.427-31, 1995.

MCCOY, M.G.; SUN, G.S.; MARCHADIER, D.; MAUGEAIS, C.; GLICK, J.M.; RADER, D.J. Characterization of the lipolytic activity of endothelial lipase. J. Lipid Res., v.43, p.921-9, 2002.

McDONALD, M.C.; DHADLY, P.; COCKERILL, G.W.; CUZZOCREA, S.; MOTA-FILIPE, H.; HINDS, C.J.; MILLER, N.E.; THIEMERMANN, C. Reconstituted high-density lipoprotein attenuates organ injury and adhesion molecule expression in a rodent model of endotoxic shock. Shock, v.20, p.551-7, 2003.

McGILL Jr., H.C.; MCMAHAN,C.A.; ZIESKE, A.W.; SLOOP, G.D.; WALCOTT, J.V.; TROXCLAIR, D.A.; MALCOM, G.T.; TRACY, R.E.; OALMANN, M.C.; STRONG, J.P. Associations of coronary heart disease risk factors with the intermediate lesion of atherosclerosis in youth. The Pathobiological Determinants of Atherosclerosis in Youth (PDAY) Research Group. Arterioscler. Thromb. Vasc. Biol., v.20, p.1998-2004, 2000.

McGOWON, N.M.; ARTISS, J.D.; STRANDBERGH, D.R.; ZACK, B. A.. peroxide-coupled method for the colorimetric determination of serum triglycerids. Clin. Chem., v. 29, p. 538-42, 1983. 
MEREDITH, I.T.; CURRIE, K.E.; ANDERSON, T.J.; RODDY, M.A.; GANZ, P.; CREAGER, M.A. Postischemic vasodilation in human forearm is dependent on endothelium-derived nitric oxide. Am. J. Physiol., v.270, p. H1435-40, 1996.

MESQUITA, C.H. Manual do programa Anacomp. Análise compartimental auxiliada por computador. São Paulo (IPEN-Pub), 1994.

MILLER, M.; SEIDLER, A.; KWITEROVICH, P.O.; PEARSON, T.A. Longterm predictors of subsequent cardiovascular events with coronary artery disease and 'desirable' levels of plasma total cholesterol. Circulation, v.86, p.1165-70, 1992.

MIURA, H.; WACHTEL, R.E.; LIU, Y. Flow-induced dilation of human coronary arterioles: important role of $\mathrm{Ca}(2+)$-activated $\mathrm{K}(+)$ channels. Circulation, v. 103, p. 1992-8, 2001.

MRC/BHF Heart Protection Study of cholesterol lowering with simvastatin in 20,536 high-risk individuals: a randomised placebo-controlled trial. Heart Protection Study Collaborative Group (HPS Study). Lancet, v.360, p.7-22, 2002. 
MOTT, S.; YU, L.; MARCIL, M.; BOUCHER, B.; RONDEAU, C.; GENEST Jr., J. Decreased cellular cholesterol efflux is a common cause of familial hypoalphalipoproteinemia: role of the ABCA1 gene mutations. Atherosclerosis, v.152, p.457-68, 2000.

NAQVI, T.Z.; SHAH, P.K.; IVEY, P.A.; MOLLOY, M.D.; THOMAS, A.M.; PANICKER, S.; AHMED, A.; CERCEK, B.; KAUL, S. Evidence that highdensity lipoprotein cholesterol is an independent predictor of acute plateletdependent thrombus formation. Am. J. Cardiol., v.84, p.1011-7, 1999.

NEELEY, W.E. Simple automated determination of serum or plasma glucose by a hexokinase-glucose-6 -phosphate dehydrogenase method. Clin. Chem., v.18, p.509-15, 1972.

O'CONNELL, B.J.; GENEST, J. High-density lipoprotem and endothelial function. Circulation, v.104, p.1978-83, 2001.

O'KEEFE Jr., J.H.; HARRIS, W.S.; NELSON, J.; WINDSOR, S.L. Effects of pravastatin with niacin or magnesium on lipid levels and postprandial lipemia. Am. J. Cardiol., v.76, p.480-4, 1995.

OLESEN, S.P.; CLAPHAM, D.E.; DAVIES, P.F. Haemodynamic shear stress activates a $\mathrm{K}(+)$ current in endothelial cells. Nature, v. 331, p. 168-70, 1988. 
OLIVEIRA, H.C.F.; HIRATA, M.H.; REDGRAVE, T.G.; MARANHÃO, R.C. Competition between chylomicrons and their remnants for plasma removal: a study with artificial emulsion models of chylomicrons. Biochim. Biophys. Acta, v.958, p.211-7, 1988.

PAJKRT, D.; DORAN, J.E.; LERCH, P.G.; ARNET, B.; van der POLL, T.; TEN CATE, J.W.; van DEVENTER, S.J.H. Anti-inflammatory effects of reconstituted High-density lipoprotein during human endotoxemia. J. Exp. Med., v.184, p.1601-8, 1996.

PAJKRT, D.; LERCH, P.G.; van der POLL, T.; van DEN ENDE, A.; LEVI, M.; ILLI, M.; DORAN, J.E.; ARNET, B.; TEN CATE, J.W.; van DEVENTER, S.J.H. Diferential Effects of Reconstitued High-density Lipoprotein on Coagulation, Fibrinolysis and Platelet Activation during Human Endotoxemia. Thromb. Haemost., v.77, p.303-7, 1997.

PERREGAUX, D.; CHAUDHURI, A.; MOHANTY, P.; UKHARI, L.; WILSON, M.F.; SUNG, B.H.; DANDONA, P.. Effect of gender differences and estrogen replacement therapy on vascular reactivity. Metabolism, v.48, p.227-232, 1999. 
PHILLIPS, M.C.; GILLOTTE, K.L.; HAYNES, M.P.; JOHNSON, W.J.; LUNDKATZ, S.; ROTHBLAT, G.H. Mechanisms of high density lipoproteinmediated efflux of cholesterol from cell plasma membranes. Atherosclerosis, v.137, p. S13-7, 1988.

POMERANTZ, K.B.; FLEISHER, L.N.; TALL, A.R.; CANNON, P.J. Enrichment of endothelial cell arachidonate by lipid transfer from high density lipoproteins: relationship to prostaglandin 12 synthesis. J. Lipid. Res., v.26, p.1269-76, 1985.

QIN, S.; KAWANO, K.; BRUCE, C.; LIN, M.; BISGAIER, C.; TALL, A.R.; JIANG, X. Phospholipid transfer protein gene knock-out mice have low high density lipoprotein levels, due to hypercatabolism, and accumulate apoA-IVrich lamellar lipoproteins. J. Lipid Res., v.41, p.269-76, 2000.

RAITAKARI, O.T.; ADAMS, M.R.; MCCREDIE, R.J.; GRIFFITHS, K.A.; CELERMAJER, D.S. Arterial endothelial dysfunction related to passive smoking is potentially reversible in healthy young adults. Ann. Intern. Med., v.130, p.578-81, 1999.

RAITAKARI, M.; ILVONEN, T; AHOTUPA, M.; LEHTIMAKI, T.; HARMOINEN, A.; SUOMINEN, P.; ELO, J.; HARTIALA, J.; RAITAKARI, O.T. Weight reduction with very-low-caloric diet and endothelial function in overweight adults: role of plasma glucose. Arterioscler. Thromb. Vasc. Biol., v. 24, p.124-8, 2004. 
RÄMET, M.E.; RÄMET, M.; LU, Q.; NICKERSON, M.; SAVOLAINEN, M.J.; MALZONE, A.; KARAS, R.H. High-density lipoprotein increases the abundance of eNOS protein in human vascular endothelial cells by increasing its half-life. J. Am. Coll. Cardiol., v.41, p.2288-97, 2003.

RANDOMISED TRIAL OF CHOLESTEROL LOWERING IN 4444 PATIENTS WITH CORONARY HEART DISEASE: THE SCANDINAVIAN SIMVASTATIN SURVIVAL STUDY (4S). Lancet, v.344, p.1383-9, 1994.

REDGRAVE, T.G.; MARANHÃO, R.C. Metabolism of protein-free lipid emulsion models of chylomicron in rats. Biochim. Biophys. Acta, v. 835, p. 104-12, 1985.

REDGRAVE, T.G.; VASSILIOU, G.G.; CALLOW, M.J. Cholesterol is necessary for triacylglycerol-phospholipid emulsions to mimic the metabolism of lipoproteins. Biochim. Biophys. Acta., v.921, p.154-7, 1987.

REMALEY, A.T.; RUST, S.; ROSIER, M.; KNAPPER, C.; NAUDIN, L.; BROCCARDO, C.; PETERSON, K.M.; KOCH, C.; ARNOULD, I.; PRADES, C.; DUVERGER, N.; FUNKE, H.; ASSMAN, G.; DINGER, M.; DEAN, M.; CHIMINI, G.; SANTAMARINA-FOJO, S.; FREDRICKSON, D.S.; DENEFLE, P.; BREWER Jr., H.B. Human ATP-binding cassette transporter 1 (ABC1): genomic organization and identification of the genetic defect in the original Tangier disease kindred. Proc. Natl. Acad. Sci. U.S.A., v.96, p.12685-90, 1999. 
REN, S.; SHEN, G.X. Impact of antioxidants and HDL-C on glycated LDLinduced generation of fibrinolytic regulators from vascular endothelial cells. Arterioscl. Thromb. Vasc. Biol., v.20, p.1688-93, 2000.

REPORT OF THE EXPERT COMMITTEE ON THE DIAGNOSIS AND CLASSIFICATION OF DIABETES MELLITUS. Diabetes Care, v.26, p.S520, 2003.

ROBINS, S.J.; COLLINS, D.; WITTES, J.T.; PAPADEMETRIOU, V.; DEEDWANIA, P.C.; SCHAEFER, E.J.; MCNAMARA, J.R.; KASHYAP, M.L.; HERSHMAN, J.M.; WEXLER, L.F.; RUBINS, H.B. VA-HIT Study Group. Veterans Affairs High-Density Lipoprotein Intervention Trial. Relation of gemfibrozil treatment and lipid levels with major coronary events: VA-HIT: a randomized controlled trial. JAMA, v.285, p.1585-91, 2001.

ROSENSON, R.S.; LOWE, G.D.O. Effects of lipids and lipoproteins on thrombosis and rheology. Atherosclerosis, v.140, p.271-80, 1998.

ROSS, R. Growth regulatory mechanisms and formation of the lesions of atherosclerosis. Ann. N. Y. Acad. Sci., v.748, p.1-4, 1995

ROSS, R. Atherosclerosis - an Inflammatory Disease . N. Engl. J. Med., v.340, p. 115-26, 1999. 
RUBIC, T.; TROTTMANN, M.; LORENZ, R.L. Stimulation of CD36 and the key effector of reverse cholesterol transport ATP-binding cassette A1 in monocytoid cells by niacin. Biochem. Pharmacol., v.67, p.411-9, 2004.

SACKS, F.M.; PFEFFER, M.A.; MOYE, L.A.; ROULEAU, J.L.; RUTHERFORD, J.D.; COLE, T.G.; BROWN, L; WARNICA, J.W.; ARNOLD, J.M.O.; WUN, C.C.; DAVIS, B.R.; BRAUNWALD, E. The Cholesterol and , Recurrent Events Trial Investigators. The Effect of Pravastatin on Coronary Events after Myocardial Infarction in Patients with Average Cholesterol Levels. N. Engl. J. Med., v.335, p.1001-9,1996.

SACKS, F.M.; TONKIN, A.M.; CRAVEN, T.; PFEFFER, M.A.; SHEPHERD, J.; KEECH, A.; FURBERG, C.D.; BRAUNWALD, E. Coronary heart disease in patients with low LDL-cholesterol: benefit of pravastatin in diabetics and enhanced role for HDL-cholesterol and triglycerides as risk factors. Circulation, v.105, p.1424-1428, 2002.

SAITTA, A.; ALTAVILLA, D.; CUCINOTTA, D.; MORABITO, N.; FRISINA, N.; CORRADO, F.; D'ANNA, R.; LASCO, A.; SQUADRITO, G.; GAUDIO, A.; CANCELLIERI, F.; ARCORACI, V.; SQUADRITO, F. Randomized, double blind, placebo-controlled study on effects of raloxifene and hormone replacement therapy on plasma NO concentrations, endothelin-1 levels and endothelium-dependent vasodilation in postmenopausal women. Arterioscler. Thromb. Vasc. Biol., v.21, p.1512-9, 2001. 
SAKAI, T.; KAMANNA, V.S.; KASHYAP, M.L. Niacin, but not gemfibrozil, selectively increases LP-AI, a cardioprotective subfraction of HDL, in patients with low HDL cholesterol. Arterioscler. Thromb. Vasc. Biol., v.21, p.1783-9, 2001.

SAMPIETRO, T.; BIGAZZI, F.; DAL PINO, B.; FUSARO, S.; GRECO, F.; TUONI, M.; BIONDA, A. Increased plasma C-reactive protein in familial hypoalphalipoproteinemia: a proinflammatory condition? Circulation, v.105, p.11-4, 2002.

SANTOS, R.D.; VENTURA, L.I.; SPOSITO, A.C.; SCHREIBER, R; RAMIRES, J.A.; MARANHAO, R.C. The effects of gemfibrozil upon the metabolism of chylomicron-like emulsions in patients with endogenous hypertriglyceridemia. Cardiovasc. Res, v.49, p.456-65, 2001.

SANTOS, R.D.; SPOSITO, A.C.; VENTURA, L.I.; CESAR, L.A.; RAMIRES, J.A., MARANHÃO, R.C. Effect of pravastatin on plasma removal of a chylomicron-like emulsion in men with coronary artery disease. Am. J. Cardiol., v.85, p.1163-6, 2000.

SAVION, N; KOTEV-EMETH, S. Cholesterol efflux from high-densitylipoproteins binding to cultured bovine vascular endothelial cells are higher than with vascular smooth muscle cells. Eur. J. Biochem., v.183, p.363-70, 1989. 
SCHACHINGER, V.; BRITTEN, M.B.; ZEIHER, A.M. Prognostic impact of coronary vasodilator dysfunction on adverse long- term outcome of coronary heart disease. Circulation, v. 101, p. 1899-906, 2000.

SCHAEFER, E.J.; EISENBERG, S.; LEVY, R.I. Lipoprotein apoprotein metabolism. J. Lipid. Res., v.19, p.667-87, 1978.

SEVER, P.S.; DAHLOF, B.; POULTER, N.R.; WEDEL, H.; BEEVERS, G.; CAULFIELD, M.; COLLINS, R.; KJELDSEN, S.E.; KRISTINSSON, A.; MCINNES, G.T.; MEHLSEN, J.; NIEMINEN. M; O'BRIEN, E.; OSTERGREN, J.; ASCOT INVESTIGATORS. Prevention of coronary and stroke events with atorvastatin in hypertensive patients who have average or lower-thanaverage cholesterol concentrations, in the Anglo-Scandinavian Cardiac Outcomes Trial--Lipid Lowering Arm (ASCOT-LLA): a multicentre randomized controlled trial. Lancet, v.361, p.1149-58, 2003.

SHAH, P.K.; AMIN, J. Low high density lipoprotein level is associated with increased restenosis rate after coronary angioplasty. Circulation, v.85, p.1279-85, 1992.

SHEPHERD, J.; COBBE, S.M.; FORD, I.; ISLES, C.G.; LORIMER, A.R.; MACFARLANE, P.W.; MCKILLOP, J.H.; PACKARD, C.J. The West of Scotland Coronary Prevention Study Group. Prevention of Coronary Heart Disease with Pravastatin in Men with Hypercholesterolemia. N. Engl. J. Med., v.333, p.1301-8, 1995. 
SIEDEL, J. apud Manual do "kit" de dosagem de ácido úrico, Roche diagnostics, Cobas Integra 400/700/800.

SMITH, R.M. Dose estimate techniques. In: Rollo FD (ed). Nuclear medicine physics, instrumentation and agents. Saint Louis, USA: C.V. Mosby, v. 14, p.513, 1977.

SORENSEN, K.E.; CELEMAJER, D.S.; SPIEGELHALTER, D.J.; GEORGAKOPOULOS, D.; ROBINSON, J.; THOMAS, O; DEANFIELD, J.E. Non-invasive measurement of human endothelium dependent arterial responses: accuracy and reproducibility. Br. Heart J., v.74, p. 247-53, 1995.

SOWBY, F. D. Statement from the 1984 Stockholm meeting of the International Commission on Radiological Protection. J. Can. Assoc. Radiol., v. 36 , p. 56-7, 1985.

SPIEKER, L.E.; SUDANO, I.; HURLIMANN, D.; LERCH PG.; LANG, M.G.; BINGGELI, C; CORTI, R; RUSCHITZKA, F; LUSCHER, TF; NOLL, G. Highdensity lipoprotein restores endothelial function in hypercholesterolemic men. Circulation, v.105, p.399-402, 2002. 
SPOSITO, A.C.; CARAMELLI, B.; SERRANO Jr., C.V.; MANSUR, A.P.; RAMIRES, J.A. Effect of niacin and etofibrate association on subjects with coronary artery disease and serum high-density lipoprotein cholesterol $<35$ mg/dl. Am. J. Cardiol., v.83, p.98-100, 1999.

SPOSITO, A.C.; MANSUR, A.P.; MARANHAO, R.C.; RODRIGUESSOBRINHO, C.R., COELHO, O.R.; RAMIRES, J.A. Etofibrate but not controlled-release niacin decreases LDL cholesterol and lipoprotein (a) in type Ilb dyslipidemic subjects. Braz J Med Biol Res., v.34, p.177-82, 2001.

SPOSITO, A.C.; SANTOS, R.D.; HUEB, W.; VENTURA, L.I.; VINAGRE, C.C.; RAMIRES, J.A.; MARANHAO, R.C. LDL concentration is correlated with the removal from the plasma of a chylomicron-like emulsion in subjects with coronary artery disease. Atherosclerosis, v.161, p.447-53, 2002.

SPOSITO, A.C.; SANTOS, R.D.; AMANCIO, R.F.; RAMIRES, J.A.; CHAPMAN, M.J.; MARANHÃO, R.C. Atorvastatin enhances the plasma clearance of chylomicron-like emulsions in subjects with atherogenic dyslipidemia: relevance to the in vivo metabolism of triglyceride-rich lipoproteins. Atherosclerosis, v.166, p.311-21, 2003. 
SUC, I.; ESCARGUEIL-BLANC, I.; TROLY, M.; SALVAYRE, R.; NEGRESALVAYRE, A. HDL-C and ApoA prevent cell death of endothelial cells induced by oxidized LDL. Arterioscler. Thromb. Vasc. Biol., v.17 p.215866, 1997.

SUGANO, M.; TSUCHIDA, K.; MAKINO; N. High-density lipoproteins protect endothelial cells from tumor necrosis factor-a-induced apoptosis. Biochim. Biophys. Res. Commun., v.272, p.872-6, 2000.

SUGATANI, J.; MIWA, M.; KOMIYAMA, Y.; ITO, S. High-density Lipoprotein inhibits the synthesis of platelet-activating factor in human vascular endothelia! cells. J. Lipid. Mediat. Cell Signal., v.13, p.73-88, 1996.

SUWAIDI, J.A.; HAMASAKI, S.; HIGANO, S.T.; NISHIMURA, R.A.; HOLMES Jr., D.R., LERMAN, A. Long term follow-up of patients with mild coronary artery disease and endothelial dysfunction. Circulation, v.101, p. 948-954, 2000.

TAKASE, B.; UEHATA, A.; AKIMA, T.; NAGAI, T.; NISHIOKA, T.; HAMABE, A.; SATOMURA, K.; OHSUZU, F.; KURITA, A. Endothelium-dependent flowmediated vasodilation in coronary and brachial arteries in suspected coronary artery disease. Am. J. Cardiol., v.15, p. 1535-1539, 1998. 
TAMAGAKI, T.; SAWADA, S.; IMAMURA, H.; TADA, Y.; YAMASAKI, S.; TORATANI A.; SATO, T.; KOMATSU, S.; AKAMATSU, N.; YAMAGAMI, M.; KOBAYASHI, K.; KATO, K.; YAMAMOTO, K.; SHIRAI, K.; YAMADA, K.; HIGAKI, T.; NAKAGAWA, K.; TSUJI, H.; NAKAGAWA, M. Effects of highdensity lipoproteins on intracellular $\mathrm{pH}$ and proliferation of human vascular endothelial cells. Atherosclerosis, v.123, p.73-82, 1996.

THE LONG-TERM INTERVENTION WITH PRAVASTATIN IN ISCHAEMIC DISEASE (LIPID) STUDY GROUP. Prevention of Cardiovascular Events and Death with Pravastatin in Patients with Coronary Heart Disease and a Broad Range of Initial Cholesterol Levels. N. Engl. J. Med., v.339, p.1349-57,1998.

THOMAS, G.N.; CHOOK, P.; QIAO, M.; HUANG, X.S.; LEONG, H.C.; CELERMAJER, D.S.; WOO, K.S. Deleterious impact of "high normal" glucose levels and other metabolic syndrome components on arterial endothelial function and intima-media thickness in apparently healthy Chinese subjects: the CATHAY study. Arterioscler Thromb Vasc Biol., v.24, p.739-43, 2004.

TOIKKA, J.O.; AHOTUPA, M.; VIIKARI, J.S.A.; NIINIKOSKI, H.; TASKINEN, M.R.; IRJALA, K; HARTIALA, J.J.; RAITAKARI, O.T. Constantly low HDLcholesterol concentrations relates to endothelial dysfunction and increase in vivo LDL-oxidation in healthy young men. Atherosclerosis, v.147, p. 133-8, 1999. 
UEDA, Y.; GONG, E.; ROYER, L.; COOPER, P.N.; FRANCONE, O.L.; RUBIN, E.M. Relationship between expression levels and atherogenesis in scavenger receptor class B, type I transgenics. J. Biol. Chem., v.275, p.20368-73, 2000.

UITTENBOGAARD, A.; SHAUL, P.W.; YUHANNA, I.S.; BLAIR, A.; SMART, E.J. High density lipoprotein prevents oxidized low density lipoproteininduced inhibition of endothelial nitric-oxide synthase localization and activation in caveolae. J. Biol. Chem., v.275, p.11278-83, 2000.

von BIRGELEN, C.; HARTMANN, M.; MINTZ, G.S.; BAUMGART, D.; SCHMERMUND, A.; ERBEL, R. Relation between progression and regression of atherosclerotic left main coronary artery disease and serum cholesterol levels as assessed with serial long-term ( $>$ or $=12$ months) followup intravascular ultrasound. Circulation, v.108, p.2757-62, 2003.

von ECKARDSTEIN, A.; NOFER, J.R.; ASSMANN, G. High density lipoproteins and arteriosclerosis. Role of cholesterol efflux and reverse cholesterol transport. Arterioscler. Thromb. Vasc. Biol., 2001 Jan;21(1):1327.

WANG, M.; BRIGGS, M.R. HDL: the metabolism, function, and therapeutic importance. Chem. Rev., v.104, p.119-37, 2004. 
WANG, J.; BURNETT, J.R.; NEAR, S.; YOUNG, K.; ZINMAN, B.; HANLEY, A.J.; CONNELLY, P.W.; HARRIS, S.B.; HEGELE, R.A. Common and rare ABCA1 variants affecting plasma HDL cholesterol. Arterioscler. Thromb. Vasc. Biol., v.20, p.1983-9, 2000.

WENDELHAG, I.; FAGERBERG, B.; HULTHE, J.; BOKEMARK, L; WIKSTRAND, J. Endothelium-dependent flow-mediated vasodilatation, insulin resistance and the metabolic syndrome in 60-year-old men. J. Intern. Med., v.252, p.305-13, 2002.

WILHELM, M.G.; COOPER, A.D. Induction of atherosclerosis by human chylomicron remnants: a hypothesis. J. Atheroscler. Thromb., v.10, p.1329, 2003.

WILLETT, W.C.; GREEN, A.; STAMPFER, M.J.; SPEIZER, F.E.; COLDITZ, G.A.; ROSNER, B.; MONSON, R.R.; STASON, W.; HENNEKENS, C.H. Relative and absolute excess risks of coronary heart disease among women who smoke cigarettes. N. Engl. J. Med., v.317, p.1303-9, 1987.

WILLIAMS, K.J.; TABAS, I. The response-to-retention hypothesis of atherogenesis reinforced. Curr. Opin.Lipidol., v.9, p.471-4, 1998. 
WILSON, S.H.; CELERMAJER, D.S.; NAKAGOMI, A.; WYNDHAM, R.N.; JANU, M.R.; BEN FREEDMAN, S. Vascular risk factors correlate to the extent as well as the severity of coronary atherosclerosis. Coron. Artery Dis., v.10, p.449-53, 1999.

WINNIFORD, M.D. Smoking and cardiovascular function. J. Hypertens. Suppl., v.8, p.S17-23, 1990.

WOO, K.S.; CHOOK, P.; LOLIN, Y.I.; SANDERSON, J.E.; METREWELI, C.; CELERMAJER, D.S. Folic acid improves arterial endothelial function in adults with hyperhomocystinemia. J. Am. Coll. Cardiol., v.34, p.2002-6, 1999.

WORLD HEALTH ORGANIZATION. Definition, diagnosis and classification of diabetes mellitus and its complications. Part 1: diagnosis and classification of diabetes mellitus. Geneva: WHO Department of Noncommunicable Disease Surveillance, 1999.

YU, L.; LI-HAWKINS, J.; HAMMER, R.E.; BERGE, K.E.; HORTON, J.D.; COHEN, J.C.; HOBBS, H.H. Overexpression of ABCG5 and ABCG8 promotes biliary cholesterol secretion and reduces fractional absorption of dietary cholesterol. J. Clin. Invest., v.110, p.671-80, 2002. 
YUI, Y.; AOYAMA, T.; MORISHITA, H.; TAKAHASHI, M.; TAKATSU, Y.; KAWAI, C. Serum prostacyclin stabilizing factor is identical to apolipoprotein A-I (Apo A-I). A novel function of Apo A-I. J. Clin. Invest., v.82, p.803-7, 1988.

ZHANG, X.; ZHAO, S.P.; LI, X.P.; GAO, M.; ZHOU, Q.C. Endotheliumdependent and -independent functions are impaired in patients with coronary heart disease. Atherosclerosis, v.149, p.19-24, 2000.

ZILVERSMIT, D.B. A proposal linking atherogenesis to the interaction of endothelial lipoprotein lipase with triglyceride-rich lipoproteins. Cir. Res., v.33, p. 633-8, 1973.

ZUCKERMAN SH, EVANS GF. Cholesteryl ester transfer protein inhibition in hypercholesterolemic hamsters: kinetics of apoprotein changes. Lipids, v.30, p.307-11, 1995. 


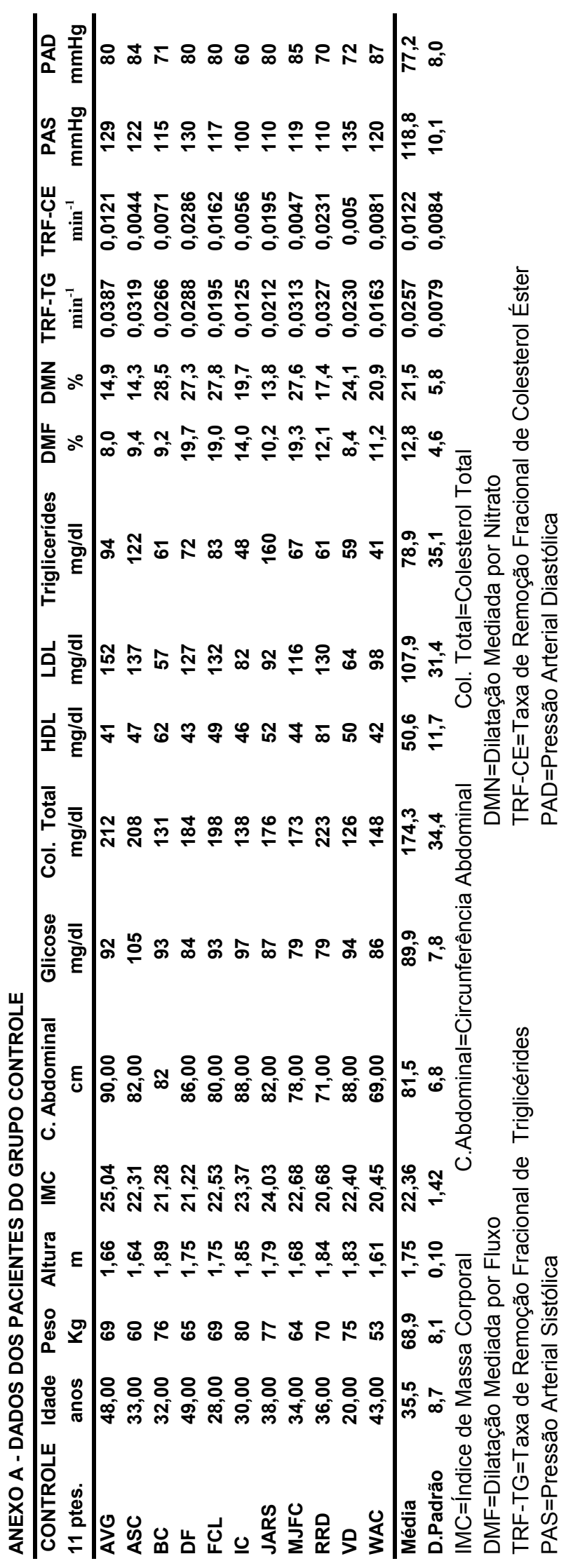




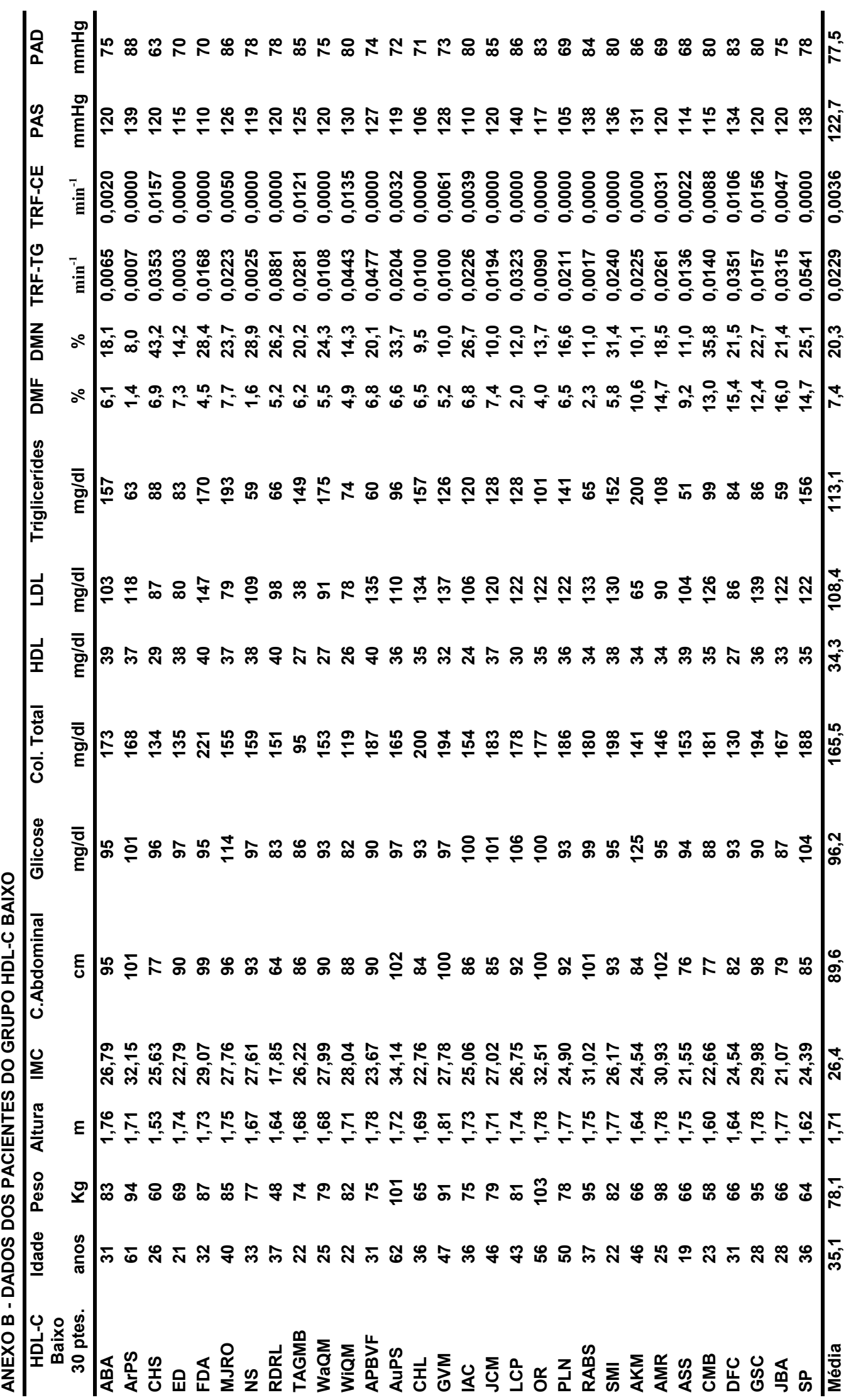



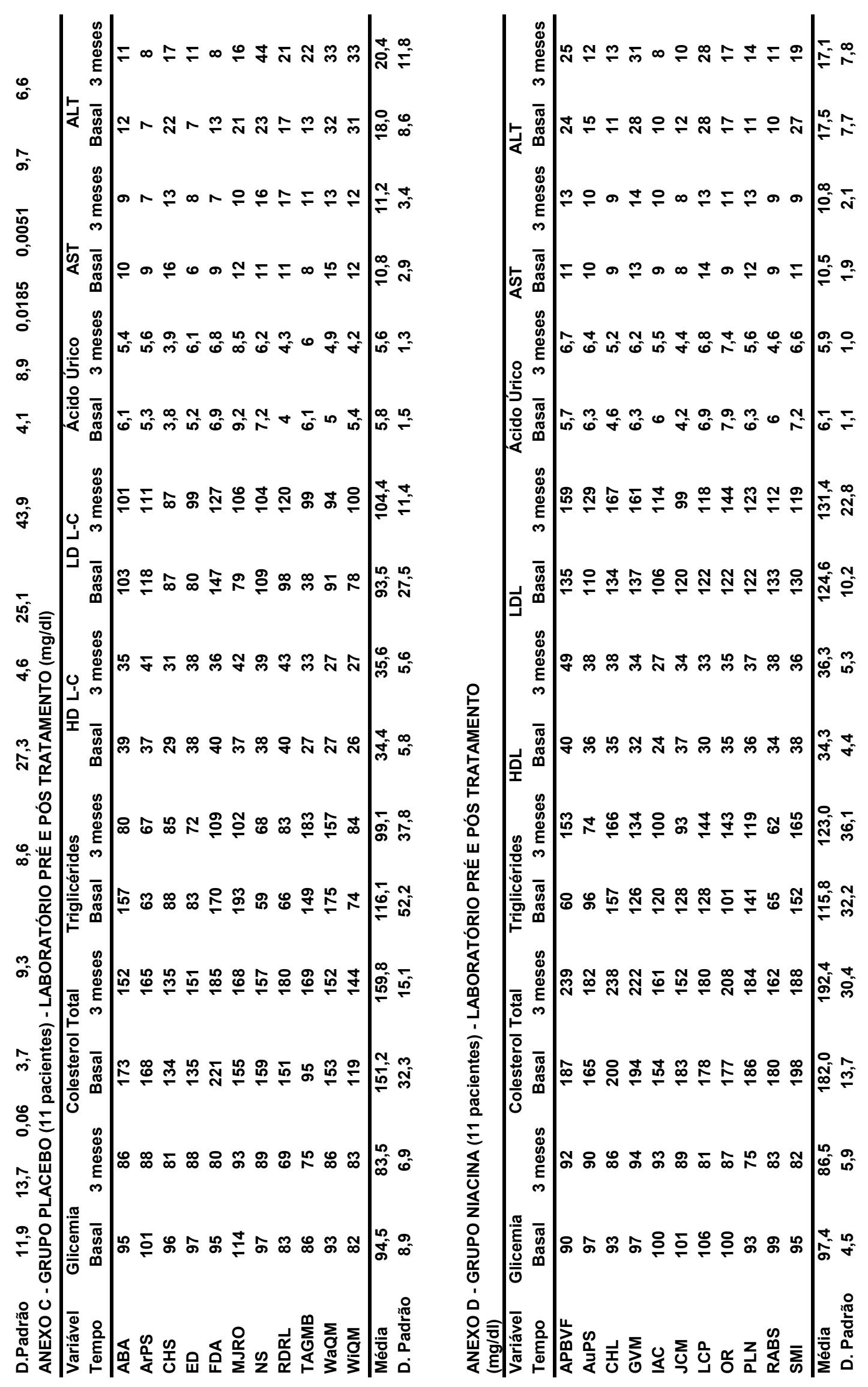


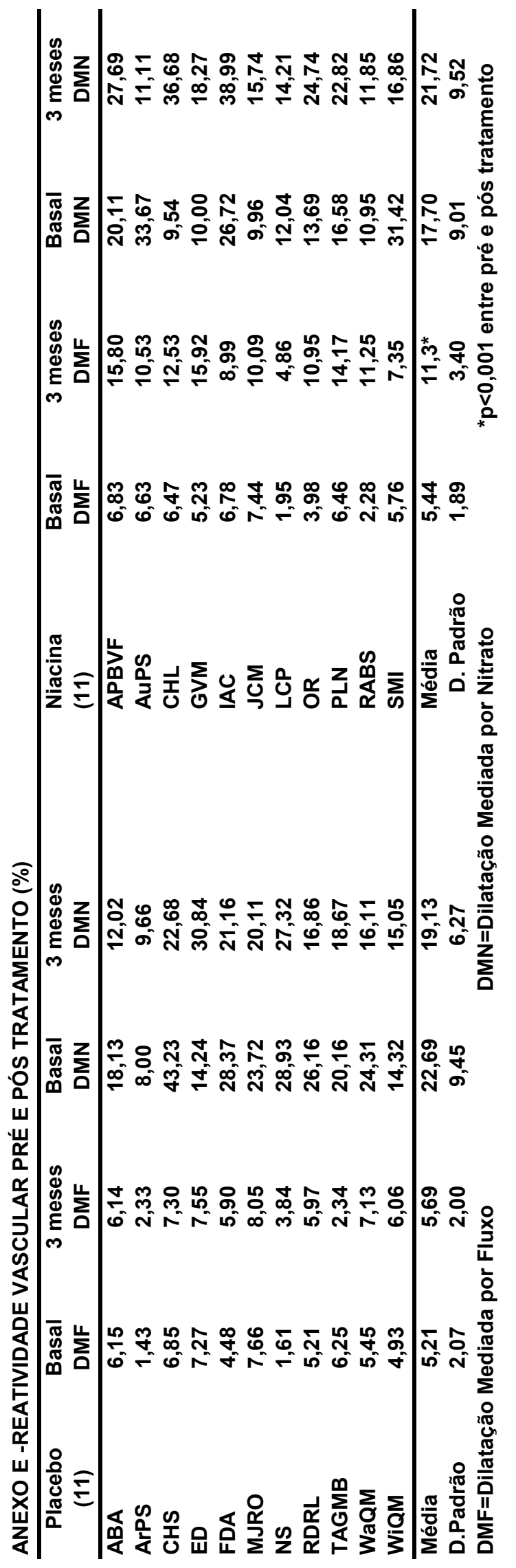




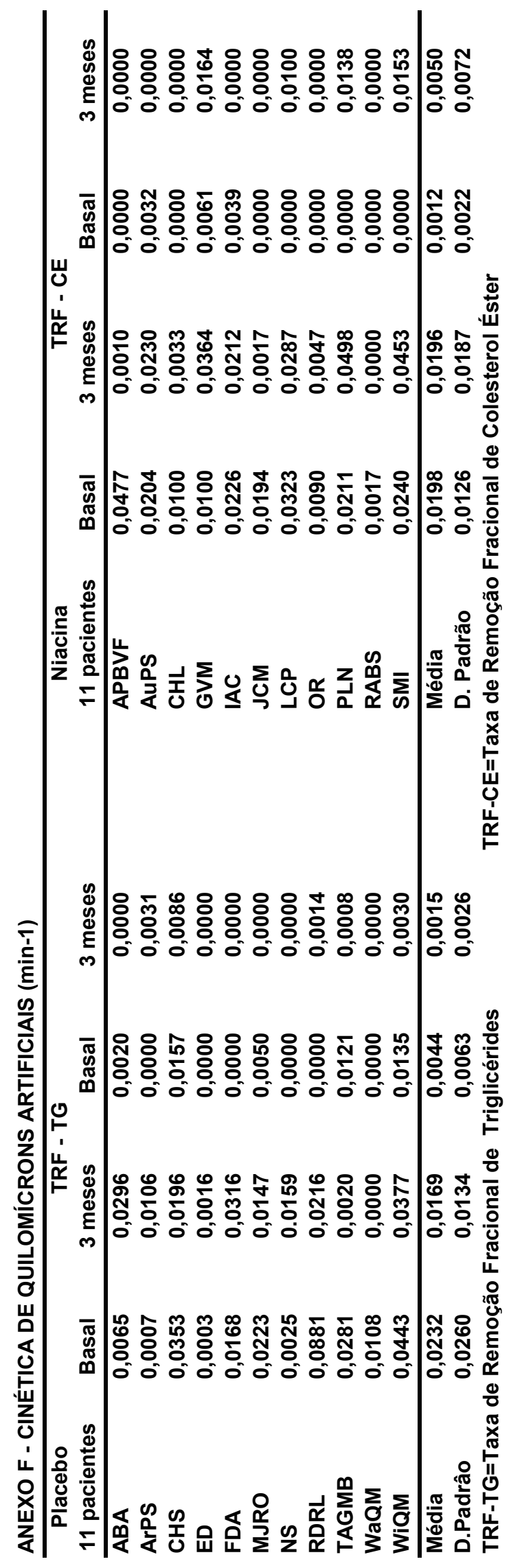




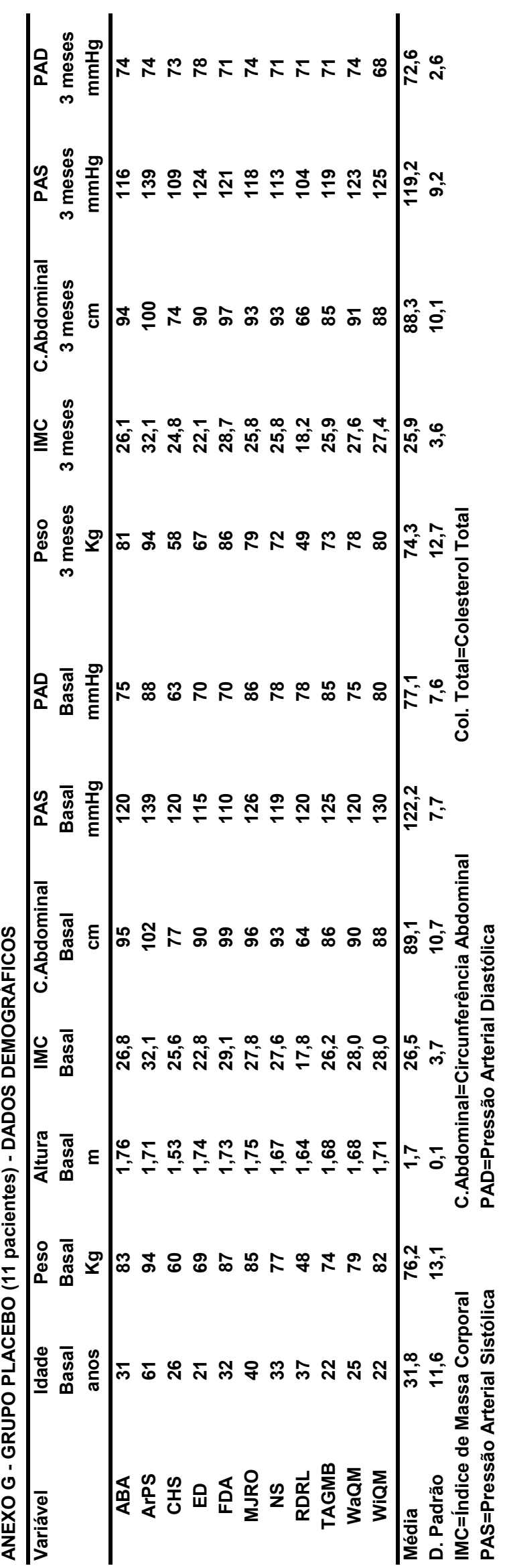




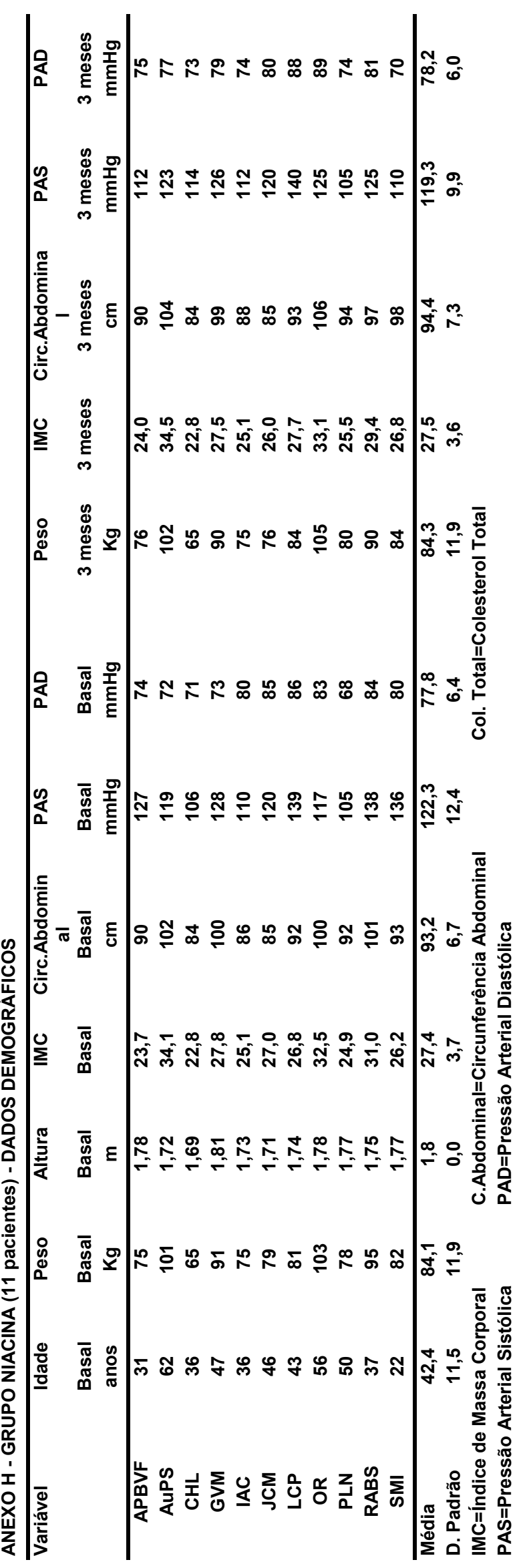

